UCRL-ID-126220

\title{
A Process and Economic Model of In-Field Heavy Oil Upgrading Using Aqueous Pyrolysis
}

C.B. Thorsness

W.C. Miller

January 21, 1997

This is an informal report intended primarily for internal or limited external distribution. The opinions and conclusions stated are those of the author and may or may not be those of the Laboratory.

Work performed under the auspices of the U.S. Department of Energy by the Lawrence Livermore National Laboratory under Contract W-7405-Eng-48. 


\section{DISCLAIMER}

This document was prepared as an account of work sponsored by an agency of the United States Government. Neither the United States Government nor the University of Calffornia nor anj of their emplojees, makes any warranty, express or implied, or assumes any legal liability or responsibility for the accuracy, completeness, or usefulness of any information, apparatus, product, or process disclosed, or represents that its use would not infringe privately owned rights. Reference herein to any specific commercial products, process, or service by trade name, trademark, manufacturer, or otherwise, does not necessarily constitute or imply its endorsement, recommendation, or favoring by the United States Government or the University of California. The views and opinions of authors expressed herein do not necessarily state or reflect those of the United States Government or the University of California, and shall not be used for advertising or product endorsement purposes.

This report has been reproduced directly from the best available copj.

Available to DOE and DOE contractors from the Onice of Scientific and Technical Information

P.O. Box 62, Oak Ridge, TN 37831

Prices available from (615) 576-8401, FTS 626-8401

Available to the public from the

National Technical Information Service

US. Department of Commerce

5285 Port Royal Rd.

Springfield, VA 22161 


\title{
A Process and Economic Model of In-Field Heavy Oil Upgrading Using Aqueous Pyrolysis
}

\author{
C. B. Thorsness \\ W. C. Miller
}

\begin{abstract}
A process and economic model for aqueous pyrolysis in-field upgrading of heavy oil has been developed. The model has been constructed using the ASPEN PLUS chemical process simulator. The process features cracking of heavy oil at moderate temperatures in the presence of water to increase oil quality and thus the value of the oil. Calculations with the model indicate that for a $464 \mathrm{Mg} /$ day $(3,000 \mathrm{bbl} /$ day) process, which increases the oil API gravity of the processed oil from $13.5^{\circ}$ to $22.4^{\circ}$, the required value increase of the oil would need to be at least $\$ 2.80 / \mathrm{Mg} \cdot{ }^{\circ} \mathrm{API}\left(\$ 0.40 / \mathrm{bbl} \cdot{ }^{\circ} \mathrm{API}\right)$ to make the process economically attractive. This level of upgrading has been demonstrated in preliminary experiments with candidate catalysts. For improved catalysts capable of halving the coke make and increasing the pyrolysis rate, a required price increase for the oil as low as $\$ 1.34 / \mathrm{Mg} \cdot{ }^{\circ} \mathrm{API}$ $\left(\$ 0.21 / \mathrm{bbl} \cdot^{\circ} \mathrm{API}\right)$ has been calculated.
\end{abstract}

\section{INTRODUCTION}

Heavy crude oil with an API gravity below $20^{\circ}$ generally has a considerably lower market value then benchmark crudes because of undesirable physical and chemical properties (e.g., high viscosity and high heteroatom content). One strategy to increase the value of these crude oils and to allow easier transport by existing pipelines is in-field upgrading. Aqueous pyrolysis is one candidate for in-field upgrading ${ }^{1}$ of heavy oils. It involves heating an oil-water mixture under pressure, in the presence of a suitable catalyst, to crack and coke the heavy constituents and thus improve the oil quality. This process is attractive since the heavy oils are often associated with some thermally assisted recovery processes, such as steam flooding. As a result the oils are often produced at somewhat elevated temperatures and with considerable water. The produced fluids, therefore, often already require some form of a dewatering step to allow them to be marketed, and the Aqueous Pyrolysis process can be viewed as an extension of the dewatering process.

The Aqueous Pyrolysis process is related to standard vis-breaking and coking operations. However, it uses water and other additives (catalysts) to allow operation at modest temperatures with a minimum of coke make. The processing is intended 
to be closely coupled to a field site and is aimed at more modest changes in oil properties than standard refinery based operations.

To evaluate the potential of the process and to allow performance goals for a catalyst system to be developed, it is useful to have a means of estimating the cost of a proposed process using a given crude oil feed. The purpose of this report is to describe such a model and report preliminary cost estimates. The model was developed using a commercially available process simulator, ASPEN PLUS.

\section{PROCESS DESCRIPTION}

A flowsheet of the proposed process is shown in Fig. 1. The primary process units include a high pressure pump, high pressure heat exchangers, a high pressure heater and a high pressure reactor vessel. In the following description, typical temperatures, compositions, and pressures are given to help clarify the discussion. These values are for results for a defined base case described later; however, the specific process to be modeled need not necessarily conform to these values.

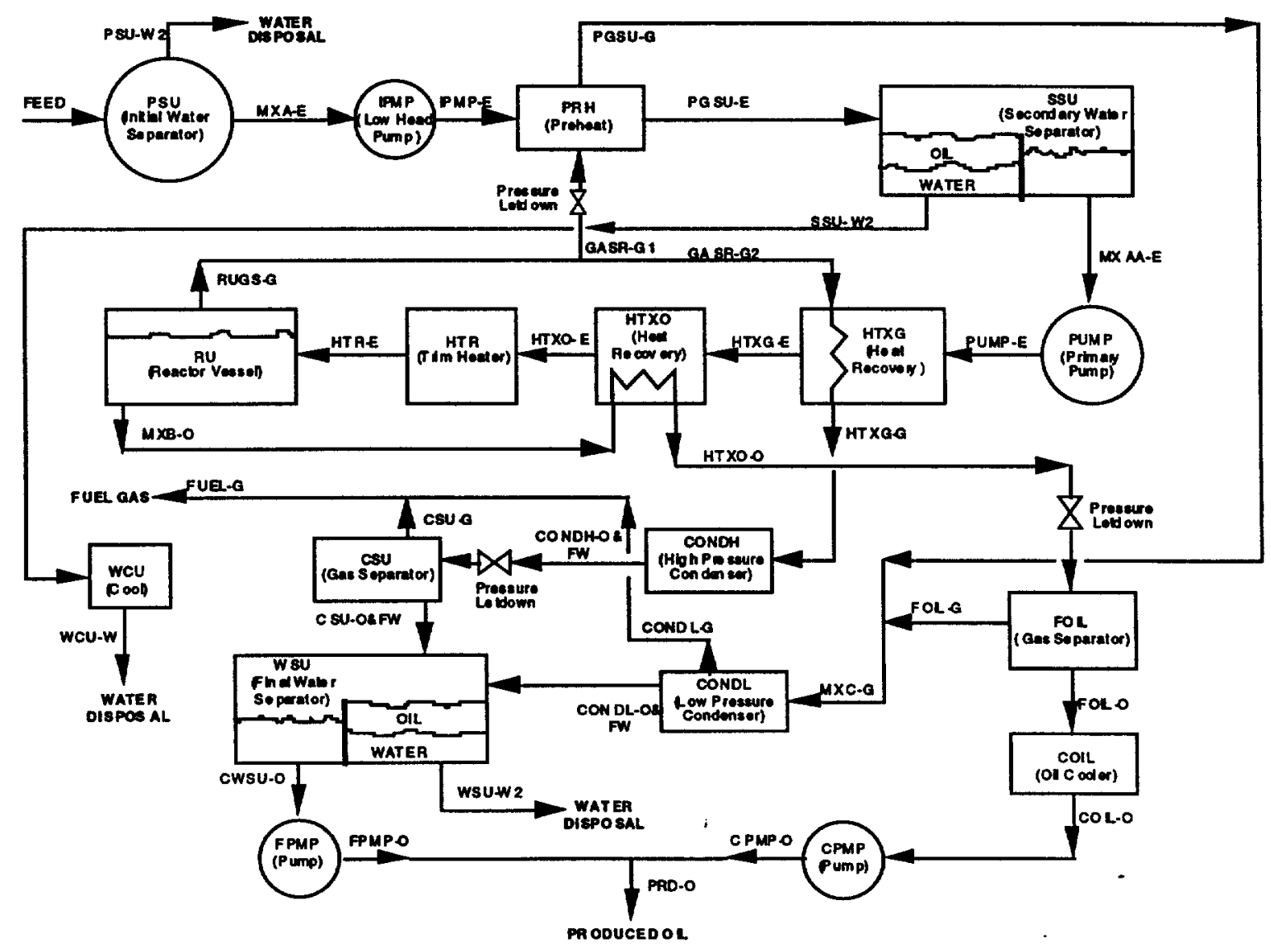

Figure 1. Aqueous pyrolysis process flowsheet. 
It is assumed that produced fluids from a thermal recovery operation (labeled FEED in flowsheet) enter the process at a modest temperature, $38^{\circ} \mathrm{C}$, and a water/oil ratio of 10:1. The first unit, labeled PSU, is a simple settling tank used to separate the bulk of the water, stream PSU-W2, from the oil. The crude oil and remaining water, $30 \%$ by weight, are fed to a pump which raises their pressure slightly $(0.7 \mathrm{MPa})$ to accommodate further dewatering.

The fluid then moves to vessel PRH where it is heated by combining it with hot vapor from downstream processing. This facilitates further dewatering of the oil. The liquid outlet stream, PGSU-E, is heated to $78^{\circ} \mathrm{C}$ in this operation. This heated fluid then enters a water separation vessel, SSU, where the water content in the primary oil stream, MXAA-E, is reduced to $10 \%$. The water exiting the water separator goes to a small heat exchanger, WCU, where it is cooled to $25^{\circ} \mathrm{C}$ before it leaves the battery limits as waste water.

The primary process stream, MXAA-E, is fed to the main high pressure pump, PUMP, where the pressure is increased to $13.8 \mathrm{MPa}$. The stream passes to two heat-recovery heat exchangers and a final trim heater. The first heat exchanger, HTXG, uses hot vapors from the reactor vessel to heat the process stream to $270^{\circ} \mathrm{C}$. The second heat exchanger, HTXO, uses the hot liquid exiting the reactor to further heat the stream. The stream exits HTXO at $317^{\circ} \mathrm{C}$ then enters a fired heater, HTR, which heats the stream to the desired final reaction temperature $\left(438^{\circ} \mathrm{C}\right)$.

The stream then enters the reactor vessel, RU. The reactor vessel allows sufficient residence time (two hours) at elevated temperature for the desired upgrading to occur. The reactor vessel separates the product stream into liquid, MXB-O, and vapor, RUGS-G, product streams.

The liquid product stream exiting the reactor, $\mathrm{MXB}-\mathrm{O}$, passes through the heat recovery heat exchanger and then goes to the pressure letdown station. Downstream of the pressure letdown is a separator vessel, FOIL, which separates liquid and vapor phases. The vapor, FOIL-G, and liquid, FOIL-O, exit the separator vessel at $284^{\circ} \mathrm{C}$ and $0.2 \mathrm{MPa}$. The liquid stream, which is essentially water free, passes through an air cooler and emerges at $93^{\circ} \mathrm{C}$. The exiting vapor stream, FOIL-G, is then combined with the vapor stream from the PRH unit and enters the low pressure condenser unit, CONDL. CONDL uses chilled water to drop the temperature of the exiting streams to $24^{\circ} \mathrm{C}$.

The part of the vapor product stream exiting the reactor, RUGS-G, which is not used for preheating passes through the heat recovery heat exchanger and then to a high pressure chilled water heat exchanger, CONDH. In the flowsheet, this unit is labeled as a condenser although in reality the stream entering it is essentially all liquid at a temperature of $117^{\circ} \mathrm{C}$. The CONDH heat exchanger cools the stream to $24^{\circ} \mathrm{C}$. The stream is then letdown in pressure to $0.2 \mathrm{MPa}$ and vapor and liquid streams are separated in vessel CSU. 
The vapor exists the $\mathrm{CSU}$ unit at $17^{\circ} \mathrm{C}$ and is combined with the vapor CONDL-G from the low pressure condenser. The combined stream exists the battery as a fuel gas containing low molecular weight hydrocarbons and carbon dioxide.

The liquid streams leaving CONDH and CONDL contain free water. This water is removed in a final water separation vessel, WSU. (Water/oil ratio entering the unit is 0.1.)

The two product oil streams are pumped to pressure (1.03 MPa, $150 \mathrm{psi})$ and combined before exiting the battery limits.

Several operations have been omitted from the flowsheet. One is the introduction and possible recovery of a catalyst. Introduction of a catalyst would be a straight forward operation and have little influence on the basic energy and material flows. Any recovery would depend on the cost of the catalyst and details of its behavior in the various fluid streams. These operations could be added to the model in the future if a specific catalyst recovery operation were to be defined.

Another operation that has been omitted is the removal of coke from the system. The tacit assumption made by the continuous nature of the process is that any coke produced is carried out of the processing units by the flowing streams. An ideal catalyst system would yield very low coke formation rates. However, if the coke levels were unacceptably high in the product oil stream then some operation would have to be added to reduce them.

\section{THE ASPEN PLUS PROCESS MODEL}

The flowsheet described above has been modeled using the ASPEN PLUS process simulator. The ASPEN PLUS program is a steady-state modular flowsheet simulator in which process models are constructed by linking together basic modules. ASPEN PLUS refers to these modules as unitoperation blocks. These blocks are linked by material and energy streams. Chemical species in the material streams have fundamental properties defined by selecting various thermodynamic models. ASPEN PLUS has a large data base of conventional chemical species and in addition allows nonconventional species to be defined. ASPEN PLUS also allows user supplied FORTRAN coding to be integrated into the simulation. A feature which has been heavily utilized in developing the Aqueous Pyrolysis flowsheet model.

In this section, the species and reactions considered by the model are outlined. This is followed by a description of the actual ASPEN PLUS computational modules used to simulate the flowsheet. The next section describes the ASPEN PLUS economic model which obtains its primary inputs from the 
flowsheet model. The flowsheet model is constructed to allow different feed compositions; however, to help clarify the description, reference to a specific feed is made. A complete listing of the ASPEN PLUS input file is provided in Appendix I. The following model description does not try to repeat all the information available in the ASPEN PLUS documentation. The reader is referred to that documentation for a more detailed description of model elements.

\section{Components}

Three basic types of chemical components or species are used in the model: conventional components, pseudocomponents, and solids. The complicated crude oil composition is simulated using a set of pseudocomponents. These pseudocomponents and their properties were obtained by using facilities available in ASPEN PLUS ${ }^{2}$. A set of six pseudocomponents representing the crude oil are defined in the model representing different boiling point fractions. Their properties are set by the ASPEN PLUS model based on measured boiling point curves. Table 1 lists the components along with their important characterizing properties for the base case. For other crude oils the properties can vary, but the pseudocomponent names would be preserved.

Table 1. Pseudocomponents used to simulate crude oil.

\begin{tabular}{|c|c|c|c|c|c|c|c|c|}
\hline Name & $\begin{array}{c}\mathrm{MW} \\
\mathrm{gm} / \mathrm{mole}\end{array}$ & wt \% & $\begin{array}{l}\text { Specific } \\
\text { gravity }\end{array}$ & $\begin{array}{c}\text { Boiling } \\
\text { Point } \\
\left.{ }^{\circ} \mathrm{C}\right)\end{array}$ & $\begin{array}{c}\text { Critical } \\
\text { Temp } \\
\text { (C) }\end{array}$ & $\begin{array}{c}\text { Critical } \\
\text { Pres } \\
\text { (MPa) }\end{array}$ & $\begin{array}{c}\text { Acentric } \\
\text { Factor }\end{array}$ & $\begin{array}{c}\text { API } \\
\text { Gravity } \\
9\end{array}$ \\
\hline HNAPH & 142 & 5.00 & 0.844 & 186 & 387 & 2.61 & 0.37 & 36.1 \\
\hline KERO & 178 & 6.00 & 0.877 & 241 & 443 & 2.19 & 0.46 & 29.9 \\
\hline AGO & 228 & 12.00 & 0.911 & 304 & 504 & 1.83 & 0.57 & 23.7 \\
\hline LVGO & 307 & 16.10 & 0.954 & 388 & 583 & 1.48 & 0.73 & 16.9 \\
\hline HVGO & 411 & 26.80 & 1 & 483 & 668 & 1.21 & 1 & 10.4 \\
\hline VR & 540 & 34.10 & 1.04 & 588 & 759 & 0.99 & 1.29 & 4.4 \\
\hline
\end{tabular}

The ASPEN PLUS PROPERTIES option computes water solubility in the oil phase. Coefficients of the solubility parameters for the oil pseudocomponents have been altered to extend their use to higher temperatures. This is a crude treatment of the solubility at elevated temperatures based on very limited information. This extension is discussed in another report ${ }^{3}$.

In addition to the pseudocomponents used to define the feed oil stream, a number of other components are defined in the model. A seventh pseudocomponent, $\mathrm{P}$-OIL, used in defining the overall aqueous pyrolysis reaction is based on an assumed boiling point and API gravity. In addition, solid carbon is used to represent coke (COKE is the component name in the model). Finally a group of conventional components are included: $\mathrm{H} 2 \mathrm{O}$, $\mathrm{CH} 4, \mathrm{C} 2 \mathrm{H} 6, \mathrm{C} 3 \mathrm{H} 8, \mathrm{HHC}, \mathrm{H} 2 \mathrm{~S}, \mathrm{CO} 2$, and $\mathrm{H} 2$. These names identify the actual 
species within the model with the exception of HHC. This is meant to be a hydrocarbon species needed to complete the definition of the pyrolysis

reaction. In the base case this component is normal butane.

\section{Aqueous Pyrolysis Reaction}

The pyrolysis reaction considered in the model is a simplified representation of what occurs. Its structure is based on limited information on potential systems of interest. Reference 3 discusses the development of the simple model. It is assumed that the crude oil reacts at some rate according to a simple first order decomposition reaction where the rate constant is given by an Arrhenius' form. The model assumes that all crude components react at a similar rate and produce coke, light hydrocarbons, hydrogen sulfide, carbon dioxide, and a light oil fraction. The reaction stoichiometry used in the base case is listed in Table 2.

Table 2. Base case reaction stoichiometry.

\begin{tabular}{|cc|}
\hline & $\begin{array}{c}\text { Weight } \\
\text { Fraction }\end{array}$ \\
\hline Coke & 0.2 \\
P-OIL & 0.6 \\
& 0.028 \\
$\mathrm{CO}_{2}$ & 0.014 \\
$\mathrm{H}_{2} \mathrm{~S}$ & 0.0006 \\
$\mathrm{H}_{2}$ & 0.053 \\
$\mathrm{CH}_{4}$ & 0.034 \\
$\mathrm{C}_{2}$ 's & 0.038 \\
$\mathrm{C}_{3}$ 's & 0.033 \\
$\mathrm{C}_{4}$ 's & \\
\hline
\end{tabular}

In the model, care is taken to preserve mass during reaction, but atomic balances are not strictly enforced since atomic compositions of oil and coke components are not explicitly defined.

\section{Unit-Operation Blocks}

The basic process flowsheet unit operations, shown in Fig. 1 do not map oneto-one into ASPEN PLUS unit-operation blocks. The ASPEN PLUS unitoperation blocks used to model the process flowsheet have been organized into five areas. These areas represents different aspects of the process and are shown in Fig. 2. In this figure material streams are shown with solid lines and energy streams with broken lines. The stream names used here, as in Fig. 1, are those names actually defined and used in the ASPEN PLUS model. 


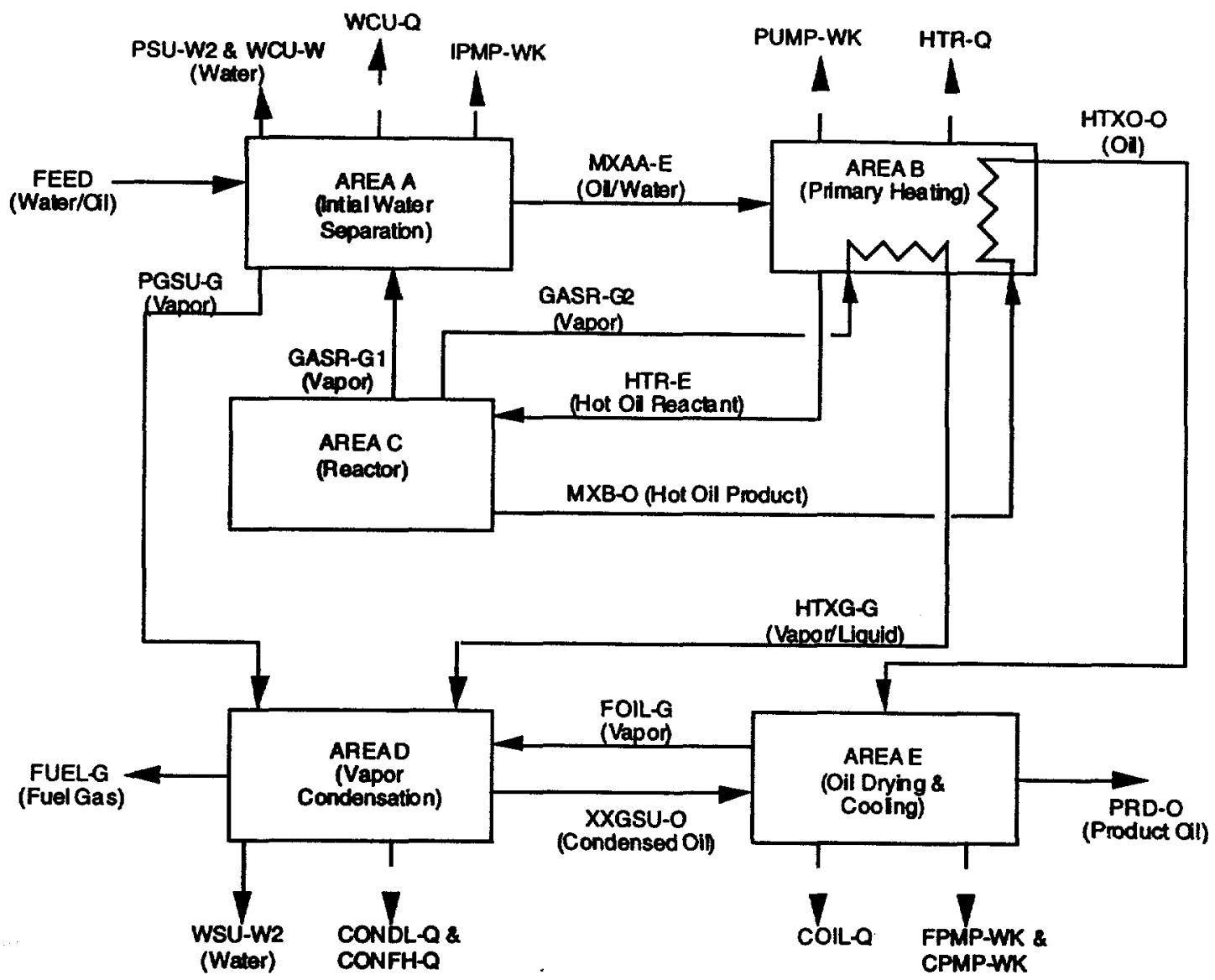

Figure 2. Process areas used in organizing the ASPEN PLUS unit-operation blocks.

In Fig. 3, Area A ASPEN PLUS blocks and streams are shown. This area models units PSU, IPMP, PRH, SSU, and WCU in the overall process flowsheet. The names shown are those of the actual ASPEN PLUS blocks. The stream names which appear on this area and the other area diagrams have been used to name streams on the overall process flowsheet, Fig. 1. The material stream names follow the convention of being composed of the unit name from which they originate, and a suffix which indicates the stream is primarily an oil/water stream (-E), a water stream (-W), a free water stream (FW), an oil stream $(-O)$, or a vapor stream $(-G)$. These conventions hold fairly well but in certain cases do not necessarily reflect the dominate phase. Energy flows are also shown (broken lines) and have a suffix indicating if it is a thermal energy stream $(-Q)$ or a mechanical energy stream (-WK). By ASPEN PLUS convention, the direction of the energy streams is always out of a block; thus, energy input streams always have a negative sign. Not included in this summary figure are streams which exist in the model, but which aregenerally zero. 


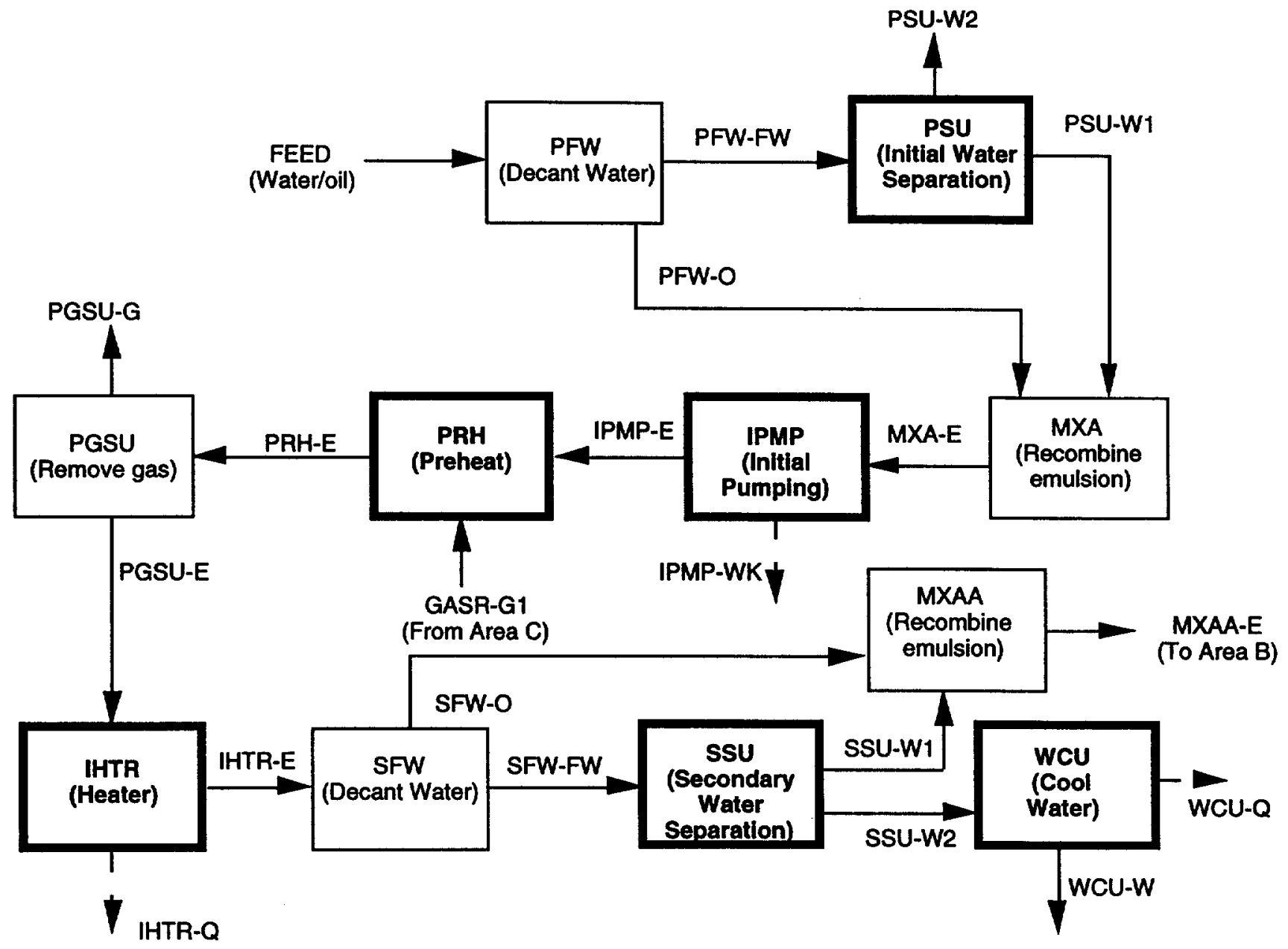

Figure 3. Model Area A, Initial Water Separation

The streams shown in the ASPEN PLUS diagrams do not necessarily represent individual streams in the actual process. For example, the free water streams represent a phase which coexists with a separate oil rich phase. Such artificial separation of streams are repeatedly used in the model to allow control over the actual amount of water remaining in a given stream. The amount of water present in the liquid phase at any point in the system in the true process is the sum of the amount dissolved in the oil phase and the amount of free water. Since the amount of free water is a function of the efficiency of separation that has occurred, plus the presence or absence of an emulsion phase, the model allows the water concentration to be set by the user at important points in the process sequence.

The function of the ASPEN PLUS unit-operation blocks for Area A are listed below. Also listed are the FORTRAN blocks associated with the unitoperation blocks. Several of the ASPEN PLUS unit-operation blocks are 
given the same names as those used for actual unit operations shown on the overall process flowsheet (Fig. 1). These blocks are closely associated with the flowsheet unit operation, but often they are only a part of the ASPEN PLUS model for that operation. The name in (\}) is the functional name of the ASPEN PLUS module (or designated as a FORTRAN code block):

- PFW \{MIXER\} - Separates free water from oil.

- PSU \{FSPLIT\} - In conjunction with the FORTRAN block FPSU sets the amount of water to be removed from the system by the first separation.

- FPSU (FORTRAN) - Sets split parameters for PSU based on stream compositions and user defined separation criteria.

- MXA \{MIXER\} - Recombines streams to represent true process flowsheet stream.

- IPMP $\{$ PUMP $\}$ - Models the pumping of process stream to intermediate pressure.

- PRH (MIXER\} - Combines vapor and process stream. Along with PGSU block it models the PRH preheat vessel.

- PGSU [FLASH2] - Models separation of gas and liquid phases in the PRH vessel.

- IHTR \{HEATER\} - A unit not shown in the process flowsheet because it is generally not needed. Based on user input it can be used to model the further heating of the process stream prior to entering the SSU unit.

- FIHTR (FORTRAN\} - Used to set exit temperature from IHTR based on user input. Handles the case when IHTR not needed.

- SFW \{MIXER\} - Separates free water from oil.

- SSU \{FSPLIT\} - In conjunction with the FORTRAN block FSSU sets the amount of water to be removed from the system by the second separation.

- FSSU \{FORTRAN\} - Sets split parameters for SSU based on stream compositions and user defined separation criteria.

- MXAA \{MIXER\} - Recombines streams to represent true flowsheet stream.

- WCU [HEATER\} - Sets the desired outlet temperature for waste water stream WCU-W and computes the required amount of cooling.

Figure 4 contains the ASPEN PLUS unit-operation blocks for Area B which model the high pressure pumping and stream heating operations:

- XGSU \{FASH2\} - Insures that no vapor phase is present in PUMP feed. The vapor stream exiting this module is always essentially zero.

- PUMP \{PUMP\} - The primary pump in the system which raises input stream to processing pressure.

- HTXG \{HEATX\} - Heat exchange between hot vapor and incoming feed.

- HTXO \{HEATX\} - Heat exchange between hot liquid and incoming feed.

- HTR \{HEATER\} - Trim temperature to desired reaction temperature. 


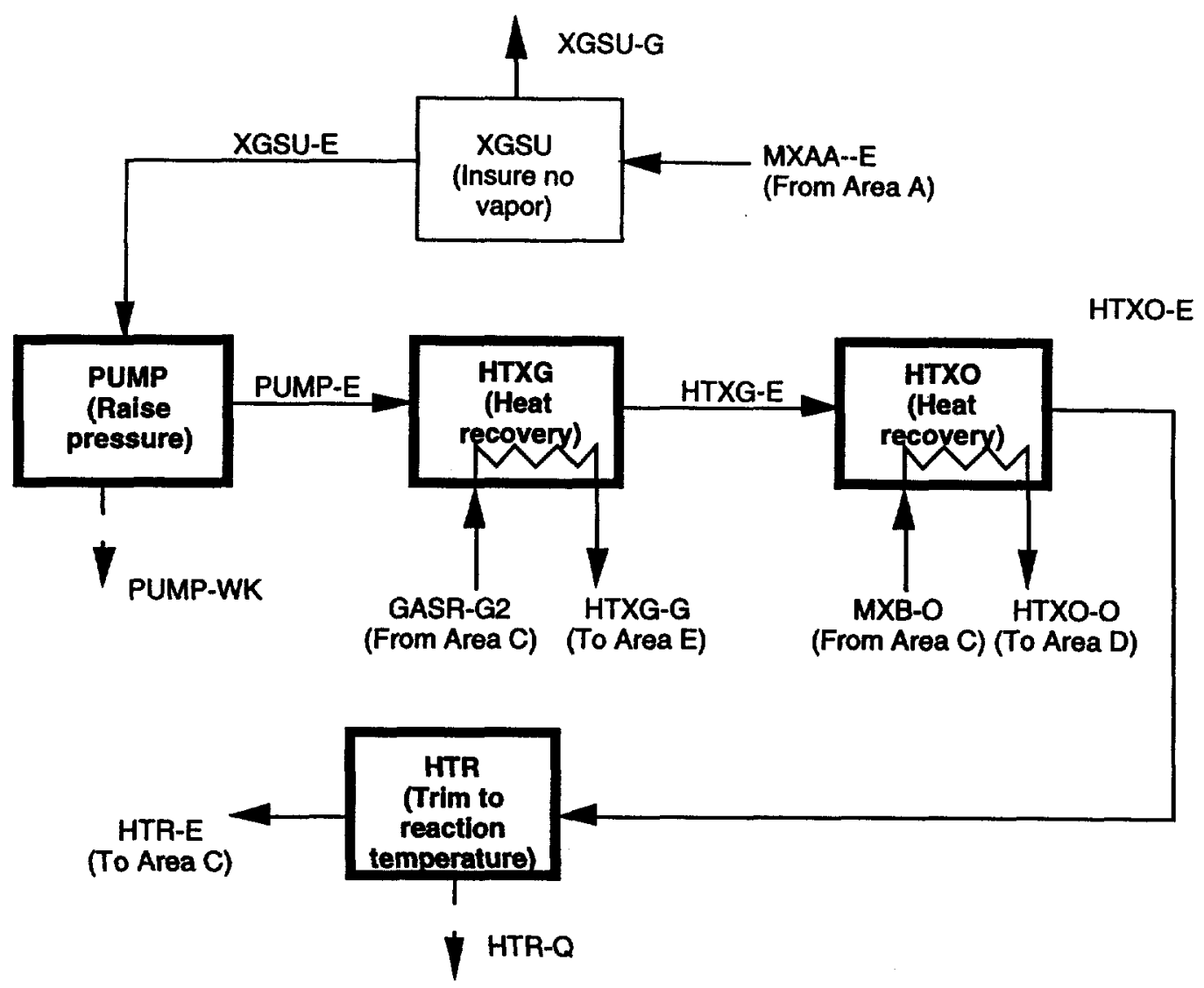

Figure 4. Model Area B, Primary Heating.

Figure 5 contains the ASPEN PLUS unit-operation blocks for Area $\mathrm{C}$ which model the reactor vessel. The model assumes that reactions within the reactor vessel can be approximated using three CSTRs in series. The pyrolysis reactions are only allowed to occur in the liquid phase.

- RU1, RU2, RU3 \{RCSTR\} - Three RCSTR unit-operation blocks which model the pyrolysis.

- FRU \{FORTRAN\} - Sets each RCSTR block volume to one third the total reactor volume. The total reactor volume is based on user requested residence time and the average of the liquid-phase volumetric flow into block RU1 (stream HTR-E) and out of block RU3 (stream RU3-E).

- RUGS \{FLASH2\} - Separate out the gas phase.

- GASR [FSPLIT) - Split the required amount to be recycled for heating the incoming feed in the PRH vessel. The split fraction is set using an ASPEN PLUS DESIGN-SPEC block, SPEC1. This design specification adjusts the split fraction until the desired temperature leaving the PRH vessel (stream PGSU-E) is reached.

- RFW (MIXER\} - Separates free water from oil. 
- RSU \{FSPLIT\} - In conjunction with the FORTRAN block FRSU sets the amount of water to be removed from the system by the second separation. In practice the model has only been used to look at cases where no free water exists, so the RSU-W2 stream flow rate is always zero.

- FRSU \{FORTRAN\} - Sets split parameters for SSU based on stream compositions and user defined separation criteria.

- MXB (MIXER) - Recombines streams to represent true flowsheet stream.

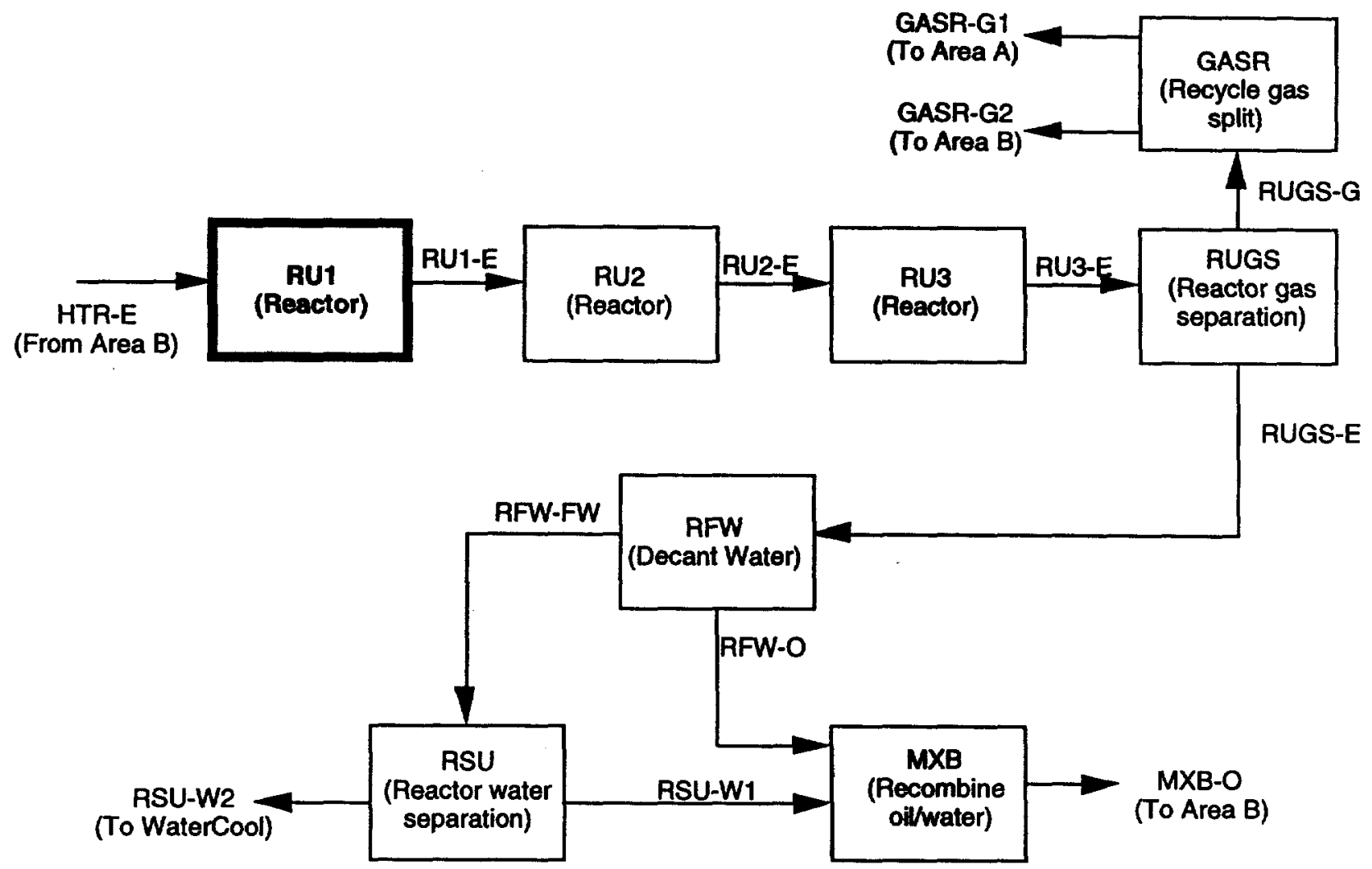

Figure 5. Model Area C, Reactor.

Figure 6 contains the ASPEN PLUS unit-operation blocks for Area E which model vapor condensation:

- MXC \{MIXER\} - Mix streams before entering low pressure condenser.

- CONDL \{FLASH2\} - Low pressure condenser, outlet temperature set.

- $\mathrm{CONDH}$ \{FLASH2\} - High pressure condenser/cooler, outlet temperature set.

- CSU \{FLASH2\} - Flash stream to low pressure and separate liquid and vapor streams.

- MXG (MIXER\} - Combine fuel gas streams. 
- MXWSU \{MIXER\} - Combine liquid streams from condensers and separate free water from oil.

- WSU \{FSPLIT\} - In conjunction with the FORTRAN block FWSU sets the amount of water to be removed from the system by the final, WSU, separation.

- FWSU \{FORTRAN] - Sets split parameters for WSU based on stream compositions and user defined separation criteria.

- CWSU \{MIXER\} - Recombines streams to represent true flowsheet stream.

- XXGSU \{FLASH2\} - Separates trace vapor phase from liquid phase to insure pump block will operate properly.

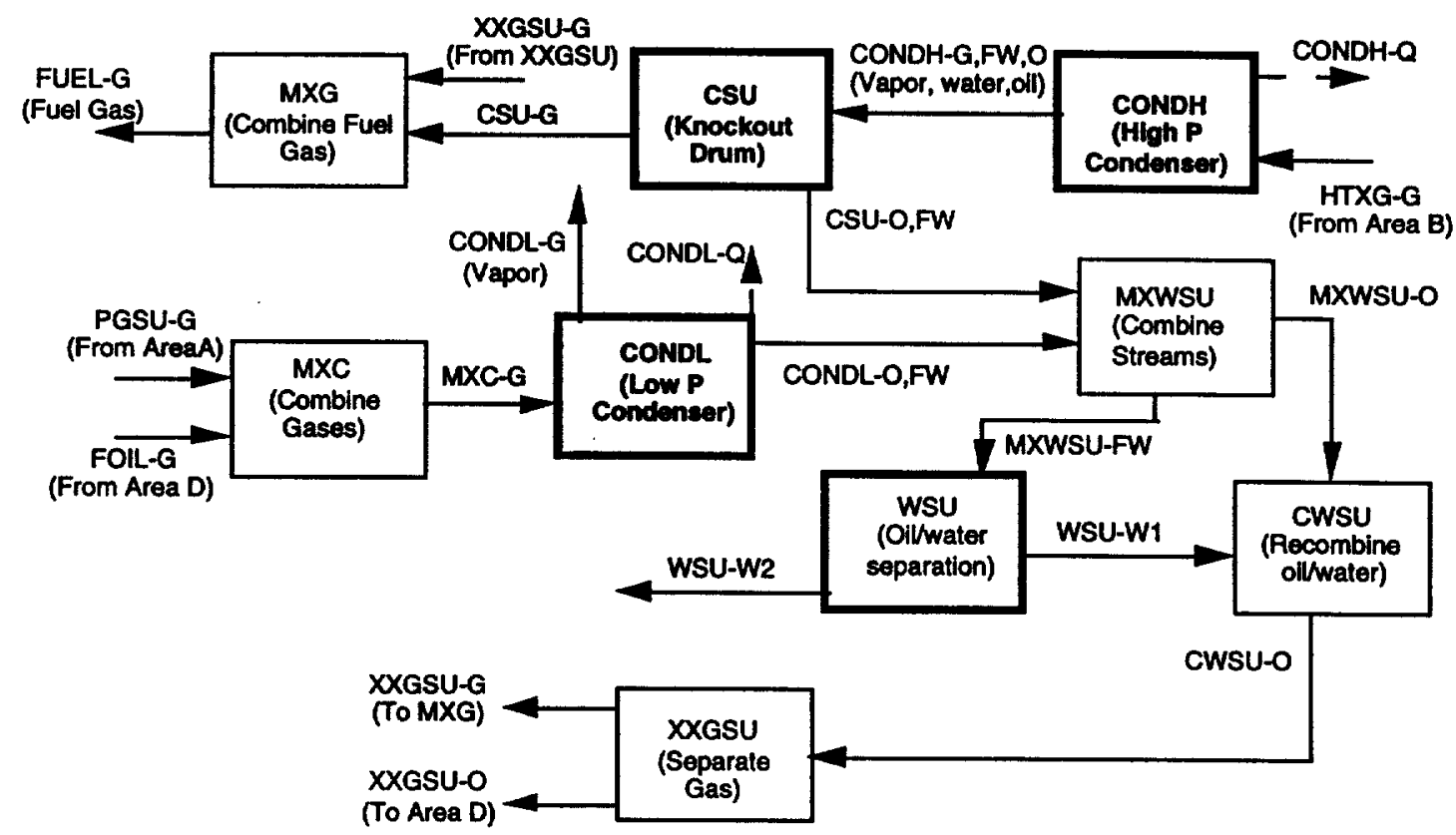

Figure 6. Model Area D, Oil Drying and Cooling

Figure 7 contains the ASPEN PLUS unit-operation blocks for Area E, which model oil drying and cooling operations, as well as low pressure pumping to reach desired delivery pressure for the product oil:

- FOIL \{FLASH2\} - Flash hot oil/water to cool and remove water.

- COIL \{HEATER\} - Cool oil.

- CPMP \& FPMP \{PUMP\} - Low pressure oil pumps to set desired delivery pressure.

- PRD \{MIXER\} - Combine oil product streams. 


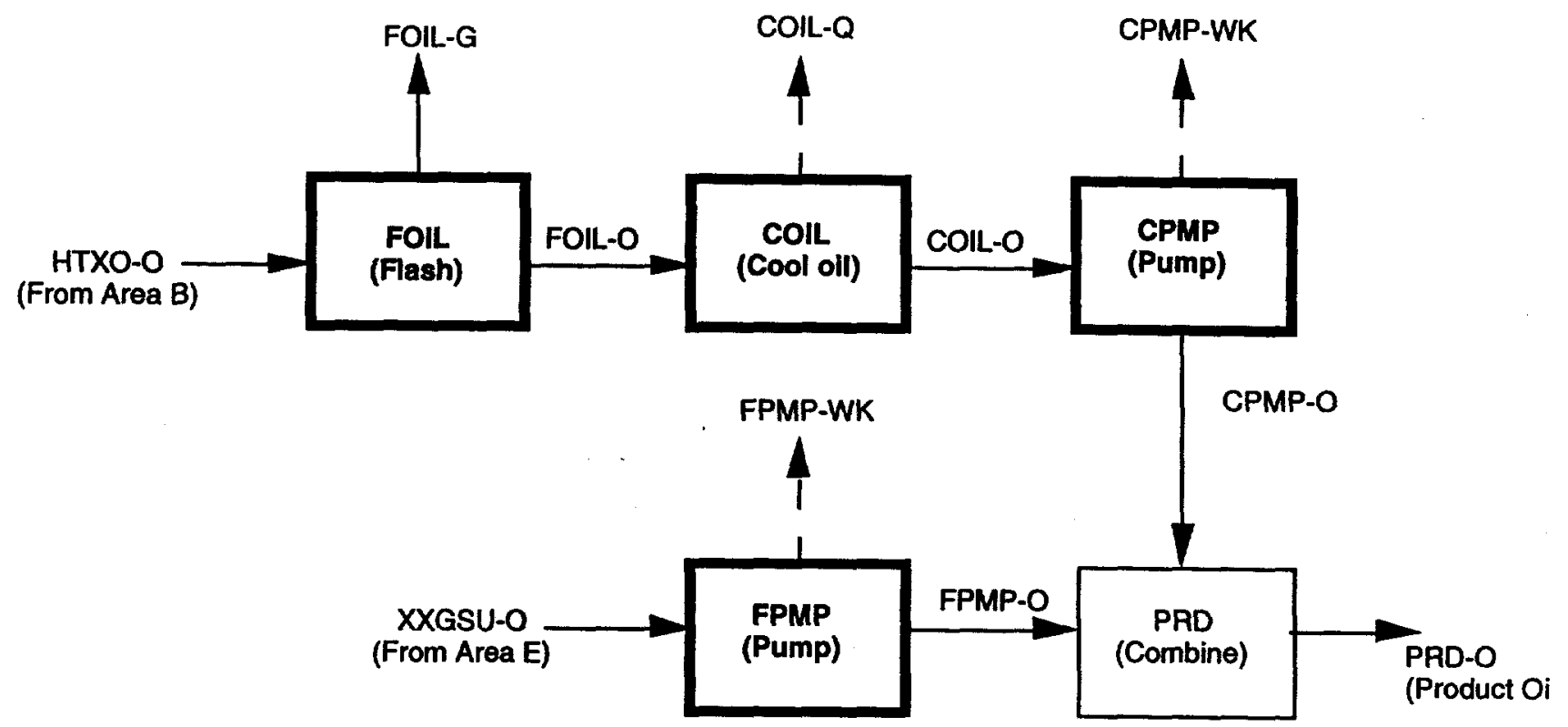

Figure 7. Model Area E, Gas Colling.

\section{Input for Unit-Operation Blocks}

Input parameters to the model are defined in the ASPEN PLUS input language file. This file not only allows specification of input parameters but also serves to define the entire flowsheet (and economic) model for the ASPEN PLUS simulation program. A listing of this file, with base case parameters, is provided in Appendix I.

The ASPEN PLUS input language file provides a great deal of flexibility in changing model parameters. Literally, thousands of model parameters can be altered by changing entries in the file. This great flexibility can lead to potential problems. The most troublesome is to distinguish the parameters which were not intended to be altered by changing the file entries from those parameters which were intended to be variable inputs to the model.

The model was constructed with a certain set parameters in mind as primary model variables. These parameters have been highlighted in the input language file in several ways. One method employed was to construct a FORTRAN code blcck in which FORTRAN variables are set to important process parameters such as reactor temperature, pressure, and residence time. 
The following is a complete list of these parameters:

- $\mathrm{pr}-$ The desired pressure of the reactor vessel in pascals $(\mathrm{Pa})$. This pressure also sets the pressure of the HTR heater and the heat recovery heat exchangers.

- tr - The desired temperature at the outlet of the HTR heater and the inlet of the reactor in degrees celcius $\left({ }^{\circ} \mathrm{C}\right)$.

- pri - The pressure of operation for the PRH vapor driven preheat vessel in pascals $(\mathrm{Pa})$. This pressure will also set the pressure of the secondary water separation vessel, SSU.

- tihtr - The desired temperature for the stream entering the secondary water separation unit, SSU. Heating is provided by hot vapor recycle. The amount of recycle is set by the DESIGN-SPEC SPEC1. If their is insufficient energy in the vapor recycle, or if vapor recycle is undesirable, SPEC1 can be deactivated and the heating will be provided by the fired heater IHTR.

- rtres - Desired residence time in the high pressure reactor vessel in minutes.

- wor1 - Desired water-to-oil ratio on a weight basis exiting the first separator, PSU. The water mass used in this ratio includes both free water and water dissolved in the oil phase; however, the water-to-oil ratio will not be lowered below the point where the free water phase disappears, regardless of the input value. Water in the vapor phase is not considered in computing the ratios.

- wor2 - Desired water-to-oil ratio on a weight basis exiting the second separator, SSU. See comments above in wor1.

- wor3 - Desired water-to-oil ratio on a weight basis exiting the reactor vessel, RU. See comments above in wor1.

- wor4 - Desired water-to-oil ratio on a weight basis exiting the final separator, WSU. See comments above in wor1.

- worf - Desired water-to-oil ratio on a weight basis in the final PRD-O. This feature is not active in the base case. It can be activated by uncommenting the DESIGN-SPEC SPEC2. SPEC2 attempts to match the desired final water content by varying the temperature difference between streams HTXG-E and HTXO-O, entering and leaving the heat exchanger HTXO. If this feature is activated the user should clearly understand the interaction between the worf and the wor4 parameters.

- prc - Delivery pressure for final oil. Used to set outlet pressure of CPMP pump.

- $\mathrm{fgr}$ - Sets initial guess for fraction of reactor gas recycled to the PRH unit. If the DESIGN-SPEC SPEC1 is commented out this will be the recycle ratio used.

- tao - Set the approach temperature $\left({ }^{\circ} \mathrm{C}\right)$ for the liquid stream heat recovery heat exchanger, HTXO. The approach temperature of exiting stream HTXO-O and entering stream HTXG-E is set by this parameter. 
- tag - Set the approach temperature $\left({ }^{\circ} \mathrm{C}\right)$ for the vapor stream heat recovery heat exchanger, HTXG. The approach temperature of exiting stream HTXG-G and entering stream PUMP-E is set by this parameter.

- wtfc \& wtfo - Sets the stoichiometry for the coke and product oil, respectively, in the pyrolysis reactions. These are ratio of weights of product to weights of reacted oil. The remaining product is assumed to be composed of gas/vapor components.

- xch4, xc2h6, xc3h8, xco2, xh2, xhhc, \& xh2s - Relative moles of gas/vapor produced by the pyrolysis reaction. These constituents represents all products of the pyrolysis except for coke and product oil. Each parameter defines the moles of component. The name of the parameter is constructed from the name of the individual component by adding the prefix ' $x$ ' (i.e. $x$ ch4 is the parameter for component $C H 4$ ). The values input are normalized to give the composition of the products, exclusive of the coke and product oil.

- akin - Pre-exponential factor in the Arrhenius' rate expression for the pyrolysis reactions. The units are reciprocal seconds $\left(\mathrm{s}^{-1}\right)$. The activation energy is set in the RU1, RU2 and RU3 RCSTR blocks.

The second type of model variables are parameters set using the ASPEN PLUS input language directly, and as a result cannot be centralized in one section of the input file. These inputs have been divided into several categories. An index of the inputs is supplied in comments in the input file, while the actual lines on which parameters are to be entered are designated with a comment of the form 'Data \# $n$ ' where ' $n$ ' is a number. These locations are easily found using an editor. Those parameters designated with numbers $0-2$ need to be changed if the crude oil composition or feed flow rate changes, while those with numbers between 21-28 are less likely to need modification. Note the parameters with numbers greater than 100 are cost parameters only and are described later.

Primary process model input parameters found on or below 'Data \#n' lines:

- $\quad 0$ - The temperature, pressure and flow rates of feed water and CRUDE. CRUDE is the name given to the input oil defined by pseudocomponents (see below). $\mathrm{H} 2 \mathrm{O}$ is the name used for water. The default units are celcius, pascals, and kilograms per second. However any units known to ASPEN PLUS $^{4}$ may be used if properly designated.

- 1 - This section is used to define the properties of the crude oil components. These are set using the ASPEN PLUS Assay Data Analysis and Pseudocomponent Correlation System. In the base case example in Appendix I the crude oil is characterized using API gravity and D86 or vacuum distillation curves for six cuts. The BLEND CRUDE statement is used to define amounts of these cuts in the composite CRUDE used in the model. 
- 2 - This section defines water solubility parameters for the crude oil components. These values override the values assigned automatically by ASPEN PLUS.

Secondary process model input parameters found on or below 'Data \#n' lines:

- 21 - Redefine activation energies or power law exponent for each reaction. Note that the pre-exponential term can be redefined only if appropriate coding is removed from the FINPUT FORTRAN block.

- 22 - Heat transfer coefficients for heat recovery heat exchangers. These parameters only effect the computed heat exchanger surface. They do not directly influence the material and energy balance calculations since the approach temperatures are used to determine operation of the heat exchangers. However, these parameters will influence the cost calculations.

- 23 - Parameters which can influence the exact size of the reactor vessel. Changes can have a small influence on energy and material balances by slightly modifying the actual residence time in the reactor. These parameters have more influence on cost calculations.

- 24 - Outlet temperature of process stream from CONDL unit.

- 25 - Outlet temperature of process stream from CONDH unit.

- 26 - Flash pressure at the CSU unit.

- 27 - Set the API gravity and normal boiling point $\left({ }^{\circ} \mathrm{C}\right)$ of the pyrolysis product oil P-OIL.

- 28 - Define the two pyrolysis reaction products COKE and HHC. The FORTRAN block SETR will compute the proper stoichiometric coefficients for the products chosen. The components are changed by changing the middle name. This name must be in the ASPEN PLUS data base or defined elsewhere in the input. (e.g., to change the HHC component from normal butane to normal pentane change the entry from 'HHC C4H10-1 HHC' to 'HHC C5H12-1 HHC').

\section{ECONOMICMODEL}

An economic evaluation of the process has been incorporated into the model using procedures available in the ASPEN PLUS system. The economic calculations draw directly on results from the process simulation to compute equipment size/cost and operating costs. Cash flow analysis and profitability analysis are carried out using procedures outlined in the ASPEN PLUS reference manual ${ }^{5}$. A start date for the project of June 1994 was used.

In general, default values available from ASPEN PLUS are used for various cost factors and economic parameters related to the estimation of total investment and profitability. However, some default values are overridden: 
- Economic life is set to 20 years.

- Costs associated with land acquisition and development are set to zero. It is assumed the process will be installed at an existing oil collection/processing facility.

- The cost for service buildings is set to zero. It is assumed general service buildings are already available.

- The total capital contingency factor is set to $15 \%$ of the Total Direct and Indirect Cost.

- Maintenance costs, including supplies and labor, are set at $4 \%$ of the Total Depreciable Costs per year.

- A single factor of $4 \%$ of the Total Depreciable Costs per year is used for property taxes, insurance, and general overhead.

- The interest rate on equity is set to $10 \%$.

Cost tables available within ASPEN PLUS are used for some equipment while other estimates are obtained from correlations taken from Walas ${ }^{6}$. The Walas correlations were used when high pressures were involved. Many equipment cost estimates in ASPEN PLUS do not adequately cover the high pressure range, and it can result in considerable cost under estimation. FORTRAN routines which are based on the Walas' correlations have been developed. Listings of these routines are presented in Appendix II. These routines are called during the ASPEN PLUS execution to establish equipment costs as needed. In the following discussion these routines are referred to as Walas Cost Routines.

Even though considerable detail on the cost analysis is reported by ASPEN PLUS, it should be remembered that the estimates are only somewhere between an "order of magnitude estimate" and a "study estimate." The basic approach used is based on estimating purchase costs of major pieces of equipment and using standard factors for installation, instrumentation, etc.

Sizing of all items include a peak allowance capacity factor. This factor defines the ratio between nominal design flows and volumes, and the flows and volumes used to size equipment. For those units costed using ASPEN PLUS algorithms, this capacity factor is set by the "PEAK" parameter; for others, this is set by the variable "capfac" in the FORTRAN INPUT block. The ASPEN PLUS default value for "PEAK" is 1.06. This value is used in the base case.

Several of the vessels are sized based on entrainment limits, as well as residence time considerations. A series of FORTRAN routines were coded to allow the entrainment limits to be incorporated with residence time specifications in determining vessel sizes. These routines are based on an 
article by R. N. Watkins ${ }^{7}$ and consider both horizontal or vertical vessels arrangements. A listing of the routines is provided in Appendix III.

Each unit shown in the process flowsheet, Fig. 1, is costed. The general methods used for each unit are outlined below. In a number of cases the equipment sizing and costing do not use standard ASPEN PLUS algorithms, and as a result certain information in the ASPEN PLUS generated output file are not valid for these units. These items are noted for each unit.

\section{PSU Unit (Cost Block C-PSU)}

This initial separation vessel is costed as a tank with enough residence time to hold 60 minutes of incoming flow (stream FEED). The ASPEN PLUS cost block TANK is used to obtain the unit cost. All ASPEN PLUS output for this unit is valid.

\section{PRH Unit (Cost Block C-PRH)}

The size of this preheat vessel is determined by using the Watkins routines and assuming a 5 minute liquid residence time. Vapor and liquid flow rates and properties are set to those in the stream exiting the unit (stream PRH-E). The sizing routine is call by FORTRAN block FCPRH. The ASPEN PLUS cost block V-VESSEL is used to cost the unit. The vessel is assumed to be carbon steel with a corrosion allowance, $0.32 \mathrm{~cm}(0.125$ in.) for the base case. ASPEN PLUS cost output related to this unit is valid except for "PEAK CAPACITY" ALLOWANCE FACTOR" and "VELOCITY RATIO."

\section{SSU Unit (Cost Block C-SSU)}

This separator vessel is sized using a 5 minute liquid residence time and assuming the vessel is $60 \%$ full. The liquid flow rate is obtained from stream PGSU-E. The ASPEN PLUS cost block H-VESSEL is used to cost the unit. A charge of $10 \%$ of the purchase cost has been added for vessel internals. All ASPEN PLUS cost output related to this unit is valid.

\section{IPMP Unit (Cost Block C-IPMP)}

This low pressure puinp size is based on a the IPMP-E stream flow and the pressure difference between the PRH and PSU units. The ASPEN PLUS cost block PUMP, assuming a stainless steel SS-ANSI pump type, is used to cost the unit. The pump is assumed to be driven by an electric motor. All ASPEN PLUS cost output related to this unit is valid. 


\section{CPMP Unit (Cost Block C-CPMP)}

This low pressure pump size is based on a the COIL-O stream flow and the pressure difference between the COIL unit and the desired product pressure. The ASPEN PLUS cost block PUMP, assuming a carbon steel SS-ANSI pump type, is used to cost the unit. The pump is assumed to be driven by an electric motor. All ASPEN PLUS cost output related to this unit is valid.

\section{FPMP Unit (Cost Block C-FPMP)}

This low pressure pump size is based on a the CWSU-O stream flow and the pressure difference between the WSU unit and the desired product pressure. The ASPEN PLUS cost block PUMP, assuming a carbon steel SS-ANSI pump type, is used to cost the unit. The pump is assumed to be driven by an electric motor. All ASPEN PLUS cost output related to this unit is valid.

\section{PUMP Unit (Cost Block C-PUMP)}

The high pressure pump cost was based on the Walas Cost routine "usrpmp." This routine is call by FORTRAN block FC-PUMP. The MXAA-E stream flow rate and the pressure difference between this stream and stream PUMP-E is used to size the pump. The pump is assumed to be stainless steel construction and driven by an electric motor. Because of the use of the Walas Cost Routine, the following ASPEN PLUS cost output is not valid for this unit "PUMP-TYPE," "MATERIAL OF CONSTRUCTION," "PEAK CAPACITY ALLOWANCE FACTOR," "MATERIAL OF CONSTRUCTION FACTOR," "PUMP EFFICIENCY," "MOTOR EFFICIENCY," "POWER REQUIRED PER PUMP, "and "CARBON STEEL COST."

\section{HTXG Unit (Cost Block C-HTXG)}

This heat recovery heat exchanger is sized (the required heat transfer area) by the ASPEN PLUS unit-operation block HEATX (user block HTXG). The cost is obtained from the Walas Cost routine "usrht1," called by FORTRAN block FCHTXG. The materials of construction are assumed to be stainless steel. Because of the use of the Walas Cost routine, the following ASPEN PLUS cost output is not valid for this unit "HEAT EXCHANGER TYPE," "SHELL MATERIAL," "TUBE MATERIAL," PEAK CAPACITY FACTOR," "NUMBER OF SHELL PASSES," NUMBER OF TUBE PASSES," "HEAT TRANSFER COEFFICIENT," "MATERIAL OF CONSTRUCTION FACTOR," and . "CARBON STEEL COST." 


\section{HTXO Unit (Cost Block C-HTXO)}

This heat recovery heat exchanger is sized by the ASPEN PLUS unit-operation block HEATX (user block HTXO). The cost is obtained from the Walas Cost routine "usrht1," called by FORTRAN block FCHTXO. The materials of construction are assumed to be stainless steel. The list of ASPEN PLUS cost output which is not valid is the same as that for the HTXG unit above.

\section{HTR Unit (Cost Block C-HTR)}

This fired heater is sized using the computed heat stream HTR-Q and an assumed efficiency. The base case efficiency factor is 0.75 . The cost is obtained from the Walas Cost routine "usrhtr," called by FORTRAN block FCHTR. This routine is used because the ASPEN PLUS cost correlations do not go to a high enough pressure. The materials of construction are assumed to be carbon steel since no free water is present at this stage of the process. Because of the use of the Walas Cost routine, the following ASPEN PLUS cost output is not valid for this unit "FIRED HEATER TYPE," PEAK CAPACITY FACTOR," "MATERIAL OF CONSTRUCTION FACTOR," “THERMAL EFFICIENCY," and "CARBON STEEL COST."

\section{RU Unit (Cost Block C-RU)}

The size of the reactor vessel is determined by using the Watkins routines and assuming a specified liquid residence time. Vapor and liquid flow rates and properties are set to the average of those in streams entering and exiting the reactor, streams HTR-E and RU-E respectively (note RU-E is equal to the sum of streams RUGS-G and MXB-O). The sizing routine is call by FORTRAN block FRU. The ASPEN PLUS cost block H-VESSEL is used to cost the unit. The vessel is assumed to be carbon steel with a corrosion allowance, $0.32 \mathrm{~cm}(0.125 \mathrm{in}$.) for the base case. ASPEN PLUS cost output related to this unit is valid except for "PEAK CAPACITY ALLOWANCE FACTOR."

\section{FOIL Unit (Cost Block C-FOIL)}

The size of this flash vessel is determined by using the Watkins routines and assuming a 5 minute liquid residence time. Vapor and liquid flow rates and properties are set to those in the stream exiting the unit, streams FOIL-O and -G. The sizing routine is called by FORTRAN block FCFOIL. The ASPEN PLUS cost block H-VESSEL is used to cost the unit. The vessel is assumed to be carbon steel with a corrosion allowance, $0.32 \mathrm{~cm}(0.125 \mathrm{in}$.) for the base case. ASPEN PLUS cost output related to this unit is valid except for "PEAK CAPACITY ALLOWANCE FACTOR." 


\section{COIL Unit (Cost Block C-COIL)}

This air cooler used to cool the oil stream is sized and costed using the aspen cost block AIRCOOL. Carbon steel construction is assumed. All ASPEN PLUS output for this unit is valid.

\section{CONDH Unit (Cost Block C-CONDH)}

This heat exchanger used to cool the mostly condensed vapor stream HTXG-G is sized by the ASPEN PLUS unit-operation block HEATX (user block CONDH). The cost is obtained from the Walas Cost routine "usrht1," called by FORTRAN block FCCONDH. The materials of construction are assumed to be stainless steel. The list of ASPEN PLUS cost output which is not valid is the same as that for the HTXG unit above.

\section{CSU Unit (Cost Block C-CSU)}

The size of this flash vessel is determined by using the Watkins routines and assuming a 5 minute liquid residence time. Vapor and liquid flow rates and properties are set to those in the stream exiting the unit, streams CSU-O -FW and $-\mathrm{G}$. The sizing routine is call by FORTRAN block FCCSU. The ASPEN PLUS cost block H-VESSEL is used to cost the unit. The vessel is assumed to be carbon steel with a corrosion allowance, $0.32 \mathrm{~cm}(0.125 \mathrm{in}$.) for the base case. ASPEN PLUS cost output related to this unit is valid except for "PEAK CAPACITY ALLOWANCE FACTOR" and "LIQUID STREAM FLOW."

\section{CONDL Unit (Cost Block C-CONDL)}

This unit condenses vapor from the FOIL flash. The unit is sized and costed by ASPEN PLUS unit-operation and cost blocks HEATX. The materials of construction are assumed to be stainless steel. All ASPEN PLUS output for this unit is valid.

\section{WCU Unit (Cost Block C-WCU)}

This unit cools the water stream, SSU-W2, exiting the oil-water spearator SSU. The unit is sized and costed by ASPEN PLUS unit-operation and cost blocks HEATX. The materials of construction of the shell and tube heat exchanger are assumed to be stainless steel and carbon steel respectively. All ASPEN PLUS output for this unit is valid. 


\section{WSU Unit (Cost Block C-WSU)}

This separator vessel is sized using a 5 minute liquid residence time and assuming the vessel is $60 \%$ full. The liquid flow rate is obtained from streams CONDL and CSU -O and -FW. The ASPEN PLUS cost block H-VESSEL is used to cost the unit. A charge of $10 \%$ of the purchase cost has been added for vessel internals. All ASPEN PLUS cost output related to this unit is valid.

\section{Other Cost Parameters}

As with the process parameters cost related parameters are input to the model through the FORTRAN INPUT block and through labeled lines. Only one purely cost related parameter is set by the a FORTRAN INPUT variable. This is capfac which is the capacity factor used by all non ASPEN PLUS sizing/costing routines. It is equivalent to the PEAK parameter used in ASPEN PLUS blocks. In the base case it is set to equal the ASPEN PLUS default value of 1.06 .

A number of cost parameters which are input using the ASPEN PLUS input language are noted in the input file using the 'Data \#1nm' tag. The ' $\mathrm{nm}$ ' is a particular number. These lines include the following:

- 101 - Residence time of the PSU, PRH, SSU, and WSU units. Base case values are 5 minutes for the PRH, SSU and WSU units and 60 minutes for the PSU unit.

- 102 - Utility costs. Base case values for January 1994 : electricity $\$ 0.05 / \mathrm{kW}$ $\mathrm{hr}$, natural gas $\$ 2.1 / \mathrm{GJ}$, and cooling water $\$ 0.088 / \mathrm{Mg}$ ( $\$ 0.04 /$ thousand-lbm).

- 103 - Labor costs and number of operators. Base case values for June 1991 is $\$ 16 / \mathrm{hr}$ for operators and $\$ 20 / \mathrm{hr}$ for June 1995 construction labor. The number of operators is set at one.

- 104 - Corrosion allowances. Base case $0.32 \mathrm{~cm}(0.125 \mathrm{in}$.)

- 105 - Parameters used by the Watkins' routines in sizing the FOIL flash vessel.

- 106 - Parameters used by the Watkins' routines in sizing the CSU flash vessel.

- 107 - Cooling water temperatures. The base case uses a supply temperature of $16^{\circ} \mathrm{C}\left(60^{\circ} \mathrm{F}\right)$ and a return temperature of $60^{\circ} \mathrm{C}\left(140^{\circ} \mathrm{F}\right)$.

- 108 - Fired heater HTR efficiency. The efficiency is defined as the heat transferred to the process fluid divided by the heat of combustion of the consumed natural gas. The base case uses 0.75 .

- 109 - Parameters used by the Watkins' routines in sizing the PSU preheat vessel.

- 110 - Pump type for the ASPEN PLUS sized units IPMP, FPMP and CPMP. 
- 111 - Cost factor, applied to purchase price, for internals for separation units SSU and WSU.

For the most part ASPEN PLUS default values were used for other cost parameters. However, several default values were changed:

- COST-INDEX - ASPEN PLUS version 9.2-1 contains cost index information up to March 1995. For dates beyond that a 0.03 escalation factor was used for all indexes except the "FUEL" index which was set at 0.05 .

- CONTINGENCY - As defined by ASPEN PLUS the "PROJECT-BASIS" contingency was set at 0.05 and the "PROJECT-DEFINITION" contingency at 0.10 .

- OPERATING-COST - "OTHER-LABOR MAINTENANCE" is set to zero since maintenance costs are included in "SUPPLIES MAINTENANCE FACTOR" which is set to 0.04. The "GENERAL-WORKS" parameters "GEN-ADMIN" and "TAX" are set to zero and these costs are lumped together in the "ADDITIONAL FACTOR" which is set to 0.04 .

\section{ASPEN PLUS OUTPUT FILES}

ASPEN PLUS produces a number of output files upon successful execution. The complete list is given in the ASPEN PLUS documentation ${ }^{8}$. The results of the simulation are present in the file "name.rep," where name is the user specified name. This file contains results originating from the ASPEN PLUS as well as results from user subroutines. User subroutines usrht1, usrpmp, usrhtr, sepv, and seph also write information to this file. These results are located near the beginning of the file just after the table of contents. The user routine output gives information about calculations performed by the user routines. These results are labeled according to the process unit with which they are associated.

Appearing just after the user results from routines associated with process units is a set of results computed by the FORTRAN block OUT. These results summarize selected performance information. At the top is a short section which summarizes the performance of HTXG and HTXO heat exchangers. This is followed by the fraction of reactor vapor flow used in the PRH vessel. Next the amount of water in the liquid oil phase at the reactor exit and in the product stream PRD-O are reported. Next is information on free water flow, vapor flow exiting the reactor, and summary injection, and production oil flows and gravity. A section on gas composition of the FUEL-G stream follows along with the energy usage of the HTR fired heater and the fraction of reaction product P-OIL which exits in the FUEL-G stream. The last section reports some economic numbers which give the required increase in oil value that leads to a profitable operation (as defined by the cash flow analysis). 
Two numbers are given: one assuming the oil has no initial value, and one assuming that the input oil is worth $\$ 64.6 / \mathrm{Mg}(\$ 10 / \mathrm{bbl})$. Since some oil is destroyed in the process, the required profit is a function of the feed oil value.

\section{BASE CASE RESULTS}

The model input language file given in Appendix I was run with ASPEN PLUS version 9.2-1 software. ASPEN PLUS produces an output file (name.rep) of more than one hundred pages. It reports results for all process streams, unit-operation blocks, cost blocks, and cash flow analysis. In the following two subsections, selected results from this output file for the base case conditions are presented.

\section{Flowsheet Results}

Figure 8 lists computed results for all major process flow streams, including the energy streams. The location of these streams can be found by referring to the overall process flowsheets representations given in Figs. 1 and 2. Specific information on detailed streams within the model system can be found by referring to the ASPEN PLUS module layouts given in Figs. 3-7.

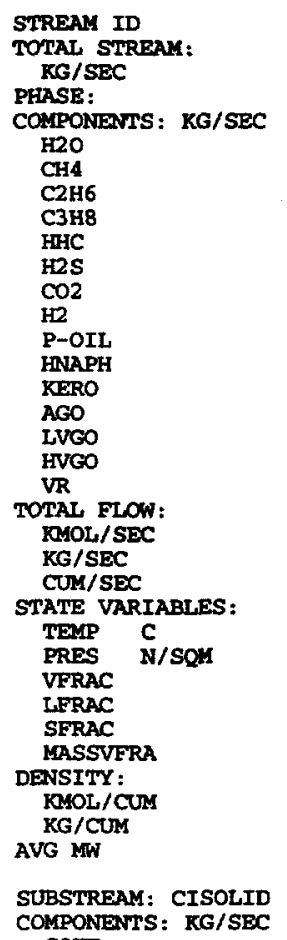

\begin{tabular}{|c|c|c|c|c|}
\hline CorL-o & CONDH-G & CONDH-FW & CONDH-O & $\cos 10 t-F H$ \\
\hline $\begin{array}{l}2.9457 \\
\text { LIQUID }\end{array}$ & $\begin{array}{l}0.0 \\
\text { MISSING }\end{array}$ & $\begin{array}{l}0.4292 \\
\text { LIQUID }\end{array}$ & $\begin{array}{l}2.0117 \\
\text { LIQUID }\end{array}$ & $\begin{array}{l}5.6752-02 \\
\text { LIOUID }\end{array}$ \\
\hline $\begin{array}{r}1.1362-03 \\
3.9074-05 \\
1.0152-04 \\
1.3433-04 \\
2.3027-04 \\
3.0895-05 \\
2.5334-05 \\
3.4292-07 \\
2.4868-02 \\
1.6349-02 \\
4.0230-02 \\
0.1568 \\
0.3723 \\
0.8517 \\
1.1827\end{array}$ & $\begin{array}{l}0.0 \\
0.0 \\
0.0 \\
0.0 \\
0.0 \\
0.0 \\
0.0 \\
0.0 \\
0.0 \\
0.0 \\
0.0 \\
0.0 \\
0.0 \\
0.0 \\
0.0\end{array}$ & $\begin{array}{l}0.4292 \\
0.0 \\
0.0 \\
0.0 \\
0.0 \\
0.0 \\
0.0 \\
0.0 \\
0.0 \\
0.0 \\
0.0 \\
0.0 \\
0.0 \\
0.0 \\
0.0\end{array}$ & $\begin{array}{r}1.2256-04 \\
6.2683-02 \\
3.9435-02 \\
4.6943-02 \\
4.0464-02 \\
1.6994-02 \\
3.2109-02 \\
6.7517-04 \\
0.6814 \\
0.1646 \\
0.1892 \\
0.3186 \\
0.2682 \\
0.1326 \\
1.7608-02\end{array}$ & $\begin{array}{c}5.6752-02 \\
0.0 \\
0.0 \\
0.0 \\
0.0 \\
0.0 \\
0.0 \\
0.0 \\
0.0 \\
0.0 \\
0.0 \\
0.0 \\
0.0 \\
0.0 \\
0.0\end{array}$ \\
\hline $\begin{array}{r}6.8163-03 \\
2.6469 \\
2.7878-03\end{array}$ & $\begin{array}{l}0.0 \\
0.0 \\
0.0\end{array}$ & $\begin{array}{r}2.3828-02 \\
0.4292 \\
4.3160-04\end{array}$ & $\begin{array}{r}1.9667-02 \\
2.0117 \\
3.1677-03\end{array}$ & $\begin{array}{l}3.1502-03 \\
5.6752-02 \\
5.7061-05\end{array}$ \\
\hline $\begin{array}{c}93.3333 \\
2.0684+05 \\
0.0 \\
1.0000 \\
0.0 \\
0.0\end{array}$ & $\begin{array}{r}\text { MISSING } \\
1.3780+07 \\
\text { MISSING } \\
\text { MISSING } \\
\text { MISSING } \\
\text { MISSING }\end{array}$ & $\begin{array}{c}23.8888 \\
1.3780+07 \\
0.0 \\
1.0000 \\
0.0 \\
0.0\end{array}$ & $\begin{array}{c}23.8888 \\
1.3780+07 \\
0.0 \\
1.0000 \\
0.0 \\
0.0\end{array}$ & $\begin{array}{c}23.8888 \\
2.0684+05 \\
0.0 \\
1.0000 \\
0.0 \\
0.0\end{array}$ \\
\hline $\begin{array}{r}2.4450 \\
949.4536 \\
388.3201\end{array}$ & $\begin{array}{l}\text { MISSING } \\
\text { MISSING } \\
\text { MISSING }\end{array}$ & $\begin{array}{r}55.2078 \\
994.5850 \\
18.0152\end{array}$ & $\begin{array}{r}6.2087 \\
635.0885 \\
102.2900\end{array}$ & $\begin{array}{r}55.2078 \\
994.5850 \\
18.0152\end{array}$ \\
\hline \multicolumn{5}{|c|}{ CONVENTIONAL } \\
\hline 0.2988 & 0.0 & 0.0 & 0.0 & 0.0 \\
\hline
\end{tabular}

Figure 8. Base case material and energy streams. 


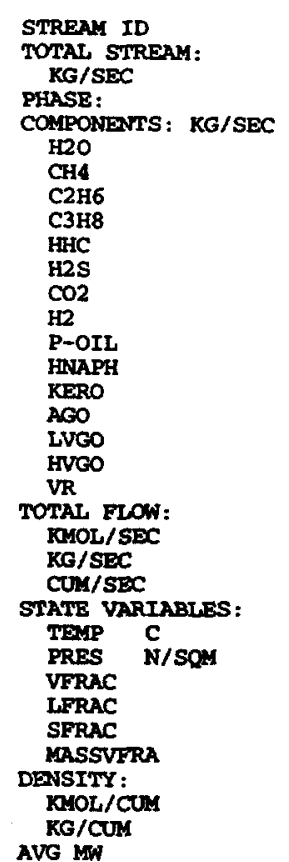

SURSTREAM: CISOLID COMPONENTS: KG/SEC COKE

\begin{tabular}{|c|c|c|c|c|}
\hline CONDL-G & CONDL-O & CPAP-O & CSU-FW & $\operatorname{cs} \theta-G$ \\
\hline $\begin{array}{c}5.4992-02 \\
\text { VAPOR }\end{array}$ & $\begin{array}{l}0.3640 \\
\text { LIQUID }\end{array}$ & $\begin{array}{l}2.9457 \\
\text { LIQUID }\end{array}$ & $\begin{array}{l}0.4279 \\
\text { LIQUID }\end{array}$ & $\begin{array}{l}0.2067 \\
\text { VAPOR }\end{array}$ \\
\hline $\begin{array}{c}5.5571-04 \\
1.6644-02 \\
1.0524-02 \\
8.1526-03 \\
4.2730-03 \\
2.8270-03 \\
9.1231-03 \\
2.2420-04 \\
2.5980-03 \\
6.2446-05 \\
7.1810-06 \\
5.1397-07 \\
2.7063-09 \\
1.0028-12 \\
0.0\end{array}$ & $\begin{array}{r}6.4248-06 \\
2.2042-04 \\
6.5765-04 \\
1.6470-03 \\
4.0504-03 \\
4.3717-04 \\
2.2421-04 \\
3.3380-07 \\
0.1877 \\
4.8467-02 \\
4.7524-02 \\
5.3167-02 \\
1.7498-02 \\
2.3668-03 \\
8.8961-05\end{array}$ & $\begin{array}{r}1.1362-03 \\
3.9074-05 \\
1.0152-04 \\
1.3433-04 \\
2.3027-04 \\
3.0895-05 \\
2.5334-05 \\
3.4292-07 \\
2.4868-02 \\
1.6349-02 \\
4.0230-02 \\
0.1568 \\
0.3723 \\
0.8517 \\
1.1827\end{array}$ & $\begin{array}{l}0.4279 \\
0.0 \\
0.0 \\
0.0 \\
0.0 \\
0.0 \\
0.0 \\
0.0 \\
0.0 \\
0.0 \\
0.0 \\
0.0 \\
0.0 \\
0.0 \\
0.0\end{array}$ & $\begin{array}{c}1.4303-03 \\
6.1704-02 \\
3.6569-02 \\
3.7107-02 \\
1.7609-02 \\
1.4118-02 \\
3.1123-02 \\
6.7406-04 \\
6.2205-03 \\
1.3456-04 \\
1.7399-05 \\
1.7785-06 \\
2.2180-08 \\
2.6888-11 \\
0.0\end{array}$ \\
\hline $\begin{array}{l}2.1025-03 \\
5.4992-02 \\
2.4867-02\end{array}$ & $\begin{array}{r}2.7911-03 \\
0.3640 \\
4.4915-04\end{array}$ & $\begin{array}{r}6.8163-03 \\
2.6469 \\
2.7875-03\end{array}$ & $\begin{array}{r}2.3754-02 \\
0.4279 \\
4.2779-04\end{array}$ & $\begin{array}{r}7.8002-03 \\
0.2067 \\
9.0317-02\end{array}$ \\
\hline $\begin{array}{r}23.8888 \\
2.0684+05 \\
1.0000 \\
0.0 \\
0.0 \\
1.0000\end{array}$ & $\begin{array}{c}23.8888 \\
2.0684+05 \\
0.0 \\
1.0000 \\
0.0 \\
0.0\end{array}$ & $\begin{array}{c}93.9652 \\
1.0340+06 \\
0.0 \\
1.0000 \\
0.0 \\
0.0\end{array}$ & $\begin{array}{c}17.9158 \\
2.0684+05 \\
0.0 \\
1.0000 \\
0.0 \\
0.0\end{array}$ & $\begin{array}{r}17.9158 \\
2.0684+05 \\
1.0000 \\
0.0 \\
0.0 \\
1.0000\end{array}$ \\
\hline $\begin{array}{r}8.4548-02 \\
2.2114 \\
26.1557\end{array}$ & $\begin{array}{r}6.2143 \\
810.6073 \\
130.4410\end{array}$ & $\begin{array}{r}2.4452 \\
949.5552 \\
388.3201\end{array}$ & $\begin{array}{r}55.5261 \\
1000.3185 \\
18.0152\end{array}$ & $\begin{array}{r}8.6364-02 \\
2.2887 \\
26.5007\end{array}$ \\
\hline
\end{tabular}

STRUCTURE : CONVENTIONAL
0.0
0.0
0.2988
0.0
0.0

Figure 8. (continued). Base case material and energy streams.

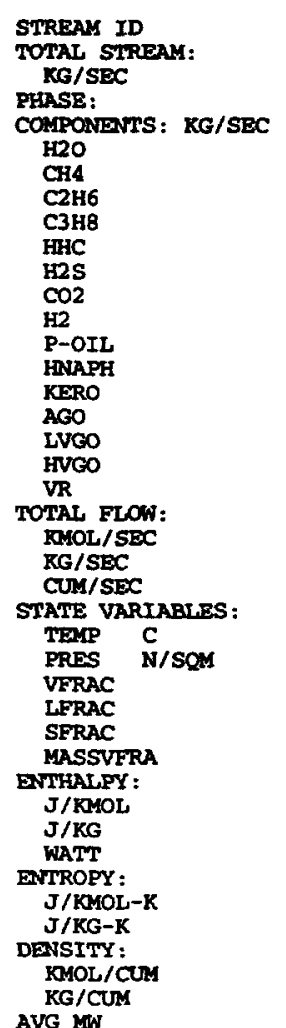

SUBSTREAM: CISOLID COMPONENTS: KG/SEC

\begin{tabular}{|c|c|c|c|c|}
\hline & & & & $I L=0$ \\
\hline & & & & \\
\hline $\begin{array}{r}2.3491-05 \\
9.7843-04 \\
2.8663-03 \\
9.8354-03 \\
2.2855-02 \\
2.8760-03 \\
9.8610-04 \\
1.1072-06 \\
0.6751 \\
0.1644 \\
0.1891 \\
0.3186 \\
0.2682 \\
0.1326 \\
1.7608-02\end{array}$ & $\begin{array}{r}2.1704-02 \\
1.1988-03 \\
3.5240-03 \\
1.1482-02 \\
2.6906-02 \\
3.3131-03 \\
1.2103-03 \\
1.4410-06 \\
0.8629 \\
0.2129 \\
0.2367 \\
0.3717 \\
0.2857 \\
0.1350 \\
1.7697-02\end{array}$ & $\begin{array}{l}55.0977 \\
0.0 \\
0.0 \\
0.0 \\
0.0 \\
0.0 \\
0.0 \\
0.0 \\
0.0 \\
0.2659 \\
0.3257 \\
0.6434 \\
0.8671 \\
1.4412 \\
1.8312\end{array}$ & $\begin{array}{l}8.0 \\
8.1 \\
7.8 \\
7.7 \\
2.4 \\
5.2 \\
9.4 \\
4.8 \\
4.7 \\
5.3 \\
1.7\end{array}$ & $\begin{array}{r}1.1362-03 \\
3.9074-05 \\
1.0152-04 \\
1.3433-04 \\
2.3027-04 \\
3.0895-05 \\
2.5334-05 \\
3.4292-07 \\
2.4868-02 \\
1.6349-02 \\
4.0230-02 \\
0.1568 \\
0.3723 \\
0.8517 \\
1.1827\end{array}$ \\
\hline $\begin{array}{r}1.1941-02 \\
1.8064 \\
2.1376-03\end{array}$ & $\begin{array}{r}1.5935-02 \\
2.1921 \\
2.6079-03\end{array}$ & $\begin{array}{r}3.0746 \\
60.4725 \\
.1748-02\end{array}$ & $\begin{array}{r}7.0908-03 \\
0.4548 \\
0.1569\end{array}$ & $\begin{array}{r}6.8163-0 \\
2.646 \\
3.2145-0\end{array}$ \\
\hline $\begin{array}{c}17.9158 \\
2.0684+05 \\
0.0 \\
1.0000 \\
0.0 \\
0.0\end{array}$ & $\begin{array}{c}18.8297 \\
2.0684+05 \\
0.0 \\
1.0000 \\
0.0 \\
0.0\end{array}$ & $\begin{array}{c}6.8948+04 \\
0.0 \\
1.0000 \\
0.0 \\
0.0\end{array}$ & $\begin{array}{r}284.0831 \\
2.0684+05 \\
1.0000 \\
0.0 \\
0.0 \\
1.0000\end{array}$ & $\begin{array}{l}.0684+05 \\
0.0 \\
1.0000 \\
0.0 \\
0.0\end{array}$ \\
\hline
\end{tabular}

$-2.5481+08-2.5066+08-2.8618+08-1.5961+08-4.3459+08$ $-1.6844+06-1.8222+06-1.4550+07-2.4885+06-1.1191+06$ $-3.0427+06-3.9944+06-8.7990+08-1.1318+06-2.9623+06$

$-9.3766+05-8.5657+05-1.6949+05-2.4426+05-1.9141+06$ $-6198.3405-6226.6539-8617.6019-3808.2895-4929.1000$ $\begin{array}{rrrrr}5.5863 & 6.1104 & 49.7936 & 4.5186-02 & 2.1008 \\ 845.0744 & 840.5804 & 979.3403 & 2.8982 & 815.8198 \\ 151.2754 & 137.5650 & 19.6679 & 64.1396 & 388.3201\end{array}$ STRUCTURE : CONVENTIONAI

$\begin{array}{lllll}0.0 & 0.0 & 0.0 & 0.0 & 0.2988\end{array}$




\begin{tabular}{|c|c|c|c|c|c|}
\hline $\begin{array}{l}\text { STREAY ID } \\
\text { TOTAL STREAM: }\end{array}$ & FRMP-O & FUEL-G & GASR-G1 & GASR-G2 & HTR $-E$ \\
\hline $\mathrm{KG} / \mathrm{SEC}$ & 2.1921 & 0.2617 & 0.5212 & 2.4410 & 6.3628 \\
\hline $\begin{array}{l}\text { PHASE: } \\
\text { COMPONENTS: KG/SEC }\end{array}$ & LIQUID & MIXED & VAPOR & MIXED & MIXED \\
\hline $\mathrm{H} 2 \mathrm{O}$ & $2.1704-02$ & $1.9860-03$ & $9.1685-02$ & 0.4293 & 0.5784 \\
\hline $\begin{array}{l}\mathrm{CH} 4 \\
\mathrm{C} 2 \mathrm{H} 6\end{array}$ & $\begin{array}{l}1.1988-03 \\
3.5240-03\end{array}$ & $\begin{array}{l}7.8348-02 \\
4.7093-02\end{array}$ & $\begin{array}{l}1.3384-02 \\
8.4205-03\end{array}$ & $\begin{array}{l}6.2683-02 \\
3.9435-02\end{array}$ & $\begin{array}{l}4.5366-03 \\
5.4032-03\end{array}$ \\
\hline $\begin{array}{l}\text { C3H8 } \\
\text { HHC }\end{array}$ & $\begin{array}{l}1.1482-02 \\
2.6906-02\end{array}$ & $\begin{array}{r}4.5260-02 \\
2.1882-02\end{array}$ & $\begin{array}{l}1.0024-02 \\
8.6402-03\end{array}$ & $\begin{array}{r}4.6943-02 \\
4.0464-02\end{array}$ & $\begin{array}{l}8.0488-03 \\
8.0374-03\end{array}$ \\
\hline H2S & $3.3131-03$ & $1.6945-02$ & $3.6287-03$ & $\begin{array}{l}.0464-02 \\
1.6994-02\end{array}$ & $2.7805-03$ \\
\hline $\mathrm{CO} 2$ & $1.2103-03$ & $4.0246-02$ & $6.8562-03$ & $3.2109-02$ & $2.7571-03$ \\
\hline $\begin{array}{l}\text { H2 } \\
\text { P-OIL }\end{array}$ & $\begin{array}{r}1.4410-06 \\
0.8629\end{array}$ & $\begin{array}{l}8.9826-04 \\
8.8185-03\end{array}$ & $\begin{array}{r}1.4417-04 \\
0.1455\end{array}$ & $\begin{array}{r}6.7517-04 \\
0.6814\end{array}$ & $\begin{array}{r}1.4157-05 \\
0.1451\end{array}$ \\
\hline HNAPH & 0.2129 & $701-04$ & $3.5151-02$ & 0.1646 & 0.3009 \\
\hline KERO & 0.2367 & $2.4580-05$ & $4.0400-02$ & 0.1892 & 0.3661 \\
\hline AGO & 1717 & & $1-02$ & 0.3186 & 0.7115 \\
\hline LVGO & 0.2857 & & $280-02$ & & 0.9244 \\
\hline HVGO & 0.1350 & 1 & $8323-02$ & 0.1326 & 1.4696 \\
\hline VR & $1.7697-02$ & & -03 & 1.76 & 1.8350 \\
\hline TOTAL FLOW: & & & & & \\
\hline KHOL/SEC & $1.5935-02$ & $9.9026-03$ & $9.2874-03$ & 4. 3495-02 & $5.1696-02$ \\
\hline $\mathrm{KG} / \mathrm{SEC}$ & 2.1921 & 0.2 & 0.5212 & 2.4410 & 6.3628 \\
\hline CUM/SBC & $2.6090-0$ & & $2.9435-03$ & $1.3785-02$ & $1.5771-02$ \\
\hline STATE VARIABLES: & & & & & \\
\hline TEMP $\mathrm{C}$ & 19.7494 & 19.2504 & 422.5409 & 422.5409 & 437.8000 \\
\hline $\begin{array}{l}\text { PRES N/SQM } \\
\text { VFRAC }\end{array}$ & $\begin{array}{c}1.0340+06 \\
0.0\end{array}$ & $\begin{array}{r}2.0684+05 \\
0.9999\end{array}$ & $1.3780+07$ & $1.3780+07$ & $1.3780+07$ \\
\hline LFRAC & 1.0000 & $7.2014-05$ & & $1.0003-07$ & 0.3412 \\
\hline SFRAC & & & 0.0 & 0.0 & \\
\hline MASSUERA & & 0.9999 & 1.0000 & 1.0000 & 0.3184 \\
\hline DENSITY : & & & & & \\
\hline KMOL/CUM & 6.1078 & $8.5957-02$ & 3.1551 & 3.1551 & 3.2779 \\
\hline $\mathrm{KG} / \mathrm{CUN}$ & 840.2285 & 2.2716 & 177.0756 & 177.0756 & 403.4613 \\
\hline AVG MW & 137.5650 & 26.4274 & 56.1222 & 56.1222 & 123.0828 \\
\hline
\end{tabular}

Figure 8. (continued). Base case material and energy streams.

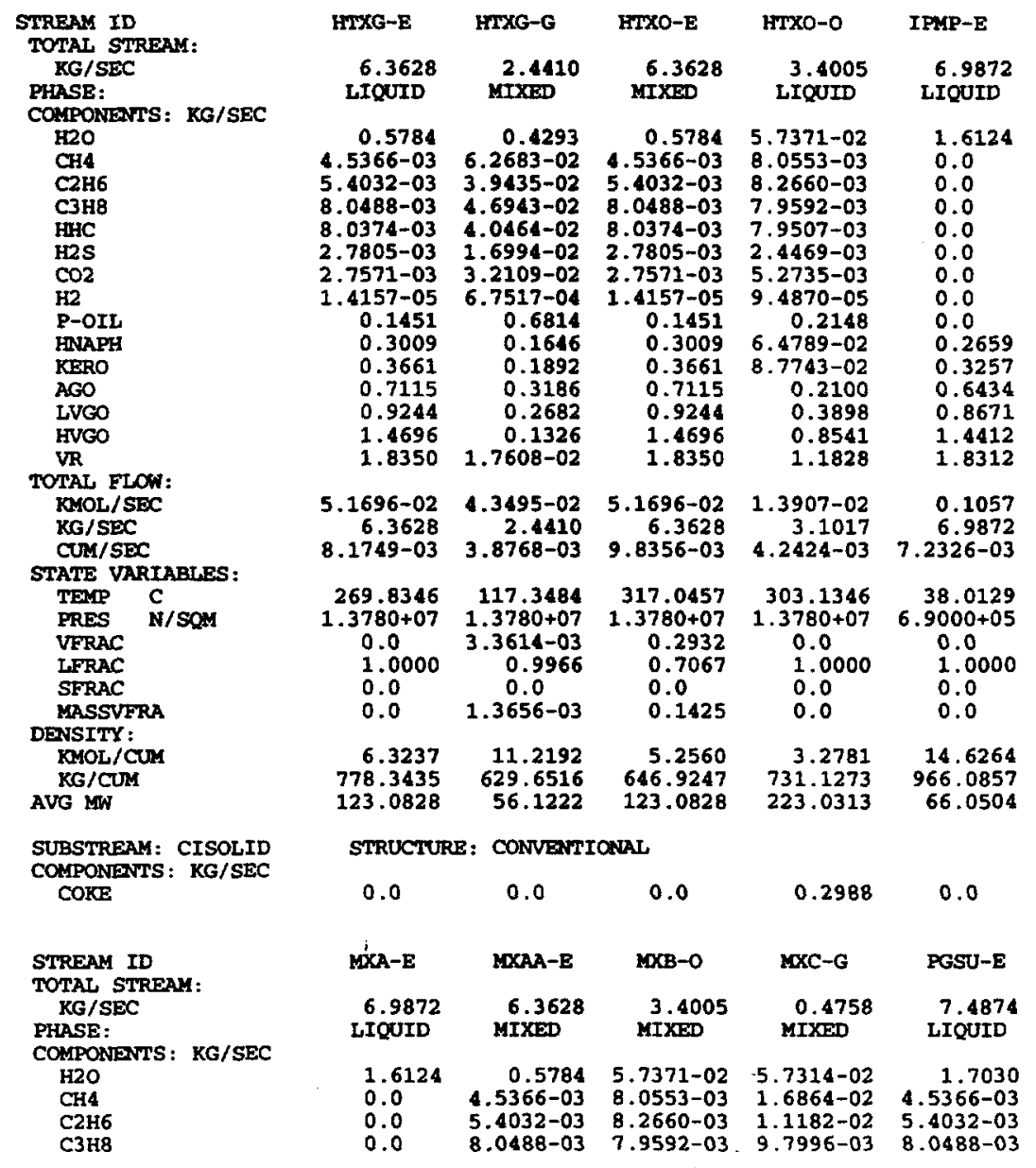




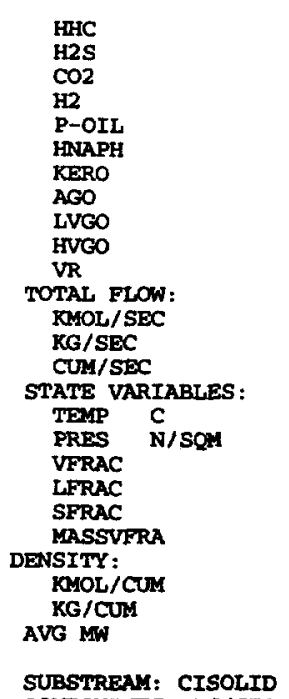

COMPONENT: KG/SEC

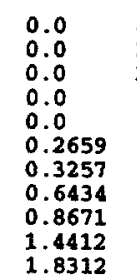

$\begin{array}{ll}8.0374-03 & 7.9507-03 \\ 2.7805-03 & 2.4469-03\end{array}$

$032.7571-03$

$\begin{array}{rrrr}\text { 4157-05 } & 9.4870-05 & 2.2454-04 & 1.4157-05\end{array}$

$\begin{array}{llll}0.1451 & 0.2148 & 0.1903 & 0.1451\end{array}$

$\begin{array}{llll}0.3009 & 6.4789-02 & 4.8529-02 & 0.3009\end{array}$

$\begin{array}{llll}0.3661 & 8.7743-02 & 4.7531-02 & 0.3661\end{array}$

$\begin{array}{llll}0.7115 & 0.2100 & 5.3167-02 & 0.7115\end{array}$

$\begin{array}{llll}0.9244 & 0.3898 & 1.7498-02 & 0.9244\end{array}$

$\begin{array}{llll}1.4696 & 0.8541 & 2.3668-03 & 1.4696\end{array}$

$\begin{array}{llll}1.8350 & 1.1828 & 8.8961-05 & 1.8350\end{array}$

$\begin{array}{llllll}0.1057 & 5.1696-02 & 1.3907-02 & 8.0438-03 & 0.1141\end{array}$

$\begin{array}{rrrrr}7.2331-03 & 6.9633-03 & 4.2038-03 & 0.1754 & 8.1570-03\end{array}$

$\begin{array}{lllll}37.7777 & 76.7789 & 422.5409 & 275.3309 & 76.7766\end{array}$

$\begin{array}{rrrrr}37.7777 & 76.7789 & 422.5409 & 275.3309 & 76.7766 \\ 6.8948+04 & 6.9000+05 & 1.3780+07 & 2.0684+05 & 6.9000+05\end{array}$

$\begin{array}{lrrrr}0.0 & 8.1933-08 & 7.3343-07 & 0.9999 & 0.0\end{array}$

$\begin{array}{ccccc}1.0000 & 1.1933-08 & 7.3343-007 & 0.9999 & 0.0 \\ 0.0 & 1.0000 & 1.0000 & 3.9598-05 & 1.0000\end{array}$

$\begin{array}{lcccl}1.000 & 1.0 & 0.0 & 0.0 & 0.0 \\ 0.0 & 1.4685-08 & 1.4473-07 & 0.9997 & 0.0\end{array}$

$\begin{array}{lllll}14.6253 & 7.4240 & 3.3082 & 4.5838-02 & 13.9905\end{array}$

$966.0111 \quad 913.7691 \quad 737.8383 \quad 9.7115 \quad 917.9158$

$\begin{array}{rrrrr}66.0504 & 123.0828 & 223.0313 & 59.1539 & 65.6098\end{array}$

STructure: COAverrioun
0.0
0.0
0.2988
0.0
0.0

Figure 8. (continued). Base case material and energy streams.

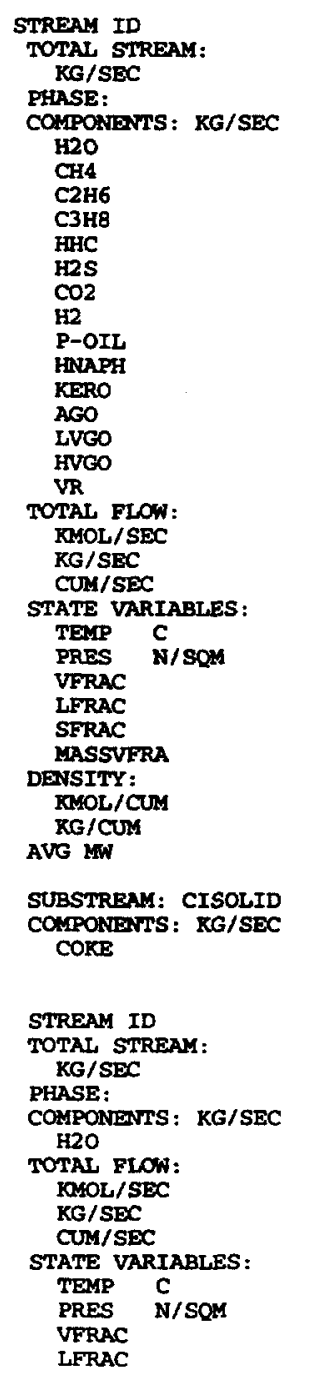

\begin{tabular}{|c|c|c|c|c|}
\hline PGSU-G & PSU-W2 & PRD -O & PUNP-E & RUGS-G \\
\hline $\begin{array}{l}.1025-02 \\
\text { VAPOR }\end{array}$ & $\begin{array}{l}53.4852 \\
\text { LIQUID }\end{array}$ & $\begin{array}{l}5.1379 \\
\text { LIQUID }\end{array}$ & $\begin{array}{l}6.3628 \\
\text { LIQUID }\end{array}$ & $\begin{array}{l}2.9622 \\
\text { VAPOR }\end{array}$ \\
\hline $\begin{array}{l}1.0791-03 \\
8.8478-03 \\
3.0173-03 \\
1.9747-03 \\
6.0287-04 \\
8.4821-04 \\
4.0991-03 \\
1.3001-04 \\
3.1342-04 \\
9.0064-05 \\
1.8361-05 \\
3.5552-06 \\
1.4076-07 \\
1.5237-09 \\
4.8023-12\end{array}$ & $\begin{array}{l}53.4852 \\
0.0 \\
0.0 \\
0.0 \\
0.0 \\
0.0 \\
0.0 \\
0.0 \\
0.0 \\
0.0 \\
0.0 \\
0.0 \\
0.0 \\
0.0 \\
0.0\end{array}$ & $\begin{array}{r}2.2841-02 \\
1.2379-03 \\
3.6255-03 \\
1.1617-02 \\
2.7136-02 \\
3.3440-03 \\
1.2356-03 \\
1.7839-06 \\
0.8877 \\
0.2293 \\
0.2769 \\
0.5286 \\
0.6580 \\
0.9867 \\
1.2004\end{array}$ & $\begin{array}{r}0.5784 \\
4.5366-03 \\
5.4032-03 \\
8.0488-03 \\
8.0374-03 \\
2.7805-03 \\
2.7571-03 \\
1.4157-05 \\
0.1451 \\
0.3009 \\
0.3661 \\
0.7115 \\
0.9244 \\
1.4696 \\
1.8350\end{array}$ & $\begin{array}{r}0.5210 \\
7.6067-02 \\
4.7856-02 \\
5.6966-02 \\
4.9105-02 \\
2.0623-02 \\
3.8966-02 \\
8.1933-04 \\
0.8269 \\
0.1997 \\
0.2296 \\
0.3866 \\
0.3255 \\
0.1609 \\
2.1368-02\end{array}$ \\
\hline $\begin{array}{l}9.5305-04 \\
2.1025-02 \\
3.9608-03\end{array}$ & $\begin{array}{r}2.9688 \\
53.4852 \\
5.4515-02\end{array}$ & $\begin{array}{r}2.2752-02 \\
4.8390 \\
5.4351-03\end{array}$ & $\begin{array}{r}5.1696-02 \\
6.3628 \\
6.9524-03\end{array}$ & $\begin{array}{r}5.2782-02 \\
2.9622 \\
1.6729-02\end{array}$ \\
\hline $\begin{array}{l}76.7766 \\
6.9000+05 \\
1.0000 \\
0.0 \\
0.0 \\
1.0000\end{array}$ & $\begin{array}{c}37.7777 \\
6.8948+04 \\
0.0 \\
1.0000 \\
0.0 \\
0.0\end{array}$ & $\begin{array}{c}57.3291 \\
1.0340+06 \\
0.0 \\
1.0000 \\
0.0 \\
0.0\end{array}$ & $\begin{array}{c}84.0484 \\
1.3780+07 \\
0.0 \\
1.0000 \\
0.0 \\
0.0\end{array}$ & $\begin{array}{r}422.5409 \\
1.3780+07 \\
1.0000 \\
0.0 \\
0.0 \\
1.0000\end{array}$ \\
\hline $\begin{array}{r}0.2406 \\
5.3081 \\
22.0601\end{array}$ & $\begin{array}{r}54.4598 \\
981.1088 \\
18.0152\end{array}$ & $\begin{array}{r}4.1860 \\
890.3333 \\
212.6903\end{array}$ & $\begin{array}{r}7.4357 \\
915.2105 \\
123.0828\end{array}$ & $\begin{array}{r}3.1551 \\
177.0756 \\
56.1222\end{array}$ \\
\hline
\end{tabular}

STRUCTURE: CONVENTIONAR
0.0
0.0
0.2988
0.0
0.0

\begin{tabular}{|c|c|c|}
\hline SSU-W2 & $w C U-w$ & WSU-W2 \\
\hline $\begin{array}{l}1.1246 \\
\text { LIQUID }\end{array}$ & $\begin{array}{l}1.1246 \\
\text { LIOUTD }\end{array}$ & $\begin{array}{l}0.4630 \\
\text { LIQUID }\end{array}$ \\
\hline 1.1246 & 1.1246 & 0.4630 \\
\hline $\begin{array}{r}2425-02 \\
1.1246 \\
.1938-03\end{array}$ & $\begin{array}{r}6.2425-02 \\
1.1246 \\
1.1307-03\end{array}$ & $\begin{array}{r}2.5701-02 \\
0.4630 \\
4.6327-04\end{array}$ \\
\hline $\begin{array}{c}76.7772 \\
.9000+05 \\
0.0 \\
1.0000\end{array}$ & $\begin{array}{c}23.8888 \\
6.9000+05 \\
0.0 \\
1.0000\end{array}$ & $\begin{array}{c}18.8297 \\
2.0684+05 \\
0.0 \\
1.0000\end{array}$ \\
\hline
\end{tabular}




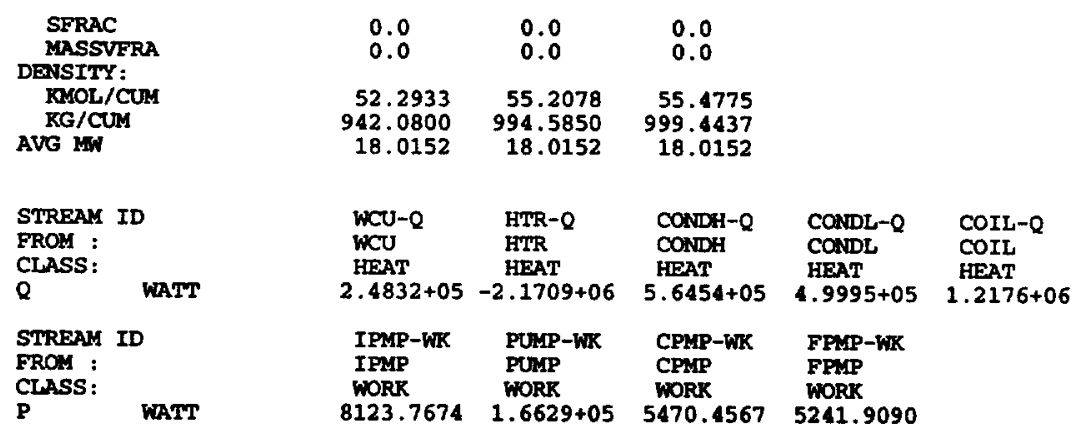

Figure 8. (continued). Base case material and energy streams.

The base case describes a process treating $464 \mathrm{Mg} /$ day $(3,000 \mathrm{bbl} /$ day) crude oil. The reactor pressure and temperature are $13.8 \mathrm{Mpa}$ and $438^{\circ} \mathrm{C}$ and the liquid residence time two hours. These conditions lead to a computed increase of oil quality as measured by API gravity of $8.9^{\circ}\left(13.5^{\circ}\right.$ for the feed and $22.4^{\circ}$ for the product oil) and a loss of $16 \%$ to gas and coke.

Most of the energy need to heat the process streams is supplied by heat recovery operations. Examination of the results show that $2.17 \mathrm{MW}$ of the energy required to heat the incoming stream is supplied by the fired heater, HTR. This represents $32 \%$ of the total needed. The rest of the energy is obtained through heat recovery operations, $41 \%$ is supplied by the HTXG heat exchanger, $16 \%$ by the HTXO heat exchanger and $11 \%$ in the preheat operation (PRH unit). Approximately $18 \%$ of the vapor stream from the reactor is diverted to the PRH unit. This represents $8 \%$ of the total mass entering the reactor unit.

The produced fuel gas flow, FUEL-G, is $0.26 \mathrm{~kg} / \mathrm{s}(9.9 \mathrm{~mol} / \mathrm{s})$. The estimated heat of combustion of this gas is $296 \mathrm{~kJ} / \mathrm{mol}$. This stream could theoretically supply $2.93 \mathrm{MW}$ of heat energy. If this stream were used to supply gas for a fired heater operating at a $75 \%$ efficiency, $2.2 \mathrm{MW}$ of process heat would be available. As it turns out this is almost exactly the energy obtained from the fired heater, HTR.

Only a small portion of the produced oil product, $\mathrm{P}$-OIL, exits in the fuel gas stream. Of the total $1.05 \mathrm{~kg} / \mathrm{s}$ of P-OIL produced about $0.01 \mathrm{~kg} / \mathrm{s}$ exits in the fuel gas.

A substantial fraction of the flow exists in the reactor in the vapor phase. Of the total $6.36 \mathrm{~kg} / \mathrm{s}$ entering the reactor $47 \%, 2.96 \mathrm{~kg} / \mathrm{s}$, exits as vapor. The vapor phase is not all generated in the reactor. Vapor, on a weight basis, is produced in nearly equal amounts in heat recovery heat exchanger HTXO, the fired heater HTR, and the reactor vessel. 
The stream enters the reactor at $438^{\circ} \mathrm{C}$ and exists at $423^{\circ} \mathrm{C}$. The small drop is a result of the net endothermic nature of the assumed pyrolysis reaction. This is in part a result of the fact that the products tend to be vapor at the conditions of the reactor.

The weight fraction of water remaining in the produced oil stream is only $0.4 \%$. Essentially all this water comes from the FPMP-O stream. The flashing of the hot product stream on the CPMP-O side reduces the water content in the CPMP-O stream to $0.04 \mathrm{wt} \%$. A little over one-half the oil comes from the CPMP-O stream.

The basic premise of the process is that it is based on aqueous pyrolysis of the oil. This implies that water is present in the liquid phase during pyrolysis. The free water in the system goes away in the HTXO heat exchanger. However, some amount of water remains dissolved in the liquid phase. The amount estimated by the model is based on assumptions about the activity of water in the oil phase. The amount of water in the liquid phase entering the reactor is approximately $4 \mathrm{wt} \%$ and exiting in the liquid phase about $1.9 \mathrm{wt} \%$. The reactor pressure $13.8 \mathrm{MPa}$ (2000 psia) was chosen to maintain a computed water content of approximately $2 \mathrm{wt} \%$ in the reactor effluent.

\section{Equipment Sizing and Economic Results}

The basis of the process cost estimate revolves around the equipment costs. The list of equipment costed and selected sizing information are given in Table 3. Included in the table is a net cost factor which is used to compute the installed cost of the equipment from its purchase cost. ASPEN PLUS contains a set of default parameters for material and labor involved in piping, concrete, steel, electrical, instrumentation, insulation, paint, and setting work for each of its cost BLOCK models. These default values were used in all cases and result in the net cost factors shown.

The most expensive piece of equipment in the process is the reactor vessel. It represents over $40 \%$ of the total cost of equipment. The next most expensive item is the fired heater which accounts for approximately $19 \%$ of the total. Vendor "budget quotes" for these two items as well as the high pressure pump, were obtained as a check of the estimates used. Sizes vary somewhat from those of this base case. The quotes are for the following items:

- Reactor Vessel (RU) - Cost estimated by model correlations is $\$ 537 \mathrm{k}$ for $47 \mathrm{~m}^{3}, 13.8 \mathrm{MPa}(2000 \mathrm{psi}$ ) vessel; vendor budget estimate is $\$ 700 \mathrm{k}$ for a 43 $\mathrm{m}^{3}$ vessel, $13.8 \mathrm{MPa}$ (vessel weight of $1.23 \times 10^{5} \mathrm{~kg}$ ). The cost of a $43 \mathrm{~m}^{3}$ vessel based on model correlations is $\$ 460 \mathrm{k}$ (9/96 purchase), indicating the model may be underestimating the reactor vessel costs. 
- Fired Heater (HT.) - Cost estimated by model correlations is $\$ 296 \mathrm{k}$ for a 2.9 MW gas-fired unit operating at 13.8 MPa (2000 psi); vendor budget estimate is $\$ 265 \mathrm{k}$ for a $5.3 \mathrm{MW}$ unit. The cost of a $5.3 \mathrm{MW}$ based on model correlations is $\$ 496 \mathrm{k}$, indicating the model may be over estimating the fired heater costs.

- High Pressure Pump (PUMP) - Cost estimated by model correlations is $\$ 95 \mathrm{k}$ for a $0.44 \mathrm{~m}^{3} / \mathrm{min}(200 \mathrm{gpm})$ unit; vendor budget estimate is $\$ 75 \mathrm{k}$ for a $0.5 \mathrm{~m}^{3} / \mathrm{min}(133 \mathrm{gpm})$ unit. The cost of a $0.5 \mathrm{~m}^{3} / \mathrm{min}$ pump based on model correlations is $\$ 99 k$, indicting the model may be over estimating

Table 3. Equipment costs for base case.

\begin{tabular}{cccccc} 
Unit & Type & Size & $\begin{array}{c}\text { Purchase Cost } \\
(\mathrm{k} \$)\end{array}$ & $\begin{array}{c}\text { Composite } \\
\text { Cost Factor }\end{array}$ & $\begin{array}{c}\text { Total Cost } \\
(\mathrm{k} \$)\end{array}$ \\
\hline COIL & Air Cooler & $34 \mathrm{~m}^{2}$ & 10.8 & 1.52 & 16.4 \\
CONDH & Heat Exchanger & $28 \mathrm{~m}^{2}$ & 33.6 & 2.24 & 75.2 \\
CONDL & Heat Exchanger & $10 \mathrm{~m}^{2}$ & 6.9 & 2.12 & 14.6 \\
CPMP & Pump & $2.6 \mathrm{~kg} / \mathrm{s}, 13 \mathrm{~kW}$ & 3.1 & 1.94 & 6.0 \\
CSU & Flash Vessel & $1.1 \mathrm{~m}^{3}$ & 3.6 & 2.22 & 8.0 \\
FOIL & Flash Vessel & $1.3 \mathrm{~m}^{3}$ & 5.2 & 2.21 & 11.5 \\
FPMP & Pump & $2.2 \mathrm{~kg} / \mathrm{s}, 13 \mathrm{~kW}$ & 3.1 & 1.94 & 6.0 \\
HTXG & Heat Exchanger & $124 \mathrm{~m}^{2}$ & 123.0 & 2.24 & 275.1 \\
HIXO & Heat Exchanger & $31 \mathrm{~m}^{2}$ & 38.4 & 2.24 & 85.9 \\
HIR & Fired Heater & $2.9 \mathrm{MW}^{2}$ & 295.7 & 1.72 & 507.5 \\
IPMP & Pump & $7 \mathrm{~kg} / \mathrm{s}, 17 \mathrm{~kW}$ & 4.9 & 1.73 & 8.5 \\
PRH & Vessel & $4.6 \mathrm{~m}^{3}$ & 10.6 & 2.98 & 31.6 \\
PSU & Separator Tank & $283 \mathrm{~m}^{3}$ & 58.1 & 4.19 & 243.7 \\
PUMP & Pump & $6.4 \mathrm{~kg} / \mathrm{s}, 166 \mathrm{~kW}$ & 94.7 & 1.98 & 187.7 \\
RU & Reactor Vessel & $47 \mathrm{~m}^{3}$ & 537.2 & 2.21 & 1189.2 \\
SSU & Separator Vessel & $4.3 \mathrm{~m}^{3}$ & 9.3 & 2.22 & 20.6 \\
WCU & Heat Exchanger & $30 \mathrm{~m}^{2}$ & 11.8 & 2.08 & 24.6 \\
WSU & Separator Vessel & $17 \mathrm{~m}^{3}$ & 4.5 & 2.22 & 10.0 \\
Total & & & & & 2,722
\end{tabular}

In one case, the fired heater, the model estimates are substantially higher than the vendor quote and in another, the vessel, they are substantially lower. In the third case, the pump, the model estimates are slightly higher. The net difference between the model base case and the vendor quotes for these three units is approximately $\$ 138 \mathrm{k}$ (i.e., the model estimates are $\$ 138 \mathrm{k}$ lower than the vendor quotes). This is about $11 \%$ of the total equipment purchase costs. The bulk of the difference is in the cost of the pressure vessel. Further analysis would need to be done to determine if this difference holds up when other vendors and/or ancillary costs are considered. The model bases the ancillary costs on the purchase cost. For the case of the pressure vessel, it 
probably could be argued that the cost factors should be lower since similar ancillary equipment would be needed for a lower pressure, hence, a less expensive vessel. The model estimates an installed cost for the vessel of $\$ 1190 \mathrm{k}$. Using the vendor estimate of $\$ 700 \mathrm{k}$ for this vessel, the difference would leave over $\$ 400 \mathrm{k}$ for installation and ancillary equipment.

ASPEN PLUS uses the total equipment costs and a series of factors to compute the total plant capital cost. The resulting costs are summarized for the base case in Table 4. The cost of process units, $\$ 3,655 \mathrm{k}$, shown in this Table is larger than the $\$ 2,722 \mathrm{k}$ shown in Table 3 . This is a result of adding costs for the following: unlisted equipment, building materials and spares. The total direct and indirect capital cost (physical plant cost) comes to $\$ 6,221 \mathrm{k}$.

Table 4. Total capital and investment costs for the base case in thousands of dollars.

\begin{tabular}{|lr|}
\hline & \\
Process Units & 3,655 \\
Contractor & 1,537 \\
Other & 1029 \\
Total Direct \& Indirect & 6,221 \\
Contingency & 933 \\
$\quad$ Total Depreciable Capital & $\mathbf{7 , 1 5 4}$ \\
Working Capital & 427 \\
Startup Cost & 531 \\
Total Investment & $\mathbf{8 , 1 1 2}$ \\
\hline
\end{tabular}

Operating cost estimates are based on utility consumption computed in the process flow sheet model, the assumed number of operators per shift, and factors which estimate a variety of costs relative to original capital investment. These later items include maintenance, taxes, insurance, and general works charges. Operating costs are summarized in Table 5. The total operating cost for the base case is approximately $\$ 1.1 \mathrm{M} / \mathrm{yr}$., of which $26 \%$ is utility costs.

In addition to capital and operating costs, the model performs a profitability analysis which computes the required selling price of the product oil (stream $\mathrm{PRD}-\mathrm{O})$. For the base case the reported value is $\$ 17.81 / \mathrm{Mg}(\$ 2.52 / \mathrm{bbl})$. This result is for the case in which the incoming oil is assumed to have no value 
Table 5. Operating costs for the base case in thousands of dollars per year (1st year dollars).

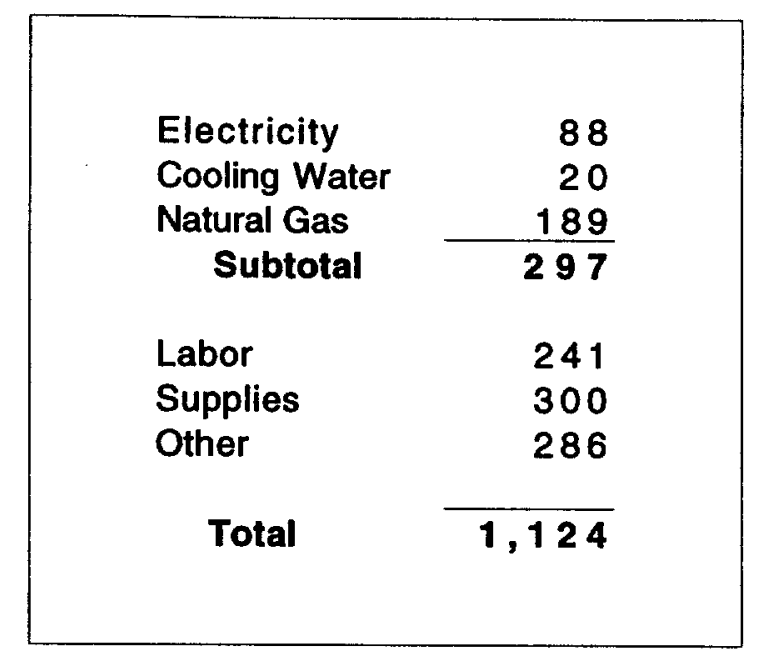

and, thus, the selling price is really a measure of the increase in selling price of the oil provided by the aqueous pyrolysis processing. Actually, the increase in price must be more than this increment because some oil is lost to coke and gas formation. This additional increment is dependent on the actual value of the feed oil. If the incoming oil has a value of $\$ 64.6 / \mathrm{Mg}(\$ 10 / \mathrm{bbl})$, then the product oil must have an increased value of $\$ 25.05 / \mathrm{Mg}(\$ 3.55 / \mathrm{bbl})$. This would represent a $\$ 2.81 / \mathrm{Mg}(\$ 0.40 / \mathrm{bbl})$ increment per unit increase in API gravity. It should be noted that this result excludes any costs for catalyst, coke removal, and waste water treatment.

\section{SENSITIVITY}

A series of runs have been made with the model to determine the sensitivity of the economics to various model parameters/assumptions. The results of these calculations are described below. All parameters are those of the base case except as noted. Of primary interest is the required increment in selling price of the product oil. In all cases described below it is assumed that the incoming crude oil has a value of $\$ 64.6 / \mathrm{Mg}(\$ 10 / \mathrm{bbl})$.

\section{Flow Rate}

Not surprisingly, the overall cost of processing declines with increased flow rates. Calculations for crude oil flow rates from $155-3,096 \mathrm{Mg} /$ day $(1,000-20,000$ $\mathrm{bbl} /$ day) show a drop in required incremental oil selling price from $\$ 35.29 / \mathrm{Mg}$ to $\$ 20.36 / \mathrm{Mg}$. For these cases only the flow rates change, the fraction of oil reacted and thus the increase in API gravity remains constant. The API gravity increases from $13.5^{\circ}$ to $22.4^{\circ}$ for all cases. 
The change in required incremental selling price is shown in Fig. 9. The change in price is steepest at low flows and begins to level out at flows higher than the base case flow of $464 \mathrm{Mg} /$ day $(3,000 \mathrm{bbl} /$ day). The figure also shows the required plant cost per unit oil processed and the gross operating costs.

The small increase in price and operating costs at intermediate flows was a result of the changes in the number of operators. One operator was assumed to be required for flows at and below $1,161 \mathrm{Mg} /$ day $(7,500 \mathrm{bbl} /$ day $)$. This was increased to two operators at flows up to and including $2,322 \mathrm{Mg} /$ day $(15,000$ $\mathrm{bbl} /$ day) and three operators at $3,096 \mathrm{Mg} /$ day $(20,000 \mathrm{bbl} /$ day).

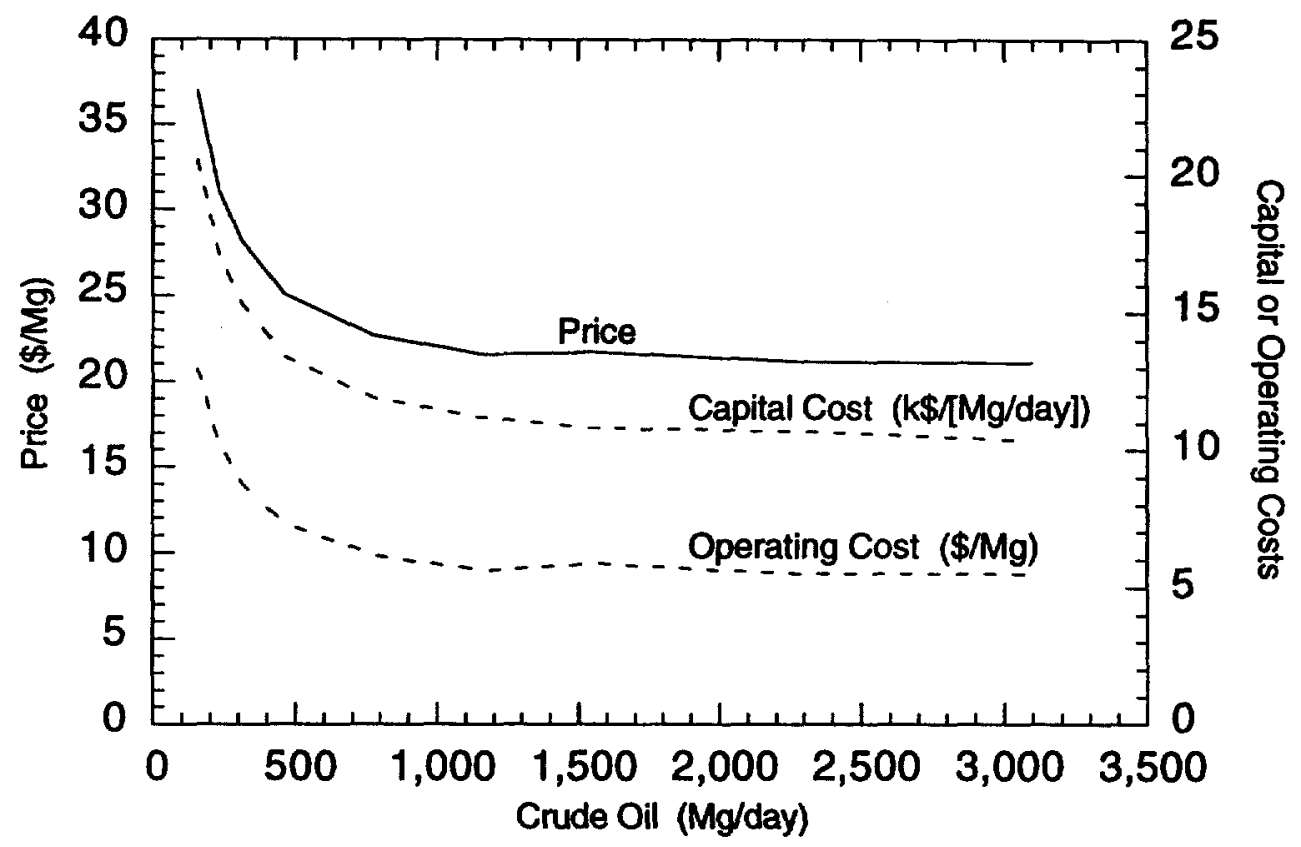

Figure 9. Required incremental selling price as a function of size of operation (Capital Costs shown are physical plant cost).

\section{Residence Time}

A series of runs were made in which residence time in the reactor was changed. Selected results are listed in Table 6. Reducing residence time directly reduces the size of the reactor. Since the reactor is the most costly piece of equipment, the cost of processing a unit of crude oil decreases with decreasing residence time. However, the reduced residence time leads to a reduced extent of reaction. Thus, the amount of upgrading, as measured by change in API gravity, goes down with decreasing residence time. The net effect is that the cost per unit oil per unit increase in API gravity goes down as residence time goes up (see Fig. 10).

Figure 10 indicates that a minimum in cost is not reached, even with 4 hours of residence time. However, at 4 hours residence time over $30 \%$ of the 
incoming heavy oil has been converted to the product P-OIL and the change in price with increased residence time is small.

\begin{tabular}{|c|c|c|c|c|c|}
\hline $\begin{array}{l}\text { Residence } \\
\text { Time } \\
\text { (hrs) }\end{array}$ & $\begin{array}{l}\text { Reactor } \\
\text { Volume } \\
\left(\mathrm{m}^{3}\right)\end{array}$ & $\begin{array}{l}\text { Product } \\
\text { Oil } \\
\text { Gravity } \\
\left({ }^{\circ} \mathrm{API}\right)\end{array}$ & $\begin{array}{c}\text { Crude } \\
\text { to } \\
\text { P-OIL } \\
\text { (wt. \%) }\end{array}$ & $\begin{array}{c}\text { Product } \\
\text { to } \\
\text { Feed } \\
\text { Ratio }\end{array}$ & $\begin{array}{c}\text { Incremental } \\
\text { Price } \\
{[\$ 64.6 / \mathrm{Mg} \mathrm{Feed}]} \\
(\$ / \mathrm{Mg})\end{array}$ \\
\hline 4 & 79.0 & 29.2 & 30.9 & 0.739 & 34.48 \\
\hline 3 & 64.5 & 25.8 & 25.5 & 0.787 & 30.14 \\
\hline 2 & 46.7 & 22.4 & 19.4 & 0.840 & 25.05 \\
\hline 1 & 25.3 & 18.7 & 12.0 & 0.903 & 19.33 \\
\hline 0.5 & 13.1 & 16.7 & 7.4 & 0.942 & 16.03 \\
\hline 0.25 & 8.4 & 15.5 & 4.5 & 0.966 & 14.32 \\
\hline
\end{tabular}

Table 6. Selected model results as a function of assumed reactor residence time.

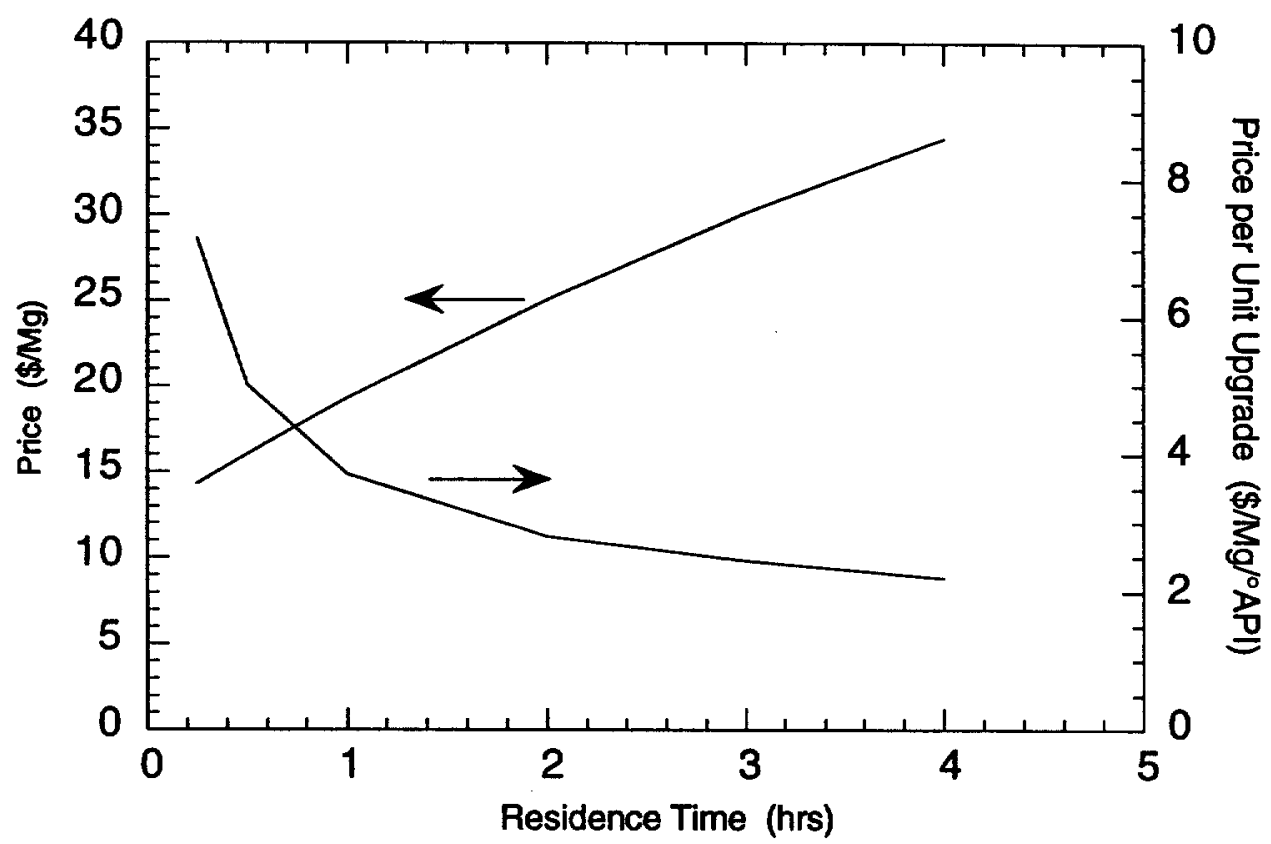

Figure 10. Required incremental selling price and incremental selling price per unit upgrade in API gravity as a function of reactor residence time (assumed input crude oil price is $\$ 64.6 \mathrm{Mg}$ ).

\section{Pressure}

Operating pressure has a fairly strong influence on process economics since the highest cost items, particularly the reactor vessel, are directly related to operating pressure. Also, pressure influences the operation and, therefore, 
the process economics in a more complex way than does a change in residence time.

Some important changes in process performance resulting from alterations in operating pressure are shown in Table 7. With a halving of operating pressure, the reactor vessel cost drops by more than a factor of two. The drop is more than directly proportional to pressure because the required vessel size to maintain a liquid residence time of two hours also drops somewhat with pressure. The reason for this is the following. Even at the lower pressure the gas velocities are relatively low within the vessel, therefore, the entrainment does not play a large role in determining vessel volume. The volume is directly related to average liquid flow. For the lower pressures, more of the product oil enters the vapor phase which leads to a higher effective residence time for the heavier components. As a result the net pyrolysis increases somewhat with pressure as seen by the increase in API gravity and reduced product to feed ratio. (The product oil amount goes down with increased reaction because of the production of coke and gas.)

Table 7. Selected model results as a function of assumed reactor pressure.

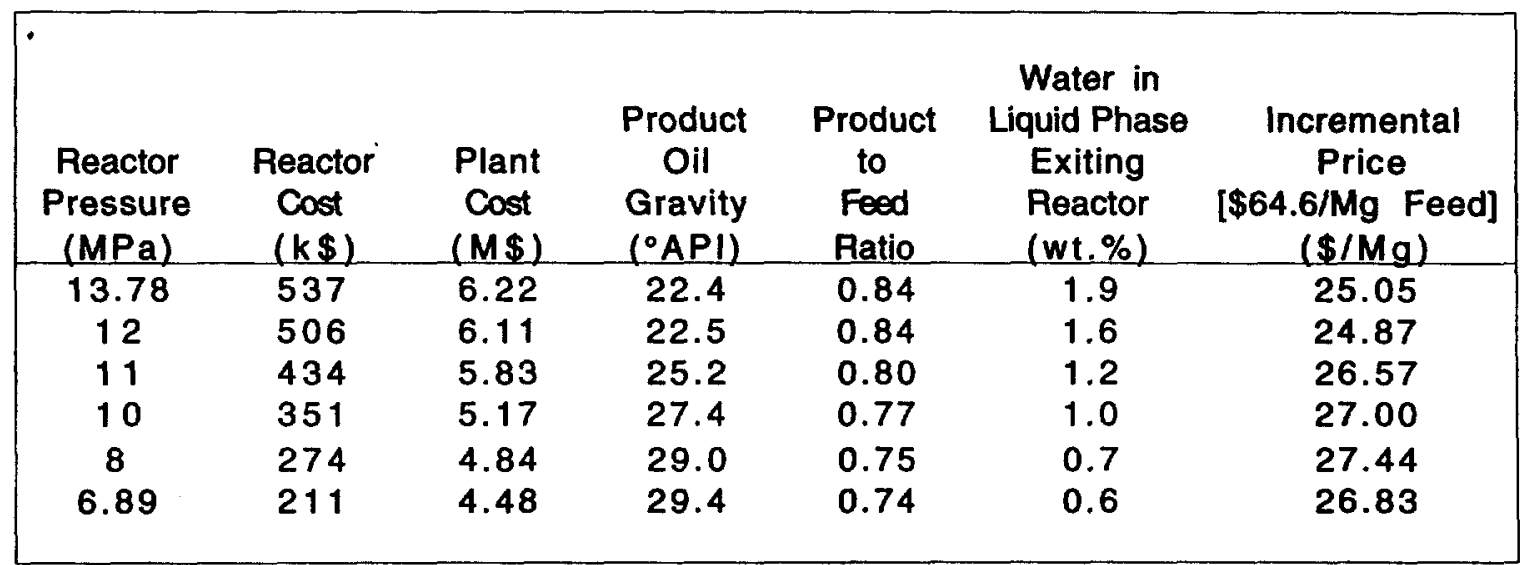

The incremental price increase required, the last column in Table 7, is a complicated function of pressure because of competing effects. Lower pressure reduces capital and operating costs, but increased extent of reaction reduces the amount of product oil. The net effect is a relatively flat incremental price as a function of pressure.

However, as shown in Fig. 11, the price per unit increase in API gravity goes down with pressure. At the lower pressure $6.89 \mathrm{MPa}(1000 \mathrm{psi})$ it is only $60 \%$ of the price at $13.78 \mathrm{MPa}(2000 \mathrm{psi})$. The steep rise between 10 and $12 \mathrm{MPa}$ is due to the discretized nature of the pricing used for certain items as a function of pressure, primarily the heat exchange units. 


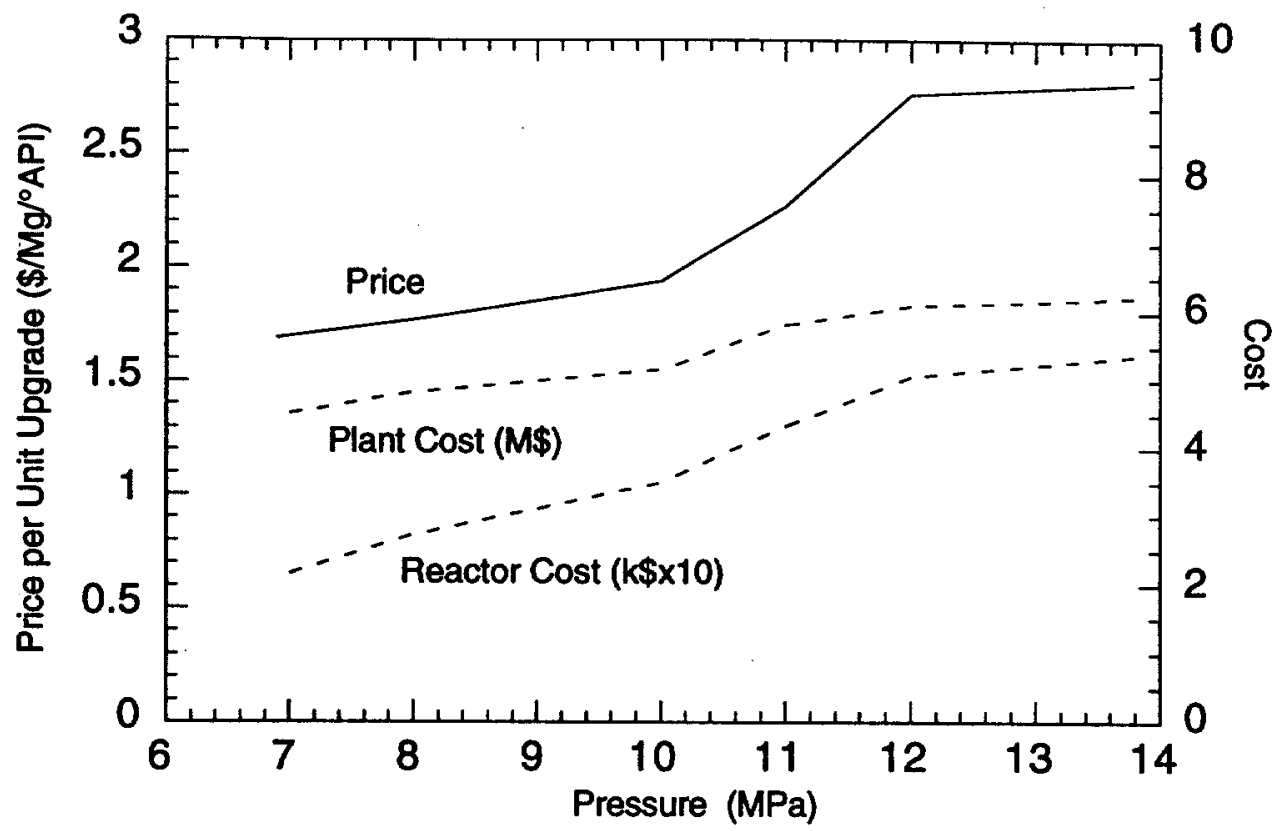

Figure 11. Required incremental selling price per unit upgrade in API gravity, reactor cost and total plant cost as a function of reactor pressure (assumed input crude oil price is $\$ 64.6 \mathrm{Mg}$ ).

As the pressure is lowered, the amount of water in the oil phase in the reactor decreases, see Table 7. Thus, if the water content of the oil phase in the reactor is an important parameter in the performance of the pyrolysis reactions, lower pressure operation may have an adverse effect not captured by the model.

\section{Temperature}

Like pressure, temperature has a relatively complicated influence on computed results. Computed results for four inlet temperatures are shown in Table 8. The temperature strongly affects the extent of reaction. This in turn influences the product oil gravity, the product-to-feed ratio, reactor volume, and the water content in liquid phase in the reactor.

Notice that the reactor volume steadily decreases with increasing temperature. This is a result of the increased production of P-OIL and a reduced liquid volume. However, the reactor cost does not monotonically decrease. This is a result of a correction made by ASPEN PLUS in computing vessel costs for changes in material strength. Algorithms in ASPEN PLUS begin to degrade the strength of carbon steel at temperatures above $350^{\circ} \mathrm{C}$, and therefore increases required wall thickness, and thus vessel costs, for a given pressure of operation. 
Table 8. Selected model results as a function of assumed reactor inlet temperature.

\begin{tabular}{|c|c|c|c|c|c|c|}
\hline $\begin{array}{c}\text { Temperature } \\
\left({ }^{\circ} \mathrm{C}\right)\end{array}$ & $\begin{array}{l}\text { Reactor } \\
\text { Volume } \\
\left(\mathrm{m}^{3}\right)\end{array}$ & $\begin{array}{c}\text { Reactor } \\
\text { Cost } \\
(\mathbf{k} \$)\end{array}$ & $\begin{array}{l}\text { Product } \\
\text { Oil } \\
\text { Gravity } \\
\text { ( } \mathrm{API})\end{array}$ & $\begin{array}{c}\text { Product } \\
\text { to } \\
\text { Feed } \\
\text { Patio } \\
\end{array}$ & $\begin{array}{l}\text { Water in } \\
\text { Liquid Phase } \\
\text { Exiting } \\
\text { Reactor } \\
\text { (wt. \%) }\end{array}$ & $\begin{array}{c}\text { Incremental } \\
\text { Price } \\
\text { [\$64.6/Mg Feed] } \\
(\$ / \mathrm{Mg})\end{array}$ \\
\hline 425 & 53.6 & 520 & 19.5 & 0.89 & 2.4 & 21.80 \\
\hline $\begin{array}{c}437.8 \\
445\end{array}$ & $\begin{array}{l}46.7 \\
41.5\end{array}$ & $\begin{array}{l}537 \\
490\end{array}$ & $\begin{array}{l}22.4 \\
24.7\end{array}$ & $\begin{array}{l}0.84 \\
0.81\end{array}$ & $\begin{array}{l}1.9 \\
1.6\end{array}$ & $\begin{array}{l}25.05 \\
26.78\end{array}$ \\
\hline 455 & 32.2 & 574 & 28.6 & 0.75 & 1.2 & 31.34 \\
\hline
\end{tabular}

The model indicates that the price per unit increase in API gravity decreases as temperature increases, see Fig. 12. This is a result of the increased extent of reaction, which increases the product oil gravity. As with pressure, operation at the lower cost, in this case higher temperature, results in lower water content in the liquid phase in the reactor which may result in adverse effects not captured by the model.

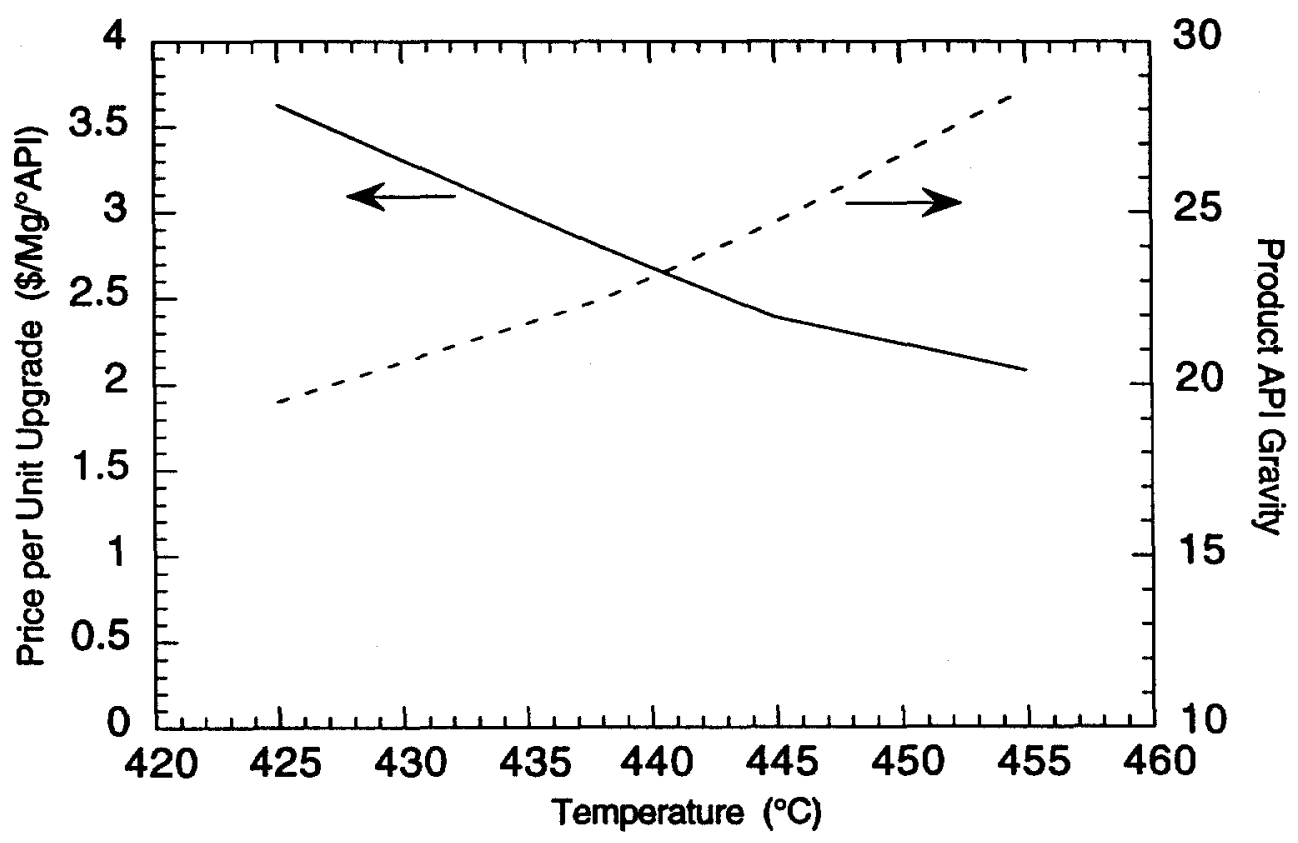

Figure 12. Required incremental selling price per unit upgrade in API gravity and product API gravity cost as a function of reactor inlet temperature (assumed input crude oil price is $\$ 64.6 / \mathrm{Mg}$ ).

\section{Constant Gravity}

The primary controllable parameters in the process are reactor pressure, temperature, and residence time. These parameters can be manipulated so 
that the same net product oil is produced using different combinations of parameters. A series of runs needed to be done to determine the relative economics of producing an oil with an API gravity equal to the base case, approximately 22.4. An additional constraint was placed on the system which required the water content of the liquid exiting the reactor to be equal to the base case, approximately $1.85 \mathrm{wt} \%$.

Results of the calculations are shown in Table 9. These results cover a temperature range from $400-450^{\circ} \mathrm{C}$ which resulted in required residence times from 1-10 hours. At $425^{\circ} \mathrm{C}$, and above, the economic performance is essentially unchanged. At the two lower temperatures the costs are somewhat higher. It appears that for a given reaction extent and specified water content the economics are relatively insensitive te the choice of pressure/temperature operating point.

Table 9. Selected model results for cases in which product oil API gravity and water content in the exiting reactor liquid were maintained approximately equal to the base case, 22.4 and $1.85 \mathrm{wt} \%$ respectively.

\begin{tabular}{|c|c|c|c|c|c|}
\hline $\begin{array}{c}\text { Temperature } \\
\left({ }^{\circ} \mathrm{C}\right)\end{array}$ & $\begin{array}{c}\text { Pressure } \\
\text { (MPa) }\end{array}$ & $\begin{array}{c}\text { Residence } \\
\text { Time } \\
(h r s) \\
\end{array}$ & $\begin{array}{l}\text { Reactor } \\
\text { Volume } \\
\left(\mathrm{m}^{3}\right)\end{array}$ & $\begin{array}{c}\text { Incremental } \\
\text { Price } \\
\text { [\$64.6/Mg Feed] } \\
(\$ / \mathrm{Mg})\end{array}$ & $\begin{array}{c}\text { Incremental } \\
\text { Price per Unit API } \\
\text { [\$64.6/Mg Feed] } \\
\left(\$ / \mathrm{Mg} /{ }^{\circ} \mathrm{API}\right)\end{array}$ \\
\hline $\begin{array}{l}400 \\
415\end{array}$ & $\begin{array}{l}10.0 \\
11.1\end{array}$ & $\begin{array}{c}10 \\
5\end{array}$ & $\begin{array}{l}170 \\
135\end{array}$ & $\begin{array}{l}30.31 \\
28.44\end{array}$ & $\begin{array}{l}3.52 \\
3.31\end{array}$ \\
\hline $\begin{array}{c}425 \\
437.8 \\
450\end{array}$ & $\begin{array}{c}12.0 \\
13.78 \\
17.0\end{array}$ & $\begin{array}{c}3.5 \\
2 \\
1\end{array}$ & $\begin{array}{l}90 \\
47 \\
21\end{array}$ & $\begin{array}{l}26.08 \\
25.05 \\
25.50\end{array}$ & $\begin{array}{l}3.03 \\
2.81 \\
2.97\end{array}$ \\
\hline
\end{tabular}

\section{Aqueous Pyrolysis Reaction}

A series of runs were done to look at the influence of changing the kinetic and stoichiometric parameters of the assumed pyrolysis reaction. In one set of runs it is assumed that the reaction rate is 10 times faster than the base case. This was done by increasing the pre-exponential factor in the kinetic rate constant expression by a factor of 10 . In the second set of runs it is assumed that no coke is produced during the reaction and the amounts of product oil increases to compensate. For all runs the product oil gravity and amount of water in the liquid exiting the reactor was held constant at values equal to the base case results.

For each assumption two sets of computed results are shown in Table 10, one in which the residence time was held equal to the base case, two hours, and a second in which the temperature was held equal to the base case. For the 
constant residence time runs, the system pressure and temperature were adjusted to maintain the desired operation; and for the base case temperature runs, the residence time was adjusted for the faster kinetics case and the residence time and pressure were adjusted for the no coke case to give the required process performance.

Table 10. Selected model results for runs in which product oil API gravity and water content in the exiting reactor liquid were maintained approximately equal to the base case, 22.4 and $1.85 \mathrm{wt} \%$ respectively.

\begin{tabular}{|c|c|c|c|c|c|c|c|c|}
\hline $\operatorname{cose}$ & $\begin{array}{c}\text { Temperature } \\
\left({ }^{\circ} \mathrm{C}\right)\end{array}$ & $\begin{array}{c}\text { Pressure } \\
\text { (MPa) }\end{array}$ & $\begin{array}{c}\text { Residence } \\
\text { Time } \\
\text { (hrs) }\end{array}$ & $\begin{array}{l}\text { Reactor } \\
\text { Volume } \\
\left(\mathrm{m}^{3}\right)\end{array}$ & $\begin{array}{c}\text { Reactor } \\
\text { Cost } \\
(k \$)\end{array}$ & $\begin{array}{c}\text { Operating } \\
\text { Cost } \\
(M \$ / y r)\end{array}$ & $\begin{array}{c}\text { Incremental } \\
\text { Price } \\
{[\$ 64.6 / \mathrm{Mg} \mathrm{Feed}]} \\
(\$ / \mathrm{Mg})\end{array}$ & $\begin{array}{c}\text { Incremental } \\
\text { Price per Unit API } \\
{[\$ 64.6 / \mathrm{Mg} \text { Feed] }} \\
\left(\$ / \mathrm{Mg} /{ }^{\circ} \mathrm{API}\right)\end{array}$ \\
\hline Base & 437.8 & 13.8 & 2.00 & 47 & 537 & 1.12 & 25.05 & 2.81 \\
\hline $10 x$ rate & 372.0 & 8.9 & 2.00 & 61 & 289 & 0.92 & 21.54 & 2.45 \\
\hline $10 x$ rate & 437.8 & 13.8 & 0.20 & 8 & 190 & 0.96 & 21.50 & 2.42 \\
\hline No coke & 437.8 & 18.0 & 0.85 & 20 & 418 & 1.16 & 20.69 & 2.32 \\
\hline No coke & 423.0 & 13.0 & 2.00 & 51 & 470 & 1.05 & 18.77 & 2.11 \\
\hline
\end{tabular}

The results in Table 10 indicate modest improvement in economics over the base for these more optimistic assumptions about the pyrolysis reaction. For the cases using the faster kinetics about $15 \%$ lowering in price is computed. This was true whether the faster rate was compensated for by lowering the temperature and pressure or by reducing the residence time in the reactor. For the cases in which zero coke production was assumed, it was more advantages to reduce the temperature to compensate than to reduce the residence time. The best of the no coke runs indicates a $25 \%$ improvement in process economics over the base case.

\section{Burning Fuel Gas}

As mentioned previously, the amount of combustion energy present in the produced fuel gas for the base case is essentially equal to the amount of energy needed to fuel the fired heater. In the base case the fired heater fuel is assumed to be natural gas. The fired heater is computed to require $2.89 \mathrm{MW}$ of combustible gas energy. At an indexed price of $\$ 2.29 / \mathrm{GJ}$ ( $2^{\text {nd }}$ quarter 1995) the yearly cost for natural gas is $\$ 189 \mathrm{k}$. This is $17 \%$ of the annual operating cost. If it is assumed that the produced fuel gas can be used instead of natural gas to fire the heater, then the total operating cost drops and, consequently, the required incremental price of the product oil would be reduced.

A case was run in which no charge was taken for fueling the fired heater, HTR. This resulted in a drop of required incremental oil price from 
$\$ 25.05 / \mathrm{Mg}$ for the base case to $\$ 23.25 / \mathrm{Mg}$, just under a $10 \%$ drop. These costs are for feed oil assumed to be worth $\$ 64.6 / \mathrm{Mg}(\$ 10 / \mathrm{bbl})$.

\section{Stainless Steel Reactor}

The base case assumes that the reactor vessel can be made from carbon steel with a corrosion allowance of $0.32 \mathrm{~cm}(0.125 \mathrm{in}$.). If for a given system the corrosion of the carbon steel is unacceptable, then an alloy vessel would be required. Other key elements of the system were already assumed to be stainless steel in the base case (e.g., heat exchanger tubes and high pressure pump).

The switch to stainless steel for the reactor vessel increases the estimated vessel purchase cost from $\$ 537 \mathrm{k}$ to $\$ 983 \mathrm{k}$. This results in an increase in the plant capital cost of about $20 \%$ and an increase in required selling price from the base case value of $\$ 25.05 / \mathrm{Mg}$ to a value of $\$ 27.93 / \mathrm{Mg}$ (slightly more than a $10 \%$ increase).

\section{Minimum Cost}

The base case assumptions leads to a required oil price increase of $\$ 2.81 / \mathrm{Mg} \cdot{ }^{\circ} \mathrm{API}$. This is higher than what has been estimated as a reasonable expectation for price increase of approximately $\$ 1.60 / \mathrm{Mg} \cdot{ }^{\circ} \mathrm{API}$

$\left(\$ 0.25 / \mathrm{bbl} .^{\circ} \mathrm{API}\right)^{9}$. This level was for the most part not reached by the cases considered in the sensitivity analysis describe above.

It is of interest to determine whether such price levels could be reached for a process in which several factors are shifted to more optimistic values. A model run was done in which the base case parameters were maintained except for the following:

- Faster reaction kinetics were assumed; the pre-exponential kinetic factor was increased ten fold.

- The coke make was set to zero and the product oil yield increased to compensate.

- The fired heater was assumed to be fed with produced fuel gas.

- Reactor residence times were chosen so that an increase in API gravity to about $25^{\circ}$ was achieved.

Selected results from the calculations are listed in Table 11. Two cases were run, each using a different assumed temperature at the reactor inlet. The pressures were adjusted in each case to maintain a water content in the exit reactor liquid of approximately $2 \mathrm{wt} \%$. Differences in results for the two cases were minor. Both show a required price increase below the $\$ 1.60 / \mathrm{Mg} \cdot{ }^{\circ} \mathrm{API}$ level. In fact the $\$ 1.60 / \mathrm{Mg} \cdot{ }^{\circ} \mathrm{API}$ can be achieved even assuming that that 
instead of no coke production, coke production is cut in half from the levels of the base case.

Table 11. Selected model results for the base case and cases in which more optimistic assumptions are made.

\begin{tabular}{|c|c|c|c|c|c|c|c|c|c|}
\hline & $\begin{array}{c}\text { Temperature } \\
\text { (C) }\end{array}$ & $\begin{array}{c}\text { Pressure } \\
\text { (MPa) }\end{array}$ & $\begin{array}{c}\text { Pesidence } \\
\text { Time } \\
\text { (hrs) }\end{array}$ & $\begin{array}{l}\text { Reactor } \\
\text { Volume } \\
\left(\mathrm{m}^{3}\right)\end{array}$ & $\begin{array}{l}\text { Product } \\
\text { Oil } \\
\text { Gravity } \\
\left({ }^{\circ} \mathrm{API}\right)\end{array}$ & $\begin{array}{l}\text { Reactor Cost } \\
\text { (\% of Listed } \\
\text { Equipment) }\end{array}$ & $\begin{array}{l}\text { Capital } \\
\text { Costs } \\
\text { (M\$) }\end{array}$ & $\begin{array}{l}\text { Operating } \\
\text { Cost } \\
(M \$ / y r)\end{array}$ & $\begin{array}{l}\text { Incremental } \\
\text { Price per Unit API } \\
\text { [\$64.6/Mg Feed] } \\
\left(\$ / \mathrm{Mg} /{ }^{\circ} \mathrm{API}\right)\end{array}$ \\
\hline Base & $\begin{array}{c}437.8 \\
360 \\
375\end{array}$ & $\begin{array}{l}13.78 \\
10 \\
11\end{array}$ & $\begin{array}{l}2 \\
2.4 \\
1.1\end{array}$ & $\begin{array}{l}46.7 \\
72.1 \\
31.7\end{array}$ & $\begin{array}{l}22.4 \\
25.2 \\
25.0\end{array}$ & $\begin{array}{l}44 \\
38 \\
25\end{array}$ & $\begin{array}{l}6.22 \\
4.68 \\
4.31\end{array}$ & $\begin{array}{l}1.12 \\
0.78 \\
0.75\end{array}$ & $\begin{array}{l}2.81 \\
1.39 \\
1.34\end{array}$ \\
\hline
\end{tabular}

\section{CONCLUSIONS}

An ASPEN PLUS model of in-field aqueous pyrolysis upgrading of heavy oils has been developed. The model indicates that for a $464 \mathrm{Mg} /$ day $(3,00 \mathrm{bbl} /$ day) process, which increases the oil API gravity of the processed oil from $13.5^{\circ}$ to $22.4^{\circ}$, the required value increase of the oil must be about $\$ 2.80 / \mathrm{Mg}^{\circ} \mathrm{API}$ (for a crude oil initially worth $\$ 64.6 / \mathrm{Mg}$ ). This level of upgrading has been demonstrated in preliminary experiments with candidate catalysts ${ }^{3}$.

As expected, the reactor vessel is the most costly piece of equipment in the process, accounting for approximately $40 \%$ of the equipment costs for the base case. If a stainless steel reactor vessel is required, this percentage increases to about $55 \%$. This increased cost raises the required selling price of the oil about $10 \%$.

A vendor "budget" quote for the reactor vessel was obtained which was substantially higher than the estimate used in the model. However, the manner in which installed costs are estimated in the model probably overestimates ancillary costs for the vessel. Further work on the installed reactor vessel costs is required to resolve this issue.

The economic performance of the process is a function of a number of factors, including operating pressure, temperature, reaction kinetics, reaction stoichiometry and total flow rate. Substantial changes in reaction stoichiometry and kinetics are required to improve the economic performance.

It is estimated that a required selling price increase for the oil of $\$ 1.34 / \mathrm{Mg} \cdot{ }^{\circ} \mathrm{API}\left(\$ 0.21 / \mathrm{bbl} \cdot{ }^{\circ} \mathrm{API}\right)$ can be reached if a catalyst can be found which both yields one-half the coke make and an order of magnitude more rapid kinetics than that already demonstrated. 


\section{REFERENCES}

1. J. G. Reynolds, A. M. Murray, E. V. Nuxoll, and G. A. Fox, "Upgrading of Heavy Oil from the San Joaquin Valley of California by Aqueous Pyrolysis," Lawrence Livermore National Laboratory, Livermore, California, UCRL-122472 (1995).

2. ASPEN PLUS Reference Manual - Ușer Guide Volume 1, (Aspen Technology, Inc., Cambridge, Massachusetts, 1994) Chapter 9.

3. C. B. Thorsness and J. G. Reynolds "Modeling a Set of Heavy Oil Aqueous Pyrolysis Experiments," Lawrence Livermore National Laboratory, Livermore, California, UCRL-ID-12567ß (1996).

4. ASPEN PLUS Reference Manual - Input Language Guide - Volume 1, (Aspen Technology, Inc., Cambridge, Massachusetts, 1996) Chapter 3.

5. ASPEN PLUS Reference Manual - Volume 4-Costing and Pressure Relief, (Aspen Technology, Inc., Cambridge, Massachusetts, 1994) Chapters 1-7, 9, 10, 12-15.

6. Stanley M. Walas, Chemical Process Equipment - Selection and Design, (Butterworth-Heinemann, Boston 1990), pp. 663-669.

7. R. N. Watkins, "Sizing Separators and Accumulators," Hydrocarbon Processing, Vol. 46, pp. 253-256 (1967).

8. ASPEN PLUS Reference Manual - Volume 5 - System Management (Aspen Technology, Inc., Cambridge, Massachusetts, 1994) Chapter 1 pp. 3-5.

9. J. G. Reynolds, Personal Communications. 


\section{APPENDIX I}

\section{ASPEN PLUS INPUT FILE}

Below is a listing of the ASPEN PLUS input language file for the base case. This input files has run successfully with ASPEN PLUS Release 9.2-1 on a HP$9000 / 730$ computer workstation running HPUX 10.10. Just under three minutes are required for execution on a dedicated machine. In order to execute successfully, the user FORTRAN routines called by the model must be available as object files at the time of execution. These files can be generated from the source listings given in Appendices II and III using the "aspcomp" command provided as part of the ASPEN PLUS software.

This base case completes execution with two warnings. These are listed at the end of the output file. The first warning concerns the unit operation block RSU. The RSU routine operates on the free-water exiting the reactor to establish a user requested split of free-water. Since no free-water is present in this case, and for nearly all cases, the ASPEN PLUS module, FSPLIT, which implements the RSU unit reports a zero feed stream warning.

The other warning concerns costing of the two pumps, FPMP and CPMP, which pump the product oil to the requested outlet pressure. For the base case, the oil flows are below the lower cutoff limit of the ASPEN PLUS cost correlations for the SS-ANSI pump type. As a result, ASPEN PLUS uses the cost of the smallest pump in its database. For the base case the volumetric flow through these pumps, about $0.003 \mathrm{~m}^{3} / \mathrm{s}$, is just below the low flow cutoff, $0.00316 \mathrm{~m}^{3} / \mathrm{s}(50 \mathrm{gpm})$. Consequently the cost estimates are satisfactory. In addition, the cost of these pumps contribute less than $1 \%$ of cost of the process for the base case.

Input file:

TITLE 'Hydrous Pyrolysis Model (HPM) [Rev 5.7]'

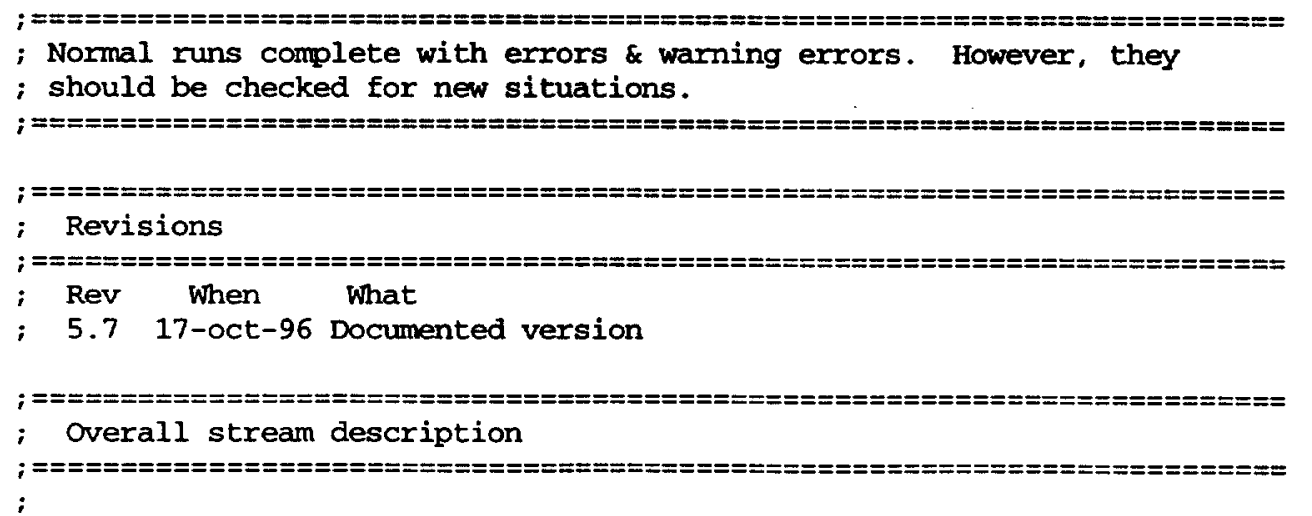


Input Streams :

FEED - Oil \& water input

Output Streams:

Material

PSU-W2 - Primary water decant stream from 1st sep.

WCU-W - Water decant stream from second sep.

WSU-W2 - Final water decant stream

PRD-O - Product oil stream

FUEL-G - Fuel gas

Thermal energy

1

HIR-Q - Heat added by trim heater

COIL-Q - Active cooling of product oil stream

IHTR-Q - Heat delivered to heater upstream of secondary water spearation (usually zero)

WCU-Q - Cooling of water from the secondary separator

CONDL $-Q$ - Heat removed in low pressure condeneser

CONDH-Q - Heat removed in high pressure condeneser

Mechanical energy

PUMP-WK - Primary pump

FPMP-WR - Product oil purmp

CPMP-WK - Product oil pump

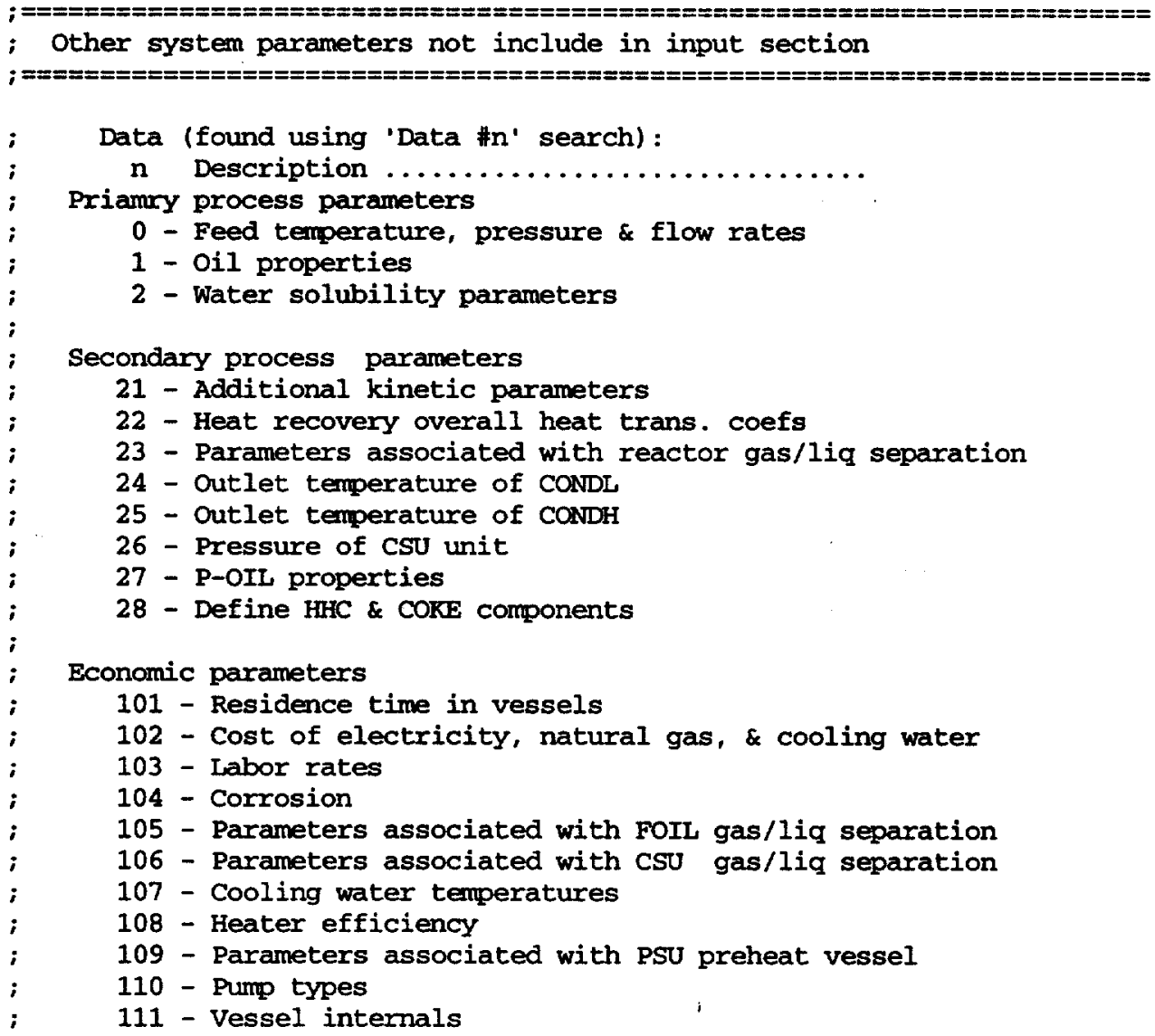




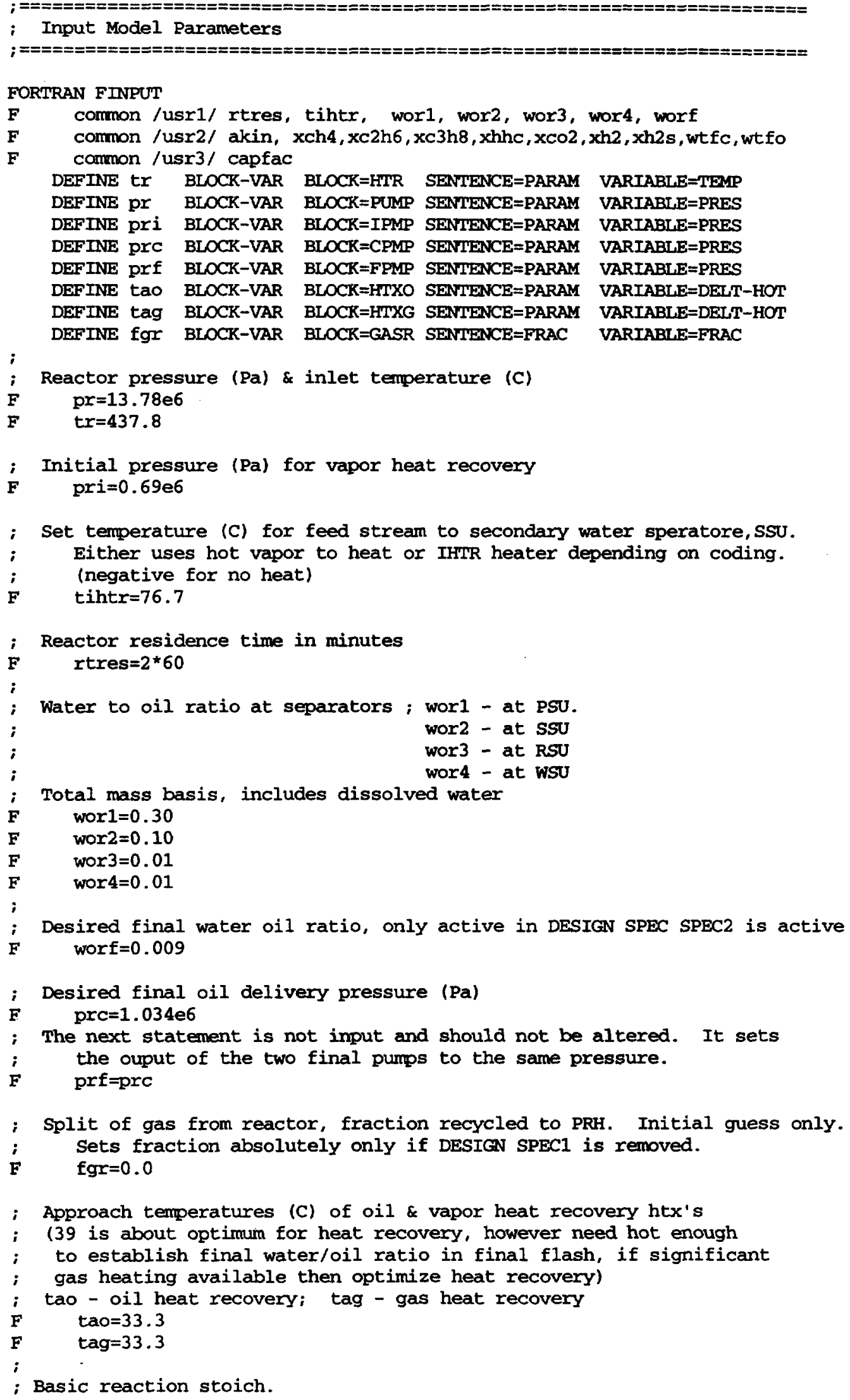




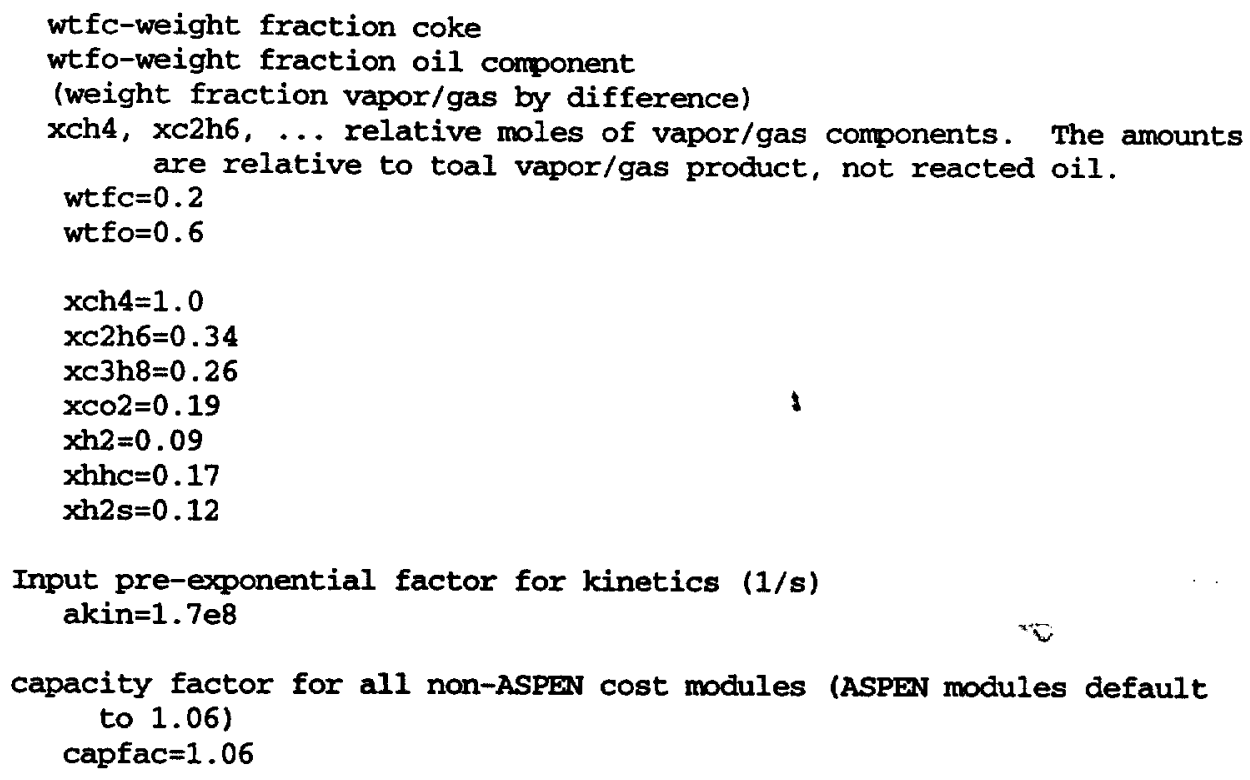

EXECUTE FIRST

FORTRAN SETR ; set kinetic and stoichiometric constants cormon /plex/plx(1)

common /usr2/ akin, xch4, xc2h6, xc3h8, xhhc, xco2 , xh2, xh2s, wtfe, wt fo dimension iplx(1)

equivalence $(\operatorname{iplx}(1), p l x(1))$

DEFINE AC1 BLOCK-VAR BLOCK=RU1 SENTENCE=STOIC VARIABLE=COEF \& ID $1=1$ ID2 $=$ CISOLID ID3 $=$ COKE

DEFINE ach41 BLOCK-VAR BLOCK=RU1 SENTENCE=STOIC VARIABLE=COEF \& ID1 $=1$ ID2 $=\mathrm{MIXPD}$ ID3 $=\mathrm{CH} 4$

DEFINE ac2h61 BLOCK-VAR BLOCK=RU1 SENTENCE=STOIC VARIABLE=COEF \& ID1=1 ID2=MIXED ID3=C2H6

DEFINE ac3h81 BLOCK-VAR BLOCK=RU1 SENTENCE=STOIC VARIABLE=COEF \& ID1=1 ID2=MIXED ID3=C3H8

DEFINE ACO21 BLOCK-VAR BLOCK=RU1 SENTENCE=STOIC VARIABLE=COEF \& ID1 $=1$ ID2 $=\mathrm{MIXFD}$ ID3 $=\mathrm{CO} 2$

DEFINE ah21 BLOCK-VAR BLOCK=RU1 SENTEANCE=STOIC VARIABLE=COEF \& ID1 $=1$ ID2 =MIXED ID3 $=\mathrm{H} 2$

DEFINE ahhc1 BLOCK-VAR BLOCK=RU1 SENTENCE=STOIC VARIABLE=COEF \& ID1=1 ID2=MIXFD ID3=hhc

DEFINE ah2s1 BLOCK-VAR BLOCK=RU1 SENTENCE=STOIC VARIABLE=COEF \& ID1 $=1 \quad$ ID2 $=$ MIXED ID3 $=\mathrm{H} 2 \mathrm{~S}$

DEFINE aO1 BLOCK-VAR BLOCK=RU1 SENTENCE=STOIC VARIABLE=COEF \& $\mathrm{ID1}=1$ ID2=MIXED ID3=P-OIL

DEFINE bC1 BLOCK-VAR BLOCK=RU1 SENTENCE=STOIC VARIABLE=COEF \& ID1 $=2$ ID2 $=$ CISOLID ID3 $=$ COKE

DEFINE bCh41 BLOCK-VAR BLOCK=RU1 SENIENCE=STOIC VARIABLE=COEF \& ID1 $=2$ ID2 =MIXED ID3 =CH4

DEFINE bc2h61 BLOCK-VAR BLOCK=RU1 SENTENCE=STOIC VARIABLE=COEF \& $I D 1=2 \quad I D 2=M I X E D \quad I D 3=C 2 H 6$

DEFINE bC3h81 BLOCK-VAR BLOCK=RU1 SENTENCE=STOIC VARIABLE=COEF \& ID1 $=2$ ID2 $=$ MIXED ID3 $=\mathrm{C} 3 \mathrm{H} 8$

DEFINE bCO21 BLOCK-VAR BLOCK=RU1 SENTENCE=STOIC VARIABLE=COEF \& ID1 $=2$ ID2 $=\mathrm{MIXED}$ ID3 $=\mathrm{CO} 2$

DEFINE bh21 BLOCK-VAR BLOCK=RU1 SENTENCE=STOIC VARIABLE=COEF \& ID1 $=2 \quad$ ID2 $=$ MIXED ID3 $=\mathrm{H} 2$

DEFINE bhhc1 BLOCK-VAR BLOCK=RU1 SENTENCE=STOIC VARIABLE=COEF \& 
ID1 $=2$ ID2=MIXED ID3=hhe

DEFINE bh2s1 BLOCK-VAR BLOCK=RU1 SENTEACE=STOIC VARIABLE=COEF \& $I D 1=2 \quad I D 2=M I X E D \quad I D 3=H 2 S$

DEFINE bO1 BLOCK-VAR BLOCK=RU1 SENTENCE=STOIC VARIABLE=COEF \& ID1=2 ID2=MIXED ID3=P-OIL

DEFINE CC1 BLOCK-VAR BLOCK=RU1 SENTENCE=STOIC VARIABLE=COEF \& ID1 $=3$ ID2 $=$ CISOLID ID3 $=$ COKE

DEFINE CCh41 BLOCK-VAR BLOCK=RU1 SENTENCE=STOIC VARIABLE=COEF \& ID1=3 ID2=MIXED ID3=CH4

DEFINE CC2h61 BLOCK-VAR BLOCK=RU1 SENTENCE=STOIC VARIABLE=COEF \& $I D 1=3 \quad$ ID2 $=\mathrm{MIXED}$ ID3 $=\mathrm{C} 2 \mathrm{H} 6$

DEFINE CC3h81 BLOCK-VAR BLOCK=RU1 SENTENCE=STOIC VARIABLE=COEF \& ID1=3 ID2 $=$ MIXED ID3 $=C 3 H 8$

DEFINE CCO21 BLOCK-VAR BLOCK=RU1 SENTENCE=STOIC VARIABLE=COEF \& $\mathrm{ID} 1=3 \quad \mathrm{ID} 2=\mathrm{MIXED} \quad \mathrm{ID} 3=\mathrm{CO} 2$

DEFINE Ch21 BLOCK-VAR BLOCK=RU1 SENTENCE=STOIC VARIABLE=COEF \& ID1 $=3$ ID2 $=$ MIXED ID3 $=\mathrm{H} 2$

DEFINE chhC1 BLOCK-VAR BLOCK=RU1 SENTENCE=STOIC VARIABLE=COEF \& ID1 $=3$ ID2=MIXED ID3=hhC

DEFINE ch2s1 BLOCK-VAR BLOCK=RU1 SENTENCE=STOIC VARIABLE=COEF \& ID1 $=3$ ID2 $=\mathrm{MIXED}$ ID3 $=\mathrm{H} 2 \mathrm{~S}$

DEFINE CO1 BLOCK-VAR BLOCK=RU1 SENTENCE=STOIC VARIABLE=COEF \& $I D 1=3 \quad I D 2=M I X E D$ ID3 $=P$-OII

DEFINE dC1 BLOCK-VAR BLOCK=RU1 SENTENCE=STOIC VARIABLE=COEF \& ID $1=4$ ID2 $=$ CISOLID ID3=COKE

DEFINE dCh41 BLOCR-VAR BLOCK=RU1 SENTENCE=STOIC VARIABLE=COEF \& ID1 4 ID2 $=$ MIXED ID3 $=\mathrm{CH} 4$

DEFINE dC2h61 BLOCK-VAR BLOCK=RU1 SENTENCE=STOIC VARIABLE=COEF \& $I D 1=4 \quad I D 2=M I X E D \quad I D 3=C 2 \mathrm{H} 6$

DEFINE dc3h81 BLOCK-VAR BLOCK=RU1 SENTEACE=STOIC VARIABLE=COEF \& ID1=4 ID2=MIXED ID3=C3H8

DEFTNE dCO21 BLOCK-VAR BLOCK=RU1 SENTENCE=STOIC VARIABLE=COEF \& $I D 1=4$ ID2 $=\mathrm{MIXXD}$ ID3 $=\mathrm{CO} 2$

DEFINE dh21 BLOCR-VAR BLOCK=RU1 SENTENCE=STOIC VARIABLE=COEF \& $I D 1=4 \quad I D 2=M I X E D \quad I D 3=\mathrm{H} 2$

DEFINE dhhC1 BLOCK-VAR BLOCK=RU1 SENIENCE=STOIC VARIABLE=COEF \& ID1=4 ID2=MIXED ID3=hhC

DEFINE dh2s1 BLOCK-VAR BLOCK=RU1 SENTENCE=STOIC VARIABLE=COEF \& ID1 $=4$ ID2 $=$ MIXED ID $3=\mathrm{H} 2 \mathrm{~S}$

DEFINE dO1 BLOCK-VAR BLOCK=RU1 SENTENCE=STOIC VARIABLE=COEF \& ID1 $=4$ ID2 $=$ MIXED ID $3=\mathrm{P}-\mathrm{OIL}$

DEFINE ECI BLOCK-VAR BLOCK=RU1 SENTENCE=STOIC VARIABLE=COEF \& ID1 $=5$ ID2=CISOLID ID3=COKE

DEFINE ECh41 BLOCK-VAR BLOCK=RU1 SENTENCE=STOIC VARIABLE=COEF \& ID1 $=5$ ID2 $=$ MIXEDD ID3 $=\mathrm{CH} 4$

DEFINE EC2h61 BLOCK-VAR BLOCK=RU1 SENTENCE=STOIC VARIABLE=COEF \& ID1 $=5$ ID2 $=\mathrm{MIXED}$ ID3 $=\mathrm{C} 2 \mathrm{H} 6$

DEFINE ec3h81 BLOCK-VAR BLOCK=RU1 SENTENCE=STOIC VARIABLE=COEF \& ID1 $=5$ ID2 $=\mathrm{MIXED}$ ID3 $=\mathrm{C} 3 \mathrm{H} 8$

DEFINE ECO21 BLOCK-VAR BLOCK=RU1 SENTENCE=STOIC VARIABLE=COEF \& ID1 $=5$ ID2 $=$ MIXED ID3 $=\mathrm{CO} 2$

DEFINE Eh21 BLOCK-VAR BLOCK=RU1 SENTENCE=STOIC VARIABLE=COEF \& $I D 1=5 \quad I D 2=M I X E D \quad I D 3=H 2$

DEFINE ehhC1 BIOCK-VAR BLOCK=RU1 SENTENCE=STOIC VARIABLE=COEF \& ID1 $=5$ ID2 =MIXED ID3=hhC

DEFINE eh2s1 BLOCK-VAR BLOCK=RU1 SENTENCE=STOIC VARIABLE=COEF \& ID1=5 ID2=MIXED ID3=H2S

DEFINE EO1 BLOCK-VAR BLOCK=RU1 SENTENCE=STOIC VARIABLE=COEF \& ID1=5 ID2 =MIXED ID3=P-OIL

DEFINE fC1 BLOCK-VAR BLOCK=RU1 SENTENCE=STOIC VARIABLE=COEF \& 
ID1 $=6$ ID2 $=$ CISOLID ID3 $=$ COKE

DEFINE fCh41 BLOCK-VAR BLOCK=RU1 SENTENCE=STOIC VARIABLE=COEF \& ID1 $=6$ ID2 $=\mathrm{MIXED}$ ID3 $=\mathrm{CH} 4$

DEFINE fc2h61 BLOCK-VAR BLOCK=RU1 SENTENCE=STOIC VARIABLE=COEF \& ID1 $=6$ ID2 $=\mathrm{MIXED}$ ID3 $=\mathrm{C} 2 \mathrm{H} 6$

DEFINE fC3h81 BLOCK-VAR BLOCK=RU1 SENTENCE=STOIC VARIABLE=COEF \& $\mathrm{ID} 1=6$ ID2 $=\mathrm{MIXED}$ ID $3=\mathrm{C} 3 \mathrm{H} 8$

DEFINE fCO21 BLOCK-VAR BLOCK=RU1 SENTENCE=STOIC VARIABLE=COEF \& ID1=6 ID2=MIXED ID3 $=\mathrm{CO} 2$

DEFINE fh21 BLOCK-VAR BLOCK=RU1 SENTENCE=STOIC VARIABLE=COEF \& ID $1=6 \quad$ ID2 $=$ MIXED ID $3=\mathrm{H} 2$

DEFINE fhhc1 BLOCK-VAR BLOCK=RU1 SENTENCE=STQIC VARIABLE=COEF \& ID1=6 ID2=MIXED ID3=hhC

DEFINE fh2s1 BLOCK-VAR BLOCK=RU1 SENIEAICE=STOIC VARIABLE=COEF \& ID1=6 ID2=MIXED ID3=H2S

DEFINE fO1 BLOCK-VAR BLOCK=RU1 SENTENCE=STOIC VARIABLE=COEF \& ID1=6 ID2=MIXED ID3=P-OIL

DEFINE AC2 BLOCK-VAR BLOCK=RU2 SENTENCE=STOIC VARIABLE=COEF \& ID1 $=1$ ID2=CISOLID ID3=COKE

DEFINE ach42 BLOCK-VAR BLOCK=RU2 SENTENCE=STOIC VARIABLE=COEF \& ID1 $=1$ ID2 $=$ MTXED ID3 $=\mathrm{CH} 4$

DEFINE ac2h62 BLOCK-VAR BLOCK=RU2 SENTENCE=STOIC VARIABLE=COEF \& ID1=1 ID2=MIXED ID3=C2H6

DEFINE ac3h82 BLOCK-VAR BLOCK=RU2 SEITENCE=STOIC VARIABLE=COEF \& ID1 $=1$ ID2 $=$ MIXED ID3 $=C 3 H 8$

DEFINE aCO22 BLOCK-VAR BLOCK=RU2 SENTENCE=STOIC VARIABLE=COEF \& ID1 1 ID2 $=\mathrm{MIXED}$ ID3 $=\mathrm{CO} 2$

DEFINE ah22 BLOCK-VAR BLOCK=RU2 SENTEANCE=STOIC VARIABLE=COEF \& ID1=1 ID2=MIXED ID3=H2

DEFINE ahhC2 BLOCK-VAR BLOCK=RU2 SENTENCE=STOIC VARIABLE=COEF \& ID1=1 ID2 =MIXED ID3=hhc

DEFINE ah2s2 BLOCK-VAR BLOCK=RU2 SENTENCE=STOIC VARIABLE=COEF \& ID1 $=1$ ID2=MIXED ID3=H2S

DEFINE aO2 BLOCK-VAR BLOCK=RU2 SENTENCE=STOIC VARIABLE=COEF \& ID1=1 ID2=MIXED ID3=P-OIL

DEFINE bC2 BLOCK-VAR BLOCK=RU2 SENTENCE=STOIC VARIABLE=COEF \& ID1=2 ID2 =CISOLID ID3 $=$ COKE

DEFINE bCh42 BLOCK-VAR BLOCK=RU2 SENIENCE=STOIC VARIABLE=COEF \& ID1 $=2$ ID2 $=\mathrm{MIXED}$ ID3 $=\mathrm{CH} 4$

DEFINE bC2h62 BLOCK-VAR BLOCK=RU2 SENTENCE=STOIC VARIABLE=COEF \& ID1 $=2$ ID2 =MIXED ID3 =C2H6

DEFINE bC3h82 BLOCK-VAR BLOCK=RU2 SENTENCE=STOIC VARIABLE=COEF \& $I D 1=2 \quad I D 2=M I X E D \quad I D 3=C 3 H 8$

DEFINE bCO22 BLOCK-VAR BLOCK=RU2 SENTENCE=STOIC VARIABLE=COEF \& $\mathrm{ID} 1=2$ ID2 $=\mathrm{MIXED}$ ID $3=\mathrm{CO} 2$

DEFINE bh22 BLOCK-VAR BLOCK=RU2 SENTENCE=STOIC VARIABLE=COEF \& ID1 $=2$ ID2 =MIXED ID3=H2

DEFINE bhhC2 BLOCK-VAR BLOCK=RU2 SENTENCE=STOIC VARIABLE=COEF \& ID1 $=2$ ID2 $=$ MIXED ID3=hhC

DEFINE bh2s2 BLOCK-VAR BLOCK=RU2 SENTENCE=STOIC VARIABLE=COEF \& ID1 $=2$ ID2 =MIXED ID3 =H2S

DEFINE bO2 BLOCK-VAR BLOCK=RU2 SEINTENCE=STOIC VARIABLE=COEF \& ID1=2 ID2=MIXED ID3=P-OIL

DEFINE CC2 BLOCK-VAR BLOCK=RU2 SENTENCE=STOIC VARIABLE=COEF \& ID1 $=3$ ID2 $=$ CISOLID ID3=COKE

DEFINE CCh42 BLOCK-VAR BLOCK=RU2 SENTENCE=STOTC VARIABLE=COEF \& ID1=3 ID2=MIXED ID3=CH4

DEFINE CC2h62 BLOCK-VAR BLOCK=RU2 SENTENCE=STOIC VARIABLE=COEF \& ID $1=3$ ID2 $=$ MIXED ID $3=\mathrm{C} 2 \mathrm{H} 6$

DEFINE CC3h82 BLOCK-VAR BLOCK=RU2 SENTENCE=STOIC VARIABLE=COEF \& ID1 $=3$ ID2 $=$ MIXED ID3 $=\mathrm{C} 3 \mathrm{HB}$ 
DEFINE CCO22 BLOCK-VAR BLOCK=RU2 SENTENCE=STOIC VARIARLE=COEF \& ID1=3 ID2 =MIXED ID3 $=\mathrm{CO} 2$

DEFINE ch22 BLOCK-VAR BLOCK=RU2 SENTENCE=STOIC VARIABLE=COEF \& $\mathrm{ID} 1=3$ ID2 $=\mathrm{MIXED}$ ID3 $=\mathrm{H} 2$

DEFINE chhc2 BLOCK-VAR BLOCK=RU2 SEMTENCE=STOIC VARTABLE=COEF \& ID1=3 ID2=MIXED ID3=hhC

DEFINE ch2s2 BLOCK-VAR BLOCK=RU2 SENTEACE=STOIC VARIABLE=COEF \& ID $1=3$ ID2=MIXED ID3=H2S

DEFINE CO2 BLOCK-VAR BLOCK=RU2 SENTENCE=STOIC VARIABLE=COEF \& ID1=3 ID2=MIXED ID $3=$ P-OIL

DEFINE dC2 BLOCK-VAR BLOCK=RU2 SENTENCE=STOIC VARIABLE=COEF \& ID1 $=4$ ID2 $=$ CISOLID ID3 $=$ COKE

DEFTNE dCh42 BLOCK-VAR BLOCK=RU2 SENTENCE=STOIC VARTABLE=COEF \& ID1 $=4$ ID2 $=\mathrm{MIXED}$ ID3 $=\mathrm{CH} 4$

DEFINE dc2h62 BLOCK-VAR BLOCR=RU2 SENTENCE=STOIC VARIABLE=COEF \& ID1 $=4$ ID2 $=\mathrm{MIXED}$ ID $3=\mathrm{C} 2 \mathrm{H} 6$

DEFINE dc3h82 BLOCK-VAR BLOCK=RU2 SENTENCE=STOIC VARIABLE=COEF \& ID1 $=4$ ID2 $=$ MIXED ID3 $=\mathrm{C} 3 \mathrm{HB}$

DEFINE dCO22 BLOCK-VAR BLOCK=RU2 SENIENCE=STOIC VARIABLE=COEF \& ID1 $=4 \quad$ ID2 $=$ MIXED ID $=\mathrm{CO} 2$

DEFINE dh22 BLOCK-VAR BLOCK=RU2 SENTENCE=STOIC VARIABLE=COEF \& ID1 $=4$ ID2 $=$ MIXED ID3 $=\mathrm{H} 2$

DEFINE dhhC2 BLOCK-VAR BLOCK=RU2 SENTENCE=STOIC VARIABLB=COEF \& ID1=4 ID2=MIXED ID3=hhC

DEFINE dh2s2 BLOCK-VAR BLOCK=RU2 SENTENCE=STOIC VARIABLE=COEF \& ID1=4 ID2=MIXED ID3=H2S

DEFINE dO2 BLOCK-VAR BLOCK=RU2 SENTENCE=STOIC VARIABLE=COEF \& ID1=4 ID2=MIXED ID3=P-OIL

DEFINE EC2 BLOCK-VAR BLOCK=RU2 SENTENCE=STOIC VARIABLE=COBF \& ID1 $=5$ ID2=CISOLID ID3=COKE

DEFINE ech42 BLOCK-VAR BLOCK=RU2 SENIENCE=STOIC VARIABLE=COEF \& ID1 $=5$ ID2=MIXED ID3=CH4

DEFINE ec2h62 BLOCK-VAR BLOCK=RU2 SENTENCE=STOIC VARIABLE=COEF \& $I D 1=5 \quad I D 2=\mathrm{MIXED} \quad \mathrm{ID} 3=\mathrm{C} 2 \mathrm{H} 6$

DEFINE EC3h82 BLOCK-VAR BLOCK=RU2 SENTENCE=STOIC VARIABLE=COEF \& ID $1=5$ ID2 $=$ MIXED ID3=C3H8

DEFINE ECO22 BLOCK-VAR BLOCK=RU2 SENTENCE=STOIC VARIABLE=COEF \& ID1 $=5$ ID2 $=\mathrm{MIXED} \quad \mathrm{ID} 3=\mathrm{CO} 2$

DEFINE eh22 BLOCK-VAR BLOCK=RU2 SENIENCE=STOIC VARIABLE=COEF \& ID1=5 ID2=MIXED ID3=H2

DEFINE ehhC2 BLOCK-VAR BLOCK=RU2 SENTENCE=STOIC VARIABLE=COEF \& ID1 $=5$ ID2=MIXED ID3=hhe

DEFINE eh2s2 BLOCK-VAR BLOCK=RU2 SENTENCE=STOIC VARIABLE=COEF \& ID $1=5$ ID2 $=$ MIXED ID3 $=\mathrm{H} 2 \mathrm{~S}$

DEFINE CO2 BLOCK-VAR BLOCK=RU2 SENTENCE=STOIC VARIABLE=COEF \& ID1=5 ID2=MIXID ID3=P-OIL

DEF INE FC2 BLOCK-VAR BLOCK=RU2 SENTENCE=STOIC VARIABLE=COEF \& ID1 $=6$ ID2=CISOLID ID3=COKE

DEFINE fCh42 BLOCK-VAR BLOCK=RU2 SENTENCE=STOIC VARIABLE=COEF \& ID1 $=6$ ID2 $=$ MIXED ID3 $=\mathrm{CH} 4$

DEFINE fC2h62 BLOCK-VAR BLOCK=RU2 SENTENCE=STOIC VARIABLE=COEF \& ID $1=6$ ID2 $=$ MIXED ID3 $=\mathrm{C} 2 \mathrm{H} 6$

DEFINE fC3h82 BLOCK-VAR BLOCK=RU2 SENTENCE=STOIC VARIABLE=COEF \& ID1 $=6$ ID2 $=$ MIXED ID3 $=\mathrm{C} 3 \mathrm{H} 8$

DEFINE fCO22 BLOCK-VAR BLOCK=RU2 SENTENCE=STOIC VARIABLE=COEF \& ID1 $=6$ ID2=MIXED ID3=CO2

DEFINE fh22 BLOCK-VAR BLOCK=RU2 SENTENCE=STOIC VARIABLE=COEF \& ID1 $=6$ ID2 $=$ MIXED ID3 $=\mathrm{H} 2$

DEFINE EhhC2 BLOCK-VAR BLOCK=RU2 SENTENCE=STOIC VARIABLE=COEF \& ID $1=6 \quad$ ID2 $=$ MIXED ID $3=$ hhC

DEFINE fh2s2 BLOCK-VAR BLOCK=RU2 SENTENCE=STOIC VARIABLE=COEF \& 
ID1=6 ID2=MIXED ID3=H2S $\begin{array}{ccc}\text { DEFINE fO2 } & \text { BLOCK-VAR BLOCK=RU2 } \\ \text { ID1 } 1=6 & \text { ID2=MIXED } & \text { ID3=P-OIL }\end{array}$

DEFINE AC3 BLOCK-VAR BLOCK=RU3 SENTENCE=STOIC VARIABLE=COEF \& ID1=1 ID2=CISOLID ID3=COKE

DEFINE ach43 BLOCK-VAR BLOCK=RU3 SENTENCE=STOIC VARIABLE=COEF \& ID1=1 ID2 =MIXED ID3 $=\mathrm{CH} 4$

DEFINE aC2h63 BLOCK-VAR BLOCK=RU3 SENTENCE=STOIC VARIABLE=COEF \& ID1 $=1$ ID2 =MIXED ID3 $=\mathrm{C} 2 \mathrm{H} 6$

DEFINE ac3h83 BLOCK-VAR BLOCK=RU3 SENTENCE=STOIC VARIABLE=COEF \& ID1=1 ID2=MIXED ID3=C3H8

DEFINE aCO23 BLOCK-VAR BLOCK=RU3 SENTENCE=STOIC VARTABLE=COEF \& ID1 $=1$ ID2=MIXED ID3 $=\mathrm{CO} 2$

DEFINE ah23 BLOCK-VAR BLOCK=RU3 SENTENCE=STOIC VARIABLE=COEF \& ID1=1 ID2=MIXED ID3=H2

DEFINE ahhc3 BLOCK-VAR BLOCK=RU3 SENIENCE=STOIC VARIABLE=COEF \& ID1=1 ID2 =MIXED ID3=hhC

DEFINE ah2s3 BLOCR-VAR BLOCK=RU3 SENTENCE=STOIC VARIABLE=COEF \& ID1 $=1$ ID2=MIXED ID3=H2S

DEFINE aO3 BLOCK-VAR BLOCK=RU3 SENTENCE=STOIC VARIABLE=COEF \& ID1=1 ID2=MIXED ID3=P-OIL

DEFINE bC3 BLOCK-VAR BLOCK=RU3 SENTEMCE=STOIC VARIABLE=COEF \& ID1=2 ID2 =CISOLID ID3 =COKE

DEFINE bCh43 BLOCK-VAR BLOCK=RU3 SENTENCE=STOIC VARIABLE=COEF \& ID1 $=2$ ID2 $=\mathrm{MIXED}$ ID $3=\mathrm{CH} 4$

DEFINE bC2h63 BLOCK-VAR BLOCK=RU3 SENTENCE=STOIC VARTABLE=COEF \& ID1=2 ID2=MTXED ID3=C2H6

DEFINE bC3h83 BLOCK-VAR BLOCK=RU3 SENTENCE=STOIC VARIABLE=COEF \& ID1 $=2$ ID2=MIXED ID3=C3H8

DEFINE bCO23 BLOCK-VAR BLOCK=RU3 SENTENCE=STOIC VARIABLE=COEF \& $\mathrm{ID} 1=2 \quad \mathrm{ID} 2=\mathrm{MIXED} \quad \mathrm{ID} 3=\mathrm{CO} 2$

DEFINE bh23 BLOCK-VAR BLOCK=RU3 SENTENCE=STOIC VARIABLE=COEF \& ID1=2 ID2 =MIXED ID3=H2

DEFINE bhhC3 BLOCK-VAR BLOCK=RU3 SENTENCE=STOIC VARIABLE=COEF \& ID1 $=2$ ID2 =MIXED ID3=hhc

DEFINE bh2 3 BLOCK-VAR BLOCK=RU3 SENTEINCE=STOIC VARIABLE=COEF \& ID1 $=2$ ID2=MIXED ID3 $=\mathrm{H} 2 \mathrm{~S}$

DEFINE bO3 BLOCK-VAR BLOCK=RU3 SENTENCE=STOIC VARIABLE=COEF \& ID1 $=2$ ID2 =MIXED ID3 =P-OIL

DEFINE CC3 BLOCK-VAR BLOCK=RU3 SENTENCE=STOIC VARIABLE=COEF \& ID1 $=3$ ID2=CISOLID ID3=COKE

DEFINE CCh43 BLOCK-VAR BLOCK=RU3 SENIENCE=STOIC VARIABLE=COEF \& ID1 $=3$ ID2 $=$ MIXEDD ID3 $=\mathrm{CH} 4$

DEF INE CC2h63 BLOCK-VAR BLOCK=RU3 SENTENCE=STOIC VARIABLE=COEF \& ID1 $=3$ ID2 $=\mathrm{MIXED}$ ID3 $=\mathrm{C} 2 \mathrm{H} 6$

DEFINE $\operatorname{cc} 3$ h83 BLOCK-VAR BLOCK=RU3 SENTENCE=STOIC VARIABLE=COEF \& ID1 $=3$ ID2 $=$ MIXED ID3 $=$ C 3 H8

DEFINE CCO23 BLOCK-VAR BLOCK=RU3 SENTENCE=STOIC VARIABLE=COEF \& ID1 $=3$ ID2 $=M I X E D$ ID3 $=\mathrm{CO} 2$

DEFINE Ch23 BLOCK-VAR BLOCK=RU3 SENTENCE=STOIC VARIABLE=COEF \& ID $1=3 \quad$ ID2 $=$ MIXED ID3 $=\mathrm{H} 2$

DEFINE chhC3 BLOCK-VAR BLOCK=RU3 SENTENCE=STOIC VARIABLE=COEF \& ID1 $=3$ ID2=MIXED ID3=hhc

DEFINE ch2s3 BLOCK-VAR BLOCK=RU3 SENTENCE=STOIC VARIABLE=COEF \& ID1 $=3$ ID2 $=$ MIXED ID3 $=\mathrm{H} 2 \mathrm{~S}$

DEFINE CO3 BLOCK-VAR BLOCK=RU3 SENTENCE=STOIC VARIABLE=COEF \& $I D 1=3 \quad$ ID2=MIXED ID3=P-OIL

DEFINE dC3 BLOCK-VAR BLOCK=RU3 SENTENCE=STOIC VARIABLE=COEF \& ID $1=4$ ID2=CISOLID ID $3=$ COKE

DEFINE dCh43 BLOCK-VAR BLOCK=RU3 SENTENCE=STOIC VARIABLE=COEF \& 
ID1 $=4 \quad$ ID2 $=\mathrm{MIXED} \quad \mathrm{ID} 3=\mathrm{CH} 4$

DEFINE dC2h63 BLOCK-VAR BLOCK=RU3 SENTENCE=STOIC VARIABLE=COFF * ID1 $=4$ ID2 $=\mathrm{MIXED}$ ID3 $=\mathrm{C} 2 \mathrm{H} 6$

DEFINE dc3h83 BLOCK-VAR BLOCK=RU3 SENTENCE=STOIC VARIABLE=COEF \& ID1 $=4$ ID2 $=\mathrm{MIXED}$ ID3 $=\mathrm{C} 3 \mathrm{H} 8$

DEFINE dCO23 BLOCK-VAR BLOCK=RU3 SENTENCE=STOIC VARIABLE=COEF \& ID1 $=4$ ID2=MIXED ID3 $=\mathrm{CO} 2$

DEFINE dh23 BLOCK-VAR BLOCK=RU3 SENTENCE=STOIC VARIABLE=COEF \& ID $1=4 \quad$ ID2 $=$ MIXEDD ID3 $=\mathrm{H} 2$

DEFINE dhhe3 BLOCK-VAR BLOCK=RU3 SENTENCE=STOIC VARIABLE=COEF \& ID1 $=4$ ID2=MIXEDD ID3=hhe

DEFINE dh2s3 BLOCK-VAR BLOCK=RU3 SENTENCE=STOIC VARIABLE=COEF \& ID1 $=4$ ID2 $=\mathrm{MIXEND}$ ID3 $=\mathrm{H} 2 \mathrm{~S}$

DEFINE do3 BLOCK-VAR BLOCK=RU3 SENTENCE=STOIC VARIABLE=COEF \& ID1 $=4$ ID2=MIXED ID3=P-OIL

DEFINE EC3 BLOCK-VAR BLOCK=RU3 SENTENCE=STOIC VARIABLE=COEF \& ID1 $=5$ ID2=CISOLID ID3 =COKE

DEFINE ECh43 BLOCK-VAR BLOCK=RU3 SENIENCE=STOIC VARTABLE=COEF \& ID1 $=5$ ID2 =MIXED ID3 $=\mathrm{CH} 4$

DEFINE EC2h63 BLOCK-VAR BLOCK=RU3 SENTENCE=STOIC VARIABLE=COEF \& ID1 $=5$ ID2 $=$ MIXED ID3 $=\mathrm{C} 2 \mathrm{H} 6$

DEFINE ec3h83 BLOCK-VAR BLOCK=RU3 SENIENCE=STOIC VARIABLE=COEF \& ID1 $=5$ ID2 $=$ MIXED ID3 $=C 3 \mathrm{H} 8$

DEFINE ECO23 BLOCK-VAR BLOCK=RU3 SENTENCE=STOIC VARIABLE=COEF \& ID1 $=5$ ID2 $=\mathrm{MIXED}$ ID3 $=\mathrm{CO} 2$

DEFINE eh23 BLOCK-VAR BLOCK=RU3 SENTENCE=STOIC VARIABLE=COEF \& ID1 $=5$ ID2=MIXED ID3=H2

DEFINE ehhC3 BLOCK-VAR BLOCK=RU3 SENTENCE=STOIC VARIABLE=COEF \& ID1=5 ID2=MIXED ID3=hhc

DEFINE eh2s3 BLOCK-VAR BLOCK=RU3 SENTENCE=STOIC VARIABLE=COEF \& ID1 $=5$ ID2 =MIXED ID3=H2S

DEFINE $O 3$ BLOCK-VAR BLOCK=RU3 SENTENCE=STOIC VARIABLE=COEF \& ID $1=5$ ID2 $=$ MIXED ID3 =P-OIL

DEFINE fC3 BLOCK-VAR BLOCK=RU3 SENTENCE=STOIC VARTABLE=COEF \& ID1 $=6$ ID2=CISOLID ID3 =COKE

DEFINE fCh43 BLOCK-VAR BLOCK=RU3 SENTENCE=STOIC VARIABLE=COEF \& ID1 $=6$ ID2 $=\mathrm{MIXED}$ ID $3=\mathrm{CH} 4$

DEFINE fC2h63 BLOCK-VAR BLOCK=RU3 SENTENCE=STOIC VARIABLE=COEF \& ID1 $=6$ ID2 $=\mathrm{MIXED}$ ID3 $=\mathrm{C} 2 \mathrm{H} 6$

DEFINE fC3h83 BLOCK-VAR BLOCK=RU3 SENTENCE=STOIC VARIABLE=COEF \& ID1 $=6$ ID2 $=\mathrm{MIXED}$ ID3 $=\mathrm{C} 3 \mathrm{H} 8$

DEFINE fCO23 BLOCK-VAR BLOCK=RU3 SENTENCE=STOIC VARIABLE=COEF \& ID1 $=6$ ID2 $=\mathrm{MIXED}$ ID3 $=\mathrm{CO} 2$

DEFINE Th23 BLOCK-VAR BLOCK=RU3 SENTENCE=STOIC VARIABLE=COEF \& ID1 $=6$ ID2 $=$ MIXED $I D 3=H 2$

DEFINE thhC3 BLOCK-VAR BLOCK=RU3 SENTENCE=STOIC VARIABLE=COEF \& ID1 $=6$ ID2 =MIXED ID $3=$ hhe

DEFINE fh2s3 BLOCK-VAR BLOCK=RU3 SENTENCE=STOIC VARIABLE=COEF \& ID1 $=6$ ID2 $=$ MTXEDD ID3 $=\mathrm{H} 2 \mathrm{~S}$

DEFINE fO3 BLOCK-VAR BLOCK=RU3 SENTENCE=STOIC VARIABLE=COEF \& ID1 $=6$ ID2=MIXED ID3=P-OIL

DEFINE aeal BLOCK-VAR BLOCK=RU1 SEINIENCE=RATE-CON VARIABLE=PRE-EXP \& ID1=1

DEFINE bea1 BLOCK-VAR BLOCK=RU1 SENTENCE=RATE-CON VARIABLE=PRE-EXP \& ID $1=2$

DEFINE cea1 BLOCK-VAR BLOCK=RU1 SENTENCE=RATE-CON VARIABLE=PRE-EXP \& ID1 $=3$

DEFINE deal BLOCK-VAR BLOCK=RU1 SENTENCE=RATE-CON VARIABLE=PRE-EXP \& ID $1=4$

DEFINE eea1 BLOCK-VAR BLOCK=RU1 SENTENCE=RATE-CON VARIABLE=PRE-EXP \& ID1 $=5$ 
DEFINE fea1 BLOCK-VAR BLOCK=RU1 ID1 $=6$

DEFINE aea2 BLOCK-VAR BLOCK=RU2 SENTENCE=RATE-CON VARIABLE=PRE-EXP \& $I D 1=1$

DEFINE bea2 BLOCK-VAR BLOCK=RU2 ID1 $=2$

DEFINE CE22 BLOCK-VAR BLOCK=RU2 ID1 $=3$

DEFINE dea2 BLOCK-VAR BLOCK=RU2 ID1 $=4$

DEFINE Eea2 BLOCK-VAR BLOCK=RU2 ID1 $=5$

DEFTNE fea2 BLOCK-VAR BLOCK=RU2 ID1 $=6$

DEFINE aea3 BLOCK-VAR BLOCK=RU3 SENTENCE=RATE-CON VARIABLE=PRE-EXP \& ID1 $=1$

DEFINE bea3 BLOCK-VAR BLOCK=RU3 SENTENCE=RATE-CON VARIABLE=PRE-EXP \& ID1 $=2$

DEFINE Cea3 BLOCK-VAR BLOCK=RU3 SENTENCE=RATE-CON VARIABLE=PRE-EXP \& ID1 $=3$

DEFINE dea3 BLOCK-VAR BLOCK=RU3 SENTENCE=RATE-CON VARIABLE=PRE-EXP \& $\mathrm{ID} 1=4$

DEFINE eea3 BLOCK-VAR BLOCK=RU3 SEMTIENCE=RATE-CON VARIABLE=PRE-EXP \& ID1 $=5$

DEFINE fea3 BLOCK-VAR BLOCK=RU3 SENIEANCE=RATE-CON VARIABLE=PRE-EXP \& $I D 1=6$

define gas mw's for later use

iof $f=$ if $\mathrm{cmnc}$ ( ' $\mathrm{MW}$ ')

$\mathrm{n}=\mathbf{k c c i d c}($ ' CH4')

$w \operatorname{ch} 4=p l \times($ ioff $+n)$

$\mathrm{n}=\mathrm{kccidc}$ ( ' $\mathrm{C2H}$ ')

wc2h6=plx (ioff $+n)$

$n=k c c i d c$ (' $\mathrm{C} 3 \mathrm{H} 8$ ')

wc $3 h 8=p l x($ iof $f+n)$

$n=\operatorname{kccide}(' \mathrm{CO} 2$ ')

$w C O 2=p l x($ iof $f+n)$

$\mathrm{n}=\mathrm{kccidc}$ ( ' $\mathrm{H} 2$ ')

wh2 $=p l \times($ iof $f+n)$

$n=k c c i d c$ ('H2S')

COKE

wh2s $=p l x($ iof $f+n)$

$n=k c c i d c($ ' COKE')

wC $=p l x($ iof $f+n)$

P-OIL

$n=$ kccidc ( ' p-orl')

HISC

wo $=p l \times($ ioff $+n)$

$\mathrm{n}=\mathrm{kccidc}$ ( ' HHC')

whhc $=p l x($ iof $f+n)$

normalize gas

sum $=x c h 4+x c 2 h 6+x c 3 h 8+x c o 2+x h 2+x h h c+x h 2 s$

xch4=xch4/sum

$\mathrm{xc} 2 \mathrm{~h} 6=\mathrm{xc} 2 \mathrm{~h} 6 / \mathrm{sum}$

$\mathrm{xc} 3 \mathrm{~h} 8=\mathrm{xc} 3 \mathrm{~h} 8 / \mathrm{sum}$

$\mathrm{xco} 2=\mathrm{xco} 2 / \mathrm{sum}$

xh2 $=x h 2 /$ sum

xhhc $=x h h c /$ sum

$\operatorname{xh} 2 s=x h 2 s /$ sum

compute gas average mw

wmix $=x c h 4$ * wch $4+x c 2 h 6{ }^{*}$ wc2h6+xc3h8 * wc $3 h 8+x c o 2{ }^{*}$ wco $2+x h 2$ * wh2

\&. +xhhc*whhc+xh2s*wh2s 


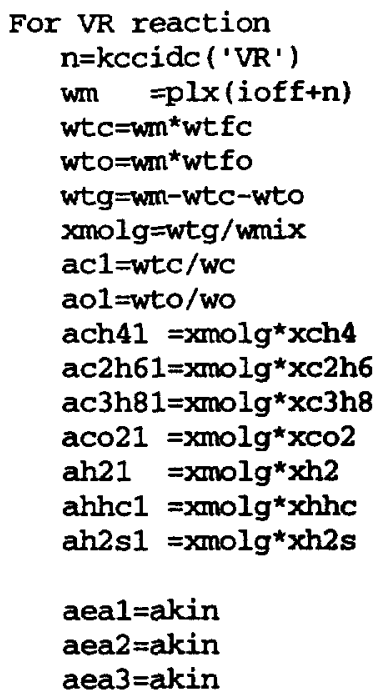

For HVGO reaction n=kccide ('HUGO')

wm $=p l x($ iof $f+n)$ $w t c=w m^{*} w t f c$

wto $=w^{*}$ "wt fo

wtg=wm-wtc-wto xmolg=wtg/wmix bc1 $1=w t c / w c$ bol=wto/wo bch $41=x m o l g * x c h 4$ bc2h61=xmolg *xc2h6 bc $3 \mathrm{~h} 81=x \operatorname{molg} *$ xc3h8 $\mathrm{bco} 21=\mathrm{xmolg}{ }^{*} \mathrm{xcO} 2$ bh21 =xmolg*xh2 bhhc1 =xmolg*xhhe bh2s $1=x m o l g * x h 2 s$

beal=akin

bea2=akin

bea3=akin

For LVGO reaction $n=$ kccidc ('LVGO')

wm $=p l \times($ ioff $+n)$ wtc $=w m^{*} w t$ fc $w t o=w m^{*} w t$ fo wtg $=w m$-wtc-wto $x$ molg=wtg/wmix cc1 $=w t c / w c$ col=wto/wo $\operatorname{cch} 41=x m o 1 g * x c h 4$ cc2h61=xmolg* xc2h6 cc $3 \mathrm{~h} 81=x m o l g * x c 3 h 8$ $\operatorname{cco} 21=x m o l g * x c o 2$ $\operatorname{ch} 21=x m o l g * x h 2$ chhcl $=$ xmolg $^{\star}$ xhhe ch2s1 =xmolg*xh2s

ceal=akin cea2=akin cea3 =akin 


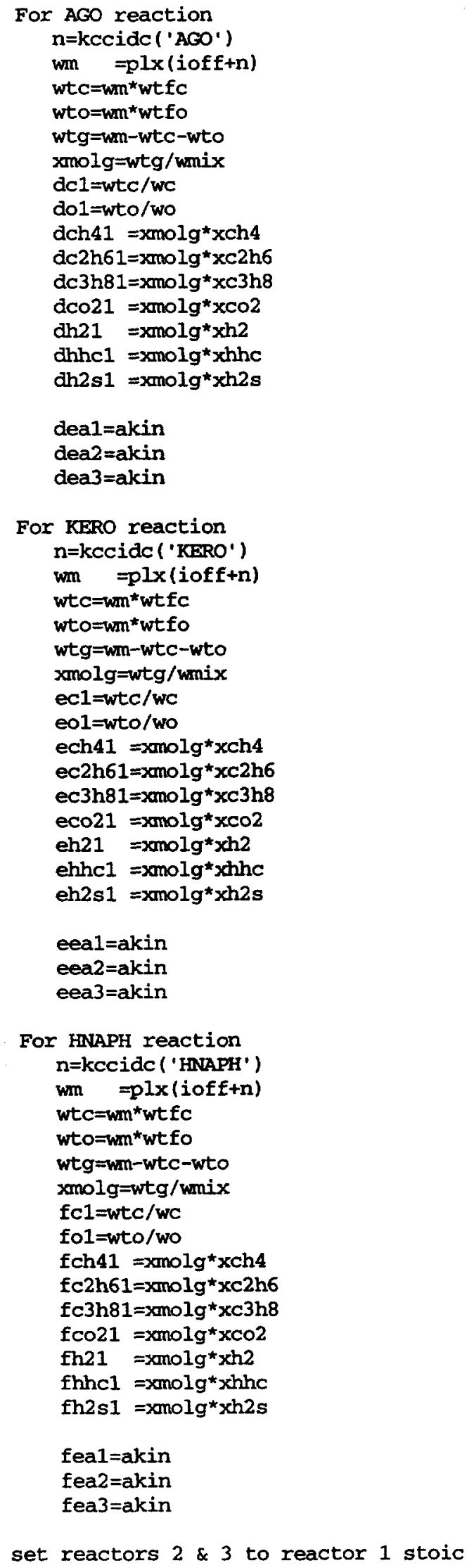




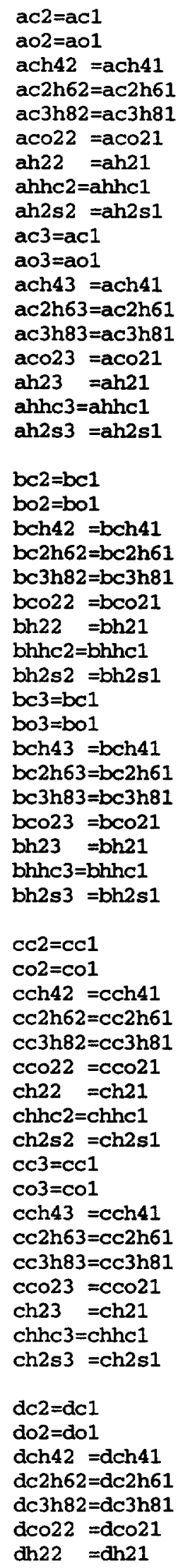




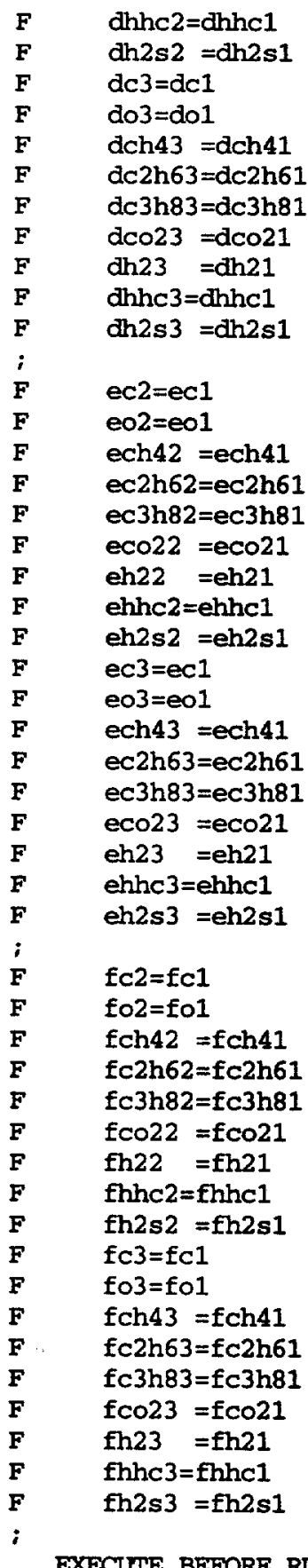

EXECUTE BEFORE RU1

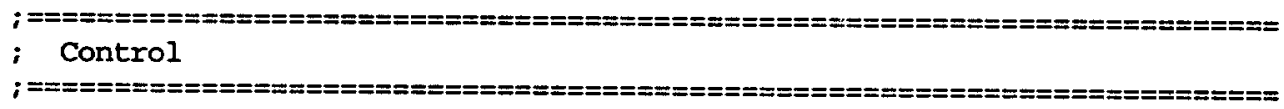

ACCOUNT-INFO ACCOUNT=HPASPEN PROJECT-ID=P \& PROJECT-NAME= "Oil Upgrading " USER-NAME= "CHE"

IN-UNITS SI TEMPERATURE=C

;OUT-UNITS ENG VOLUME-FLOW='BBL/DAY' ENTHALPY-FLO='MMBTU/HR' \& ; VOLUME=BBL HEAD=FT HEAT=MMBTU 


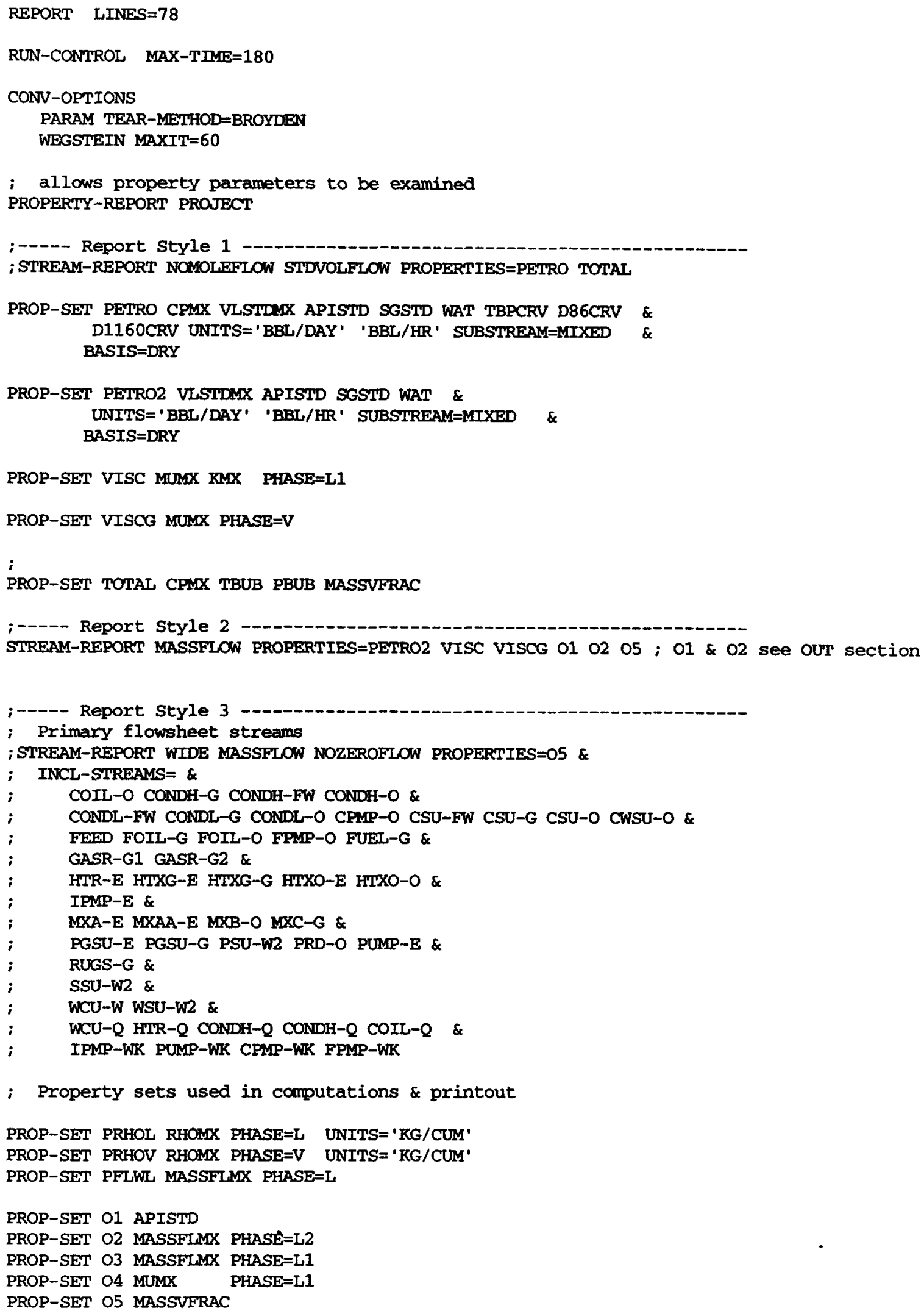




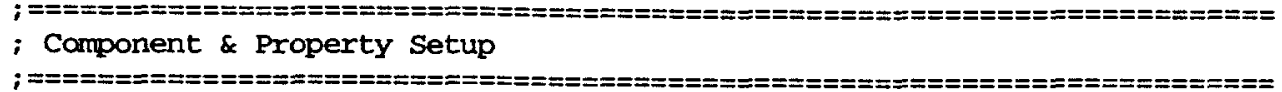

$\begin{array}{cc}\exp (c 1+c 2 / T+c 3 * T) \\ C i 2 & \\ 0.0 & 0 \\ 0.0 & 0 \\ 0.0 & 0 \\ 0.0 & 0\end{array}$

PVAL HVGO

$-4352.68$

$-4328.52$

$-4303.77$

$-4275.15$

$-4247.13$

EVAL VR

$-4219.96$

- Active values (parameters with maxima in solubility curve)

$\begin{array}{lllll}\text { PVAL } & \text { HNAPH } & 24.35 & -8000 & -0.019 \\ \text { PVAL } & \text { KERO } & 24.35 & -8000 & -0.019 \\ \text { PVAL } & \text { AGO } & 24.35 & -8000 & -0.019 \\ \text { PVAL } & \text { LVGO } & 24.35 & -8000 & -0.019 \\ \text { PVAL } & \text { HVGO } & 24.35 & -8000 & -0.019 \\ \text { PVAL } & \text { VR } & 24.35 & -8000 & -0.019\end{array}$

COMPONENTS

$\mathrm{H} 2 \mathrm{O} \mathrm{H} 2 \mathrm{O} \mathrm{H2O} \mathrm{/} \mathrm{CH4} \mathrm{CH4} \mathrm{CH4} \mathrm{/} \mathrm{C} 2 \mathrm{H} 6 \mathrm{C} 2 \mathrm{H} 6 \mathrm{C2H} 6 / \mathrm{C} 3 \mathrm{H} 8 \mathrm{C} 3 \mathrm{H} 8 \mathrm{C} 3 \mathrm{H} 8$ \&

$/$ HHC C4H1O-1 HHC / H2S H2S H2S / $\mathrm{CO} 2 \mathrm{CO} 2 \mathrm{CO} 2 / \mathrm{H} 2 \mathrm{H} 2 \mathrm{H} 2 \&$

/ P-OIL / COKE C COKE

PC-USER

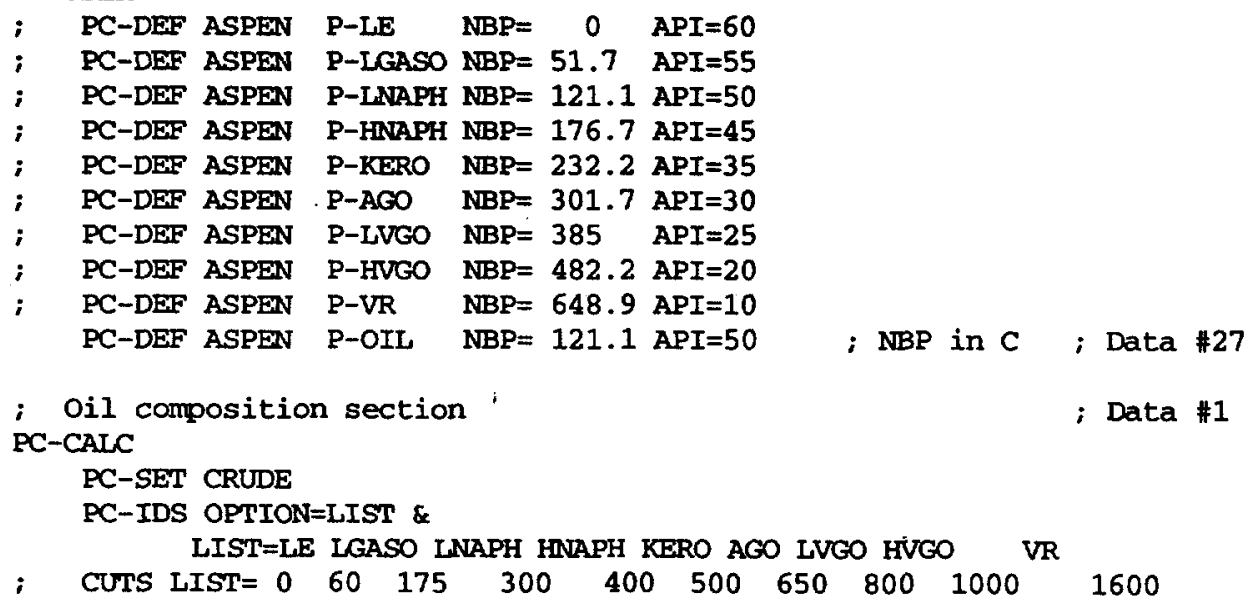




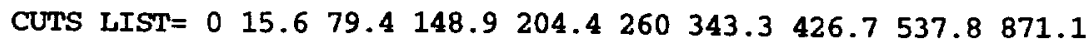

ADA-SETUP

ADA-SETUP PROCEDURE $=$ REL 9

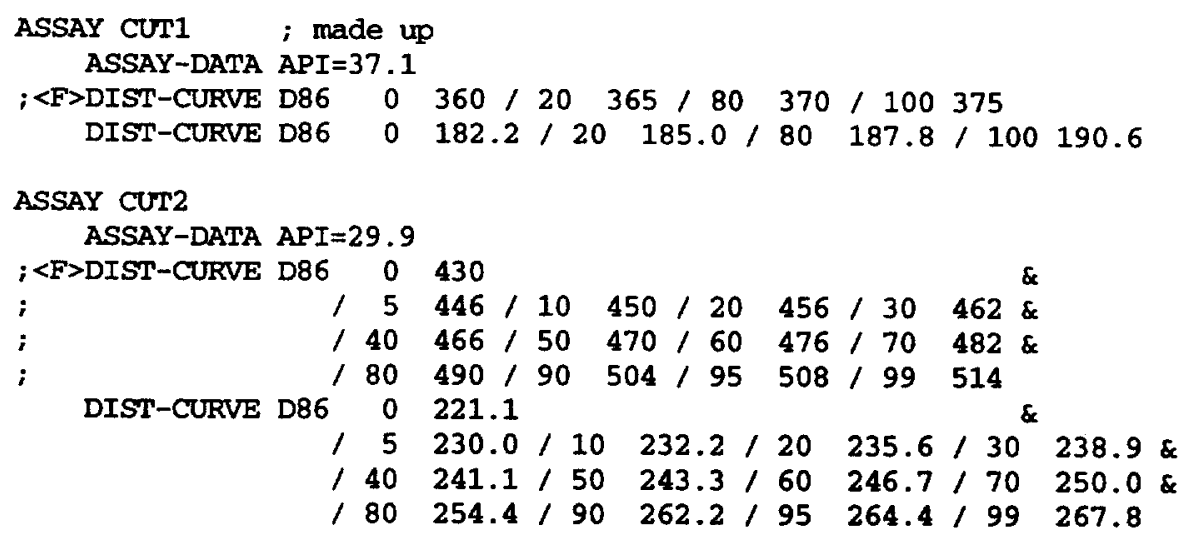




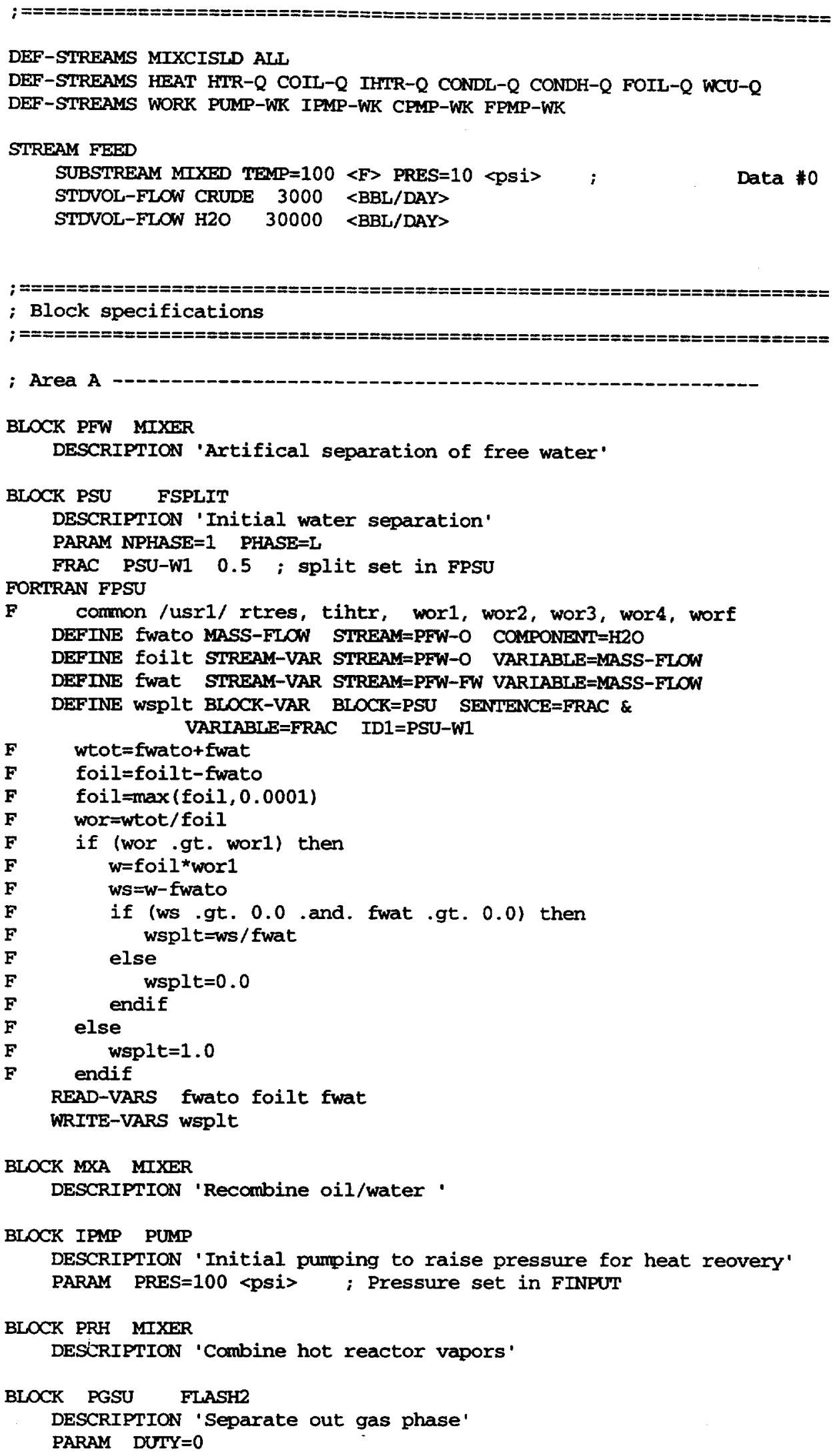




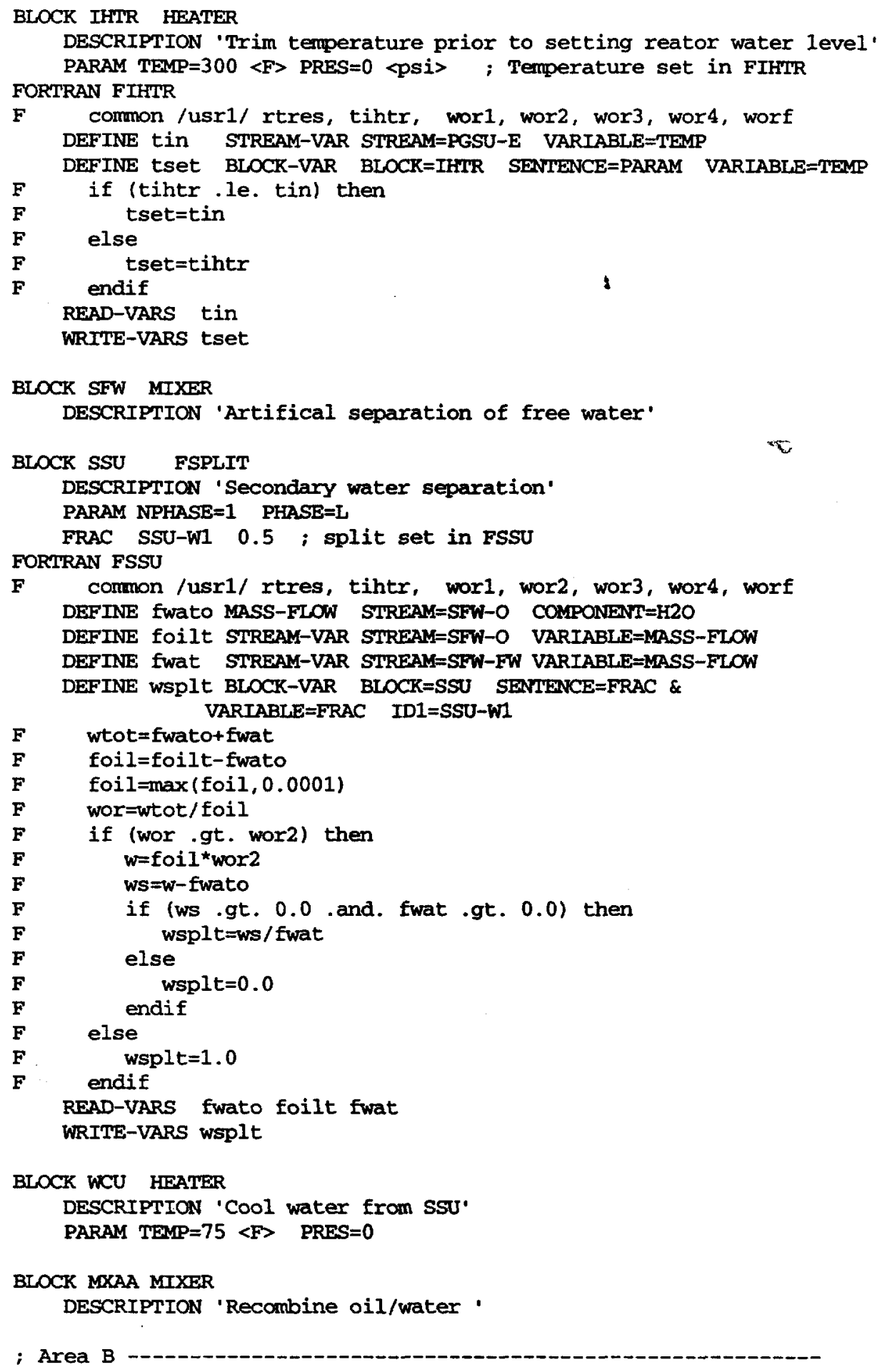


BLOCK HTXG HEATX

DESCRIPTION 'Heat recovery heat exchanger (gas/oil)'

PARAM DELT-HOT=70 <F> ; Approach temp set in FINPUT

HEAT-TR-COEF U=50 <BTU/HR-SQFT-R> ; Overall heat tx coef Data \#22

FEEDS HOT=GASR-G2 COLD=PUMP-E

PRODUCTS HOT=FTKG-G COLD=HTXG-E

BLOCK HTXO HEATX

DESCRIPTION 'Heat recovery heat exchanger (oil/oil)'

PARAM DELT-HOT $=70$; Approach temp (F) set in FINPUT

; HEAT-TR-COEF $U=60$ <BTU/HR-SQFT-R> ; Overall heat tx coef Data \#22

HEAT-TR-COEF L-L=30 <BTU/HR-SOFT-R> \&

$\mathrm{L}-\mathrm{B}=100<\mathrm{BTU} / \mathrm{HR}-\mathrm{SQFT}-\mathrm{R}>\&$

$\mathrm{L}-\mathrm{V}=10<\mathrm{BTU} / \mathrm{HR}-\mathrm{SQFT}-\mathrm{R}>$;

FLASH-SPECS HTXO-O NPHASE=1 PHASE=L

Data \#22

FEEDS HOT $=\mathrm{MXB}-\mathrm{O} \quad \mathrm{COLD}=\mathrm{HTXG}-\mathrm{E}$

PRODUCTS HOT $=$ HTXO-O COLD=HTXO-E

BLOCK HTR HEATER

DESCRIPTION 'Trim temperature for reactor/separator'

PARAM TEMP $=600<$ F> PRES $=0$; Reactor temperature set in FINPUT

; Area C

BLOCK RU1 RCSTR

DESCRIPTION 'Reactor unit 1'

PARAM DUTY $=0$ NPHASE $=2$ PHASE $=L$ VOL=10 <BBL> REACT-VOL $=10<B B L>$ PRES $=0$

; reaction controlled by react-vol set in FRU

STOIC 1 MIXED VR -1 / MIXED P-OIL * ; components \& ceoffs set in SETR

RATE-CON $114.2 \mathrm{e} 739.74[\mathrm{kcal} / \mathrm{mol}]$; Eact \& pre-exp (1/s) Data \#21

POWLAW-EXP 1 VR 1 ;

Data $\$ 21$

STOIC 2 MIXED HVGO -1 / MIXED P-OIL * ; components \& ceoffs set in SETR RATE-CON $214.2 \mathrm{e} 739.74[\mathrm{kcal} / \mathrm{mol}]$; Eact \& pre-exp $(1 / \mathrm{s})$ Data \#21

POWLAW-EXP 2 HVGO 1 ; Data \#21

STOIC 3 MIXED LVGO -1 / MIXED P-OIl * ; components \& ceoffs set in SETR RATE-CON $314.2 \mathrm{e} 739.74[\mathrm{kcal} / \mathrm{mol}]$; Eact \& pre-exp (1/s) Data \#21

POWLAW-EXP 3 LVGO 1 ; Data \#21

STOIC 4 MIXED AGO -1 / MIXED P-OIL *; components \& ceoffs set in SETR RATE-CON 4 14.2e7 39.74[kcal/mol] ; Eact \& pre-exp (1/s) Data \#21 POWLAW-EXP 4 AGO 1 ;

Data \#21

STOIC 5 MIXED KERO -1 / MIXED P-OIL *; components \& ceoffs set in SETR RATE-CON 5 14.2e7 $39.74[\mathrm{kcal} / \mathrm{mol}]$; Eact \& pre-exp $(1 / \mathrm{s})$ Data \#21 POWLAW-EXXP 5 KERO 1 ;

Data $\# 21$

STOIC 6 MIXED HNAPH $-1 /$ MIXED P-OIL *; components \& ceoffs set in SETR RATE-CON $614.2 \mathrm{e} 739.74[\mathrm{kcal} / \mathrm{mol}]$; Eact \& pre-exp $(1 / \mathrm{s})$ Data \#21 POWLAW-EXP 6 HNAPH 1 ; Data $\$ 21$

BLOCK RU2 RCSTR

DESCRIPTION 'Reactor unit 2 '

PARAM DUTY=0 NPHASE=2 PHASE=L VOL=10 <BBL> REACT-VOL=10 <BBL> PRES=0 ; reaction controlled by react-vol set in FRU

STOIC 1 MIXED VR -1 / MIXED P-OIL * ; components \& ceoffs set in SETR RATE-CON 1 14.2e7 $39.74[\mathrm{kcal} / \mathrm{mol}]$; Eact \& pre-exp $(1 / \mathrm{s})$ Data \#21 POWLAW-EXP 1 VR 1 ; Data \$21

STOIC 2 MIXED HVGO -1 / MIXED P-OIL * ; components \& ceoffs set in SETR RATE-CON $214.2 \mathrm{e} 739.74[\mathrm{kcal} / \mathrm{mol}]$; Eact \& pre-exp $(1 / \mathrm{s})$ Data \#21 
POWLAW-EXP 2 HVGO 1 ;

Data \#21

STOIC 3 MIXED LVGO -1 / MIXED P-OIL * ; components \& ceoffs set in SETR RATE-CON $314.2 \mathrm{e} 739.74[\mathrm{kcal} / \mathrm{mol}]$; Eact \& pre-exp (1/s) Data \#21 POWLAW-EXP 3 LVGO 1 ; Data \#21

STOIC 4 MIXED AGO -1 / MIXED P-OIL *; components \& ceoffs set in SETR RATE-CON 4 14.2e7 39.74[kcal/mol] ; Eact \& pre-exp $(1 / \mathrm{s})$ Data *21 POWLAW-EXP 4 AGO 1 ;

Data \#21

STOIC 5 MIXED KERO -1 / MIXED P-OIL * ; components \& ceoffs set in SETR RATE-CON 5 14.2e7 $39.74[\mathrm{kcal} / \mathrm{mol}]$; Eact \& pre-exp (1/s) Data \#21 POWLAW-EXP 5 KERO 1 ; Data \#21

STOIC 6 MIXED HINAPH -1 / MIXED P-OIL * ; components \& ceoffs set in SETR RATE-CON $614.2 \mathrm{e} 739.74[\mathrm{kcal} / \mathrm{mol}]$; Eact s pre-exp $(1 / \mathrm{s})$ Data $\$ 21$ POWLAW-EXP 6 HNAPH 1 ;

BLOCK RU3 RCSTR $\times$

DESCRIPTION 'Reactor unit 3'

PARAM DUTY=0 NPHASE=2 PHASE=L VOL=10 <BBL> REACT-VOL=10 <BBL> PRES=0 ; reaction controlled by react-vol set in FRU

STOIC 1 MIXED VR -1 / MIXED P-OIL * ; components \& ceoffs set in SETR RATE-CON $114.2 \mathrm{e} 739.74[\mathrm{kcal} / \mathrm{mol}]$; Eact \& pre-exp $(1 / \mathrm{s})$ Data 21 POWLAW-EXP 1 VR 1 ; Data \#21

STOIC 2 MIXED HVGO -1 / MIXED P-OIL * ; components \& ceoffs set in SETR RATE-CON $214.2 \mathrm{e} 739.74[\mathrm{kcal} / \mathrm{mol}]$; Eact \& pre-exp $(1 / \mathrm{s})$ Data \#21 POWLAW-EXP 2 HVGO 1 ; Data \#21

STOIC 3 MIXED LVGO -1 / MIXED P-OIL * ; components \& ceoffs set in SETR RATE-CON $314.2 \mathrm{e} 739.74[\mathrm{kcal} / \mathrm{mol}]$; Eact \& pre-exp $(1 / \mathrm{s})$ Data \#21 POWLAW-EXP 3 LVGO 1 ;

Data \#21

STOIC 4 MIXED AGO -1 / MIXED P-OIL * ; components \& ceoffs set in SETR RATE-CON $414.2 \mathrm{e} 739.74[\mathrm{kcal} / \mathrm{mol}]$; Eact \& pre-exp $(1 / \mathrm{s})$ Data \#21 POWLAW-EXP 4 AGO 1 ; Data \#21

STOIC 5 MIXED KERO -1 / MIXED P-OIL * ; components * ceoffs set in SETR RATE-CON $514.2 \mathrm{e} 739.74[\mathrm{kcal} / \mathrm{mol}]$; Eact \& pre-exp $(1 / \mathrm{s})$ Data \#21 POWLAW-EXP 5 KERO 1 ;

Data \#21

STOIC 6 MIXED HNAPH -1 / MIXED P-OIL * ; components \& ceoffs set in SETR RATE-CON $614.2 \mathrm{e} 739.74[\mathrm{kcal} / \mathrm{mol}]$; Eact \& pre-exp $(1 / \mathrm{s})$ Data $\$ 21$ POWLAW-EXP 6 HENAPH 1 ;

Data \#21

FORTRAN FRU

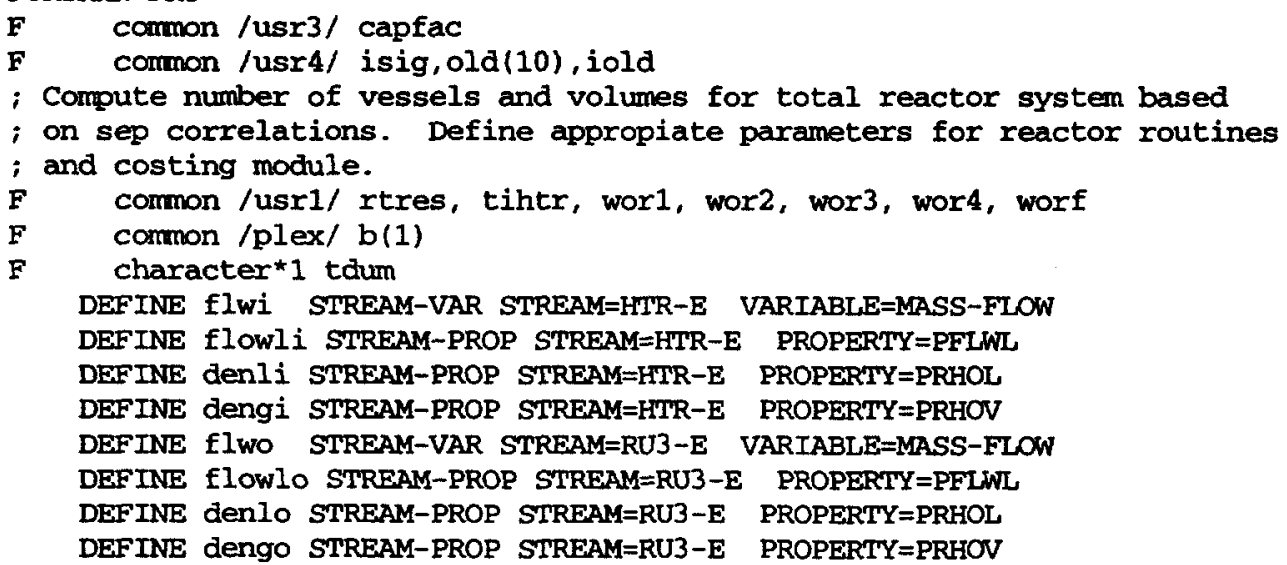


DEFINE pres BLOCK-VAR BLOCK=PUMP SENTENCE=PARAM VARTABLE=PRES DEFINE Vol1 BLOCK-VAR BLOCK=RU1 SENTENCE=PARAM VARIABLE=VOL DEFINE VOIr1 BLOCK-VAR BLOCK=RU1 SENTENCE=PARAM VARIABLE=REACT-VOL DEFINE Vo12 BLOCK-VAR BLOCK=RU2 SENIENCE=PARAM VARIABLE=VOL DEFINE VOIr2 BLOCK-VAR BLOCK=RU2 SENIENCE=PARAM VARIABLE=REACT-VOL DEFINE VO13 BLOCK-VAR BLOCK=RU3 SENTENCE=PARAM VARIABLE=VOL DEFINE VOIr3 BLOCK-VAR BLOCK=RU3 SENTEICE=PARAM VARIABLE=REACT-VOL DEFINE volc CBLOCK-VAR CBLOCK=C-RU SENTENCE=SIZING-DATA \& VARIABLE $=$ VOL

DEFINE teIm BLOCK-VAR BLOCK=HTR SENTENCE=PARAM VARIABLE=TEMP DEFINE diamC CBLOCK-VAR CBLOCK=C-RU SEAIENCE=SIZING-DATA \& VARIABLE $=D I A M$

DEFINE presC CBLOCK-VAR CBLOCK=C-RU SENIENCE=SIZING-DATA \& VARIABLE $=$ PRES

DEFINE tempC CBLOCK-VAR CBLOCK=C-RU SENIENCE=SIZING-DATA \& VARIABLE=TEMP

DEFINE nEquip CBLOCK-VAR CBLOCK=C-RU SENTENCE=COSTING-DATA \& VARTABLE $=$ NEQUIP

used average properties in/out of reactor (except on 1st pass)

(wti weighting factor for in flow, [1-wti] used for outflow) Data \#23

if (flwo.gt.0.0 and. flwo.1t. 1elo) then $w t i=0.50$

wto $=1.0-w t i$

flw=wto* flwo+wti $i$ flwi

flowl=wto* flowlo+wti flowli

deng $=w t o^{\star}$ dengo+wt $i *$ dengi

denl=wto*denlo+wti ${ }^{\star}$ denli

else

$f l w=f l w i$

flowl=flowli

deng=dengi

denl=denli

endif

flw=capfac ${ }^{\mathrm{fl}} \mathbf{l w}$

flowl=capfac* flowl

set liquid volume in $\mathrm{m}^{\star \star} 3$ based on residence time and average liq flow vliq $=$ rtres ${ }^{*} 60 *$ flowl/denl

flowg $=f l w-f l o w l$

maximum vessel volume

vmax $=2521 * \exp (-$ pres $/ 4.723 \mathrm{e} 6)$

minimum $L / D$ ratio

Data 23

$x l d r=3.0$

minimum diameter (m)

Data 23

dmin $=5.0 * 0.3048$

minimum void height if horizontal (m)

Data 23

hmin $=1.0 * 0.3048$

Data $\# 23$

write (nrpt. '(' 'C-RU' ')')

protect against bad flows, use old values if set,

otherwise use default values

if (flowl.le.0.0.or.flowl.ge.1.0e10) then

if (isig.eq.1234) then

vol=old (1)

number $=i o l d$

vliq $=0 l d(2)$

diam=old (3)

else

vol $=10.0$

number $=1$

vliq $=8$

else endif

call sep (nrpt, 'H', 'S', 'Y', 'N' , flowg, flowl, vliq, vmax, denl, deng, 


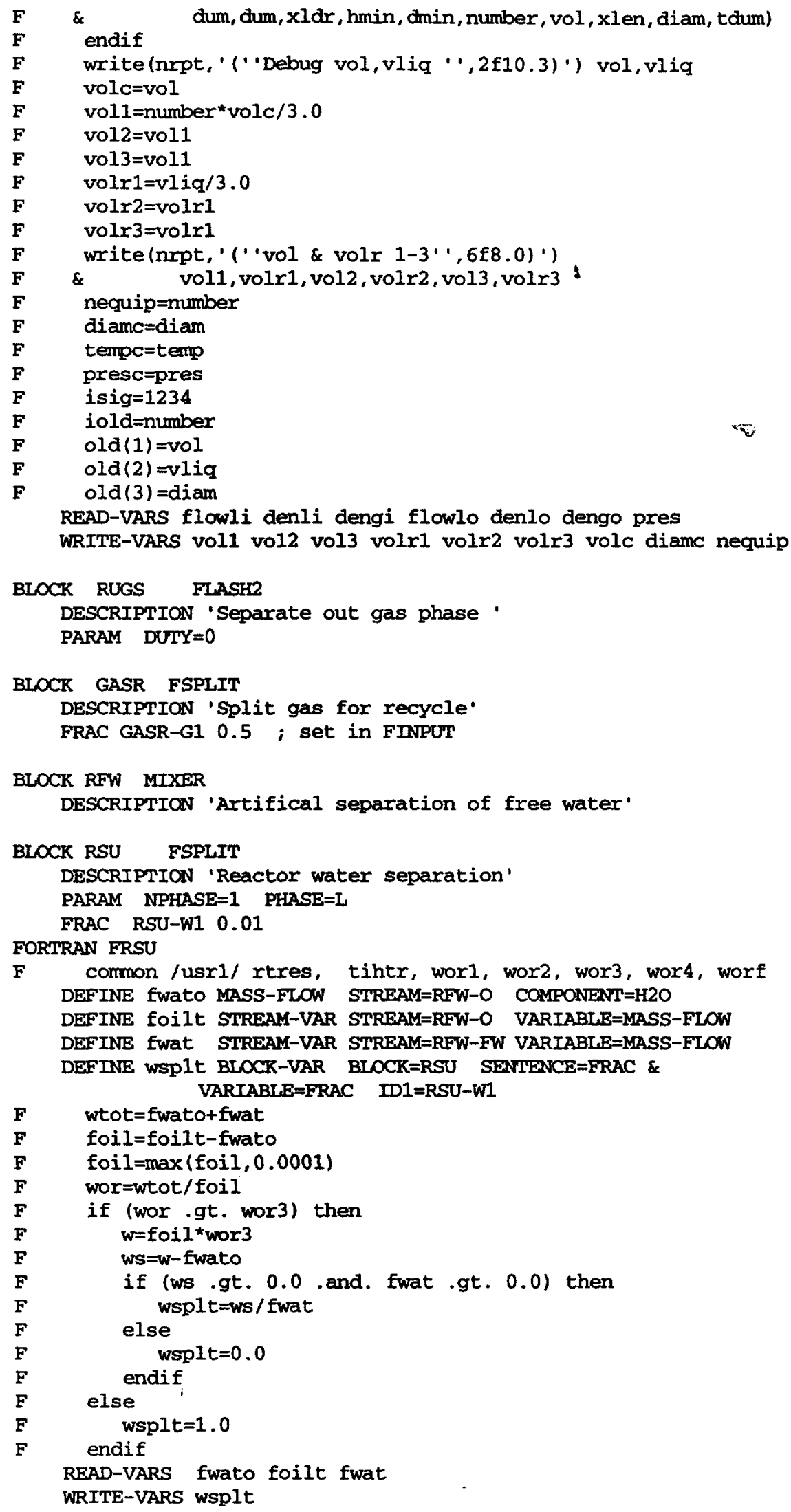




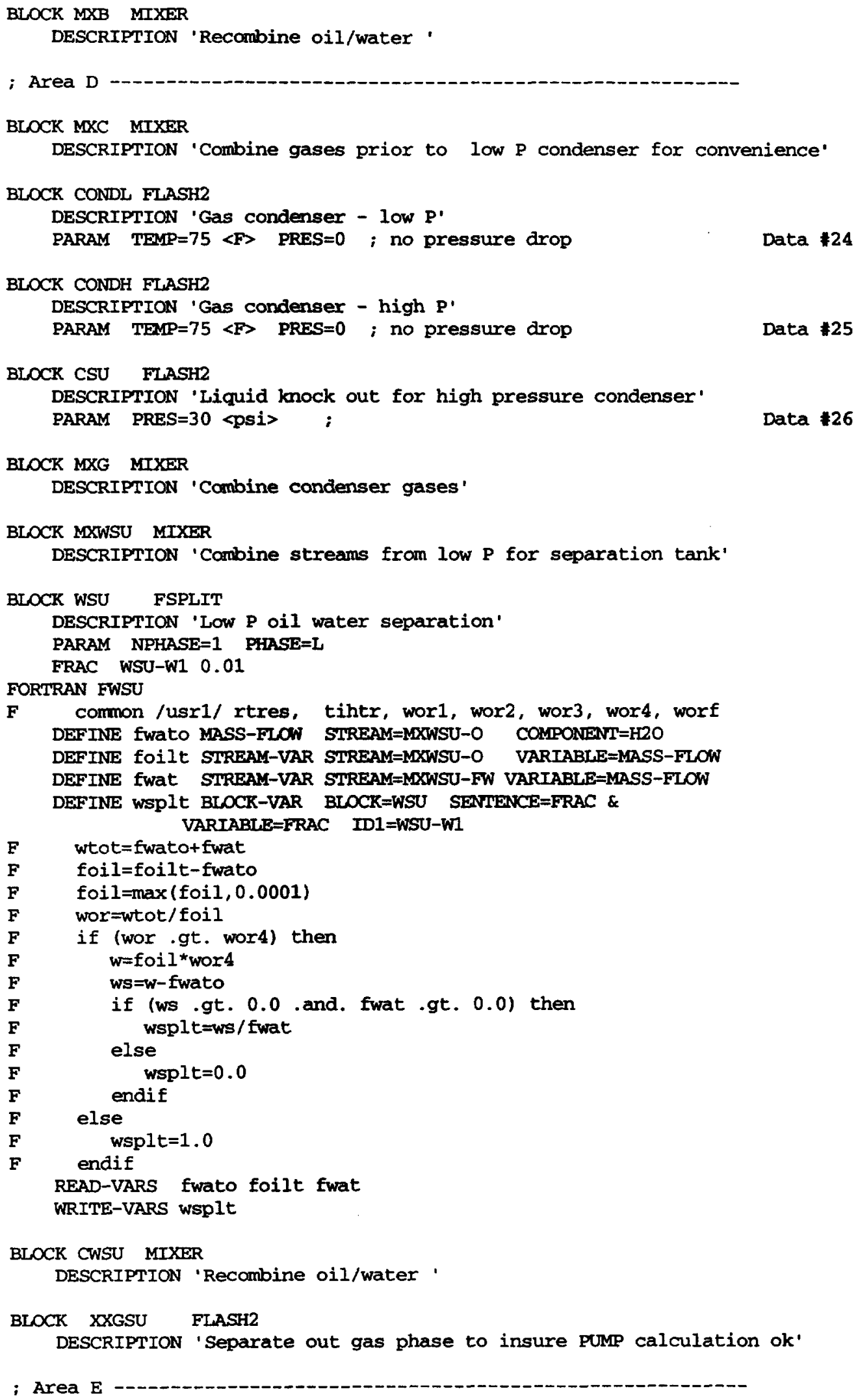


DEFINE tOCO STREAM-VAR STREAM=HTXO-E VARIABLE=TEMP

DEFINE fo STREAM-VAR STREAM=PUMP-E VARIABLE=MASS-FLOW

DEFINE aO BLOCK-VAR BLOCK=HTXO SENTENCE=RESULTS VARIABLE=AREA-CALC

DEFINE dutYO BLOCK-VAR BLOCK=HTXO SENTENCE=RESULTS VARIABLE=DUTY

DEFINE tghi STREAM-VAR STREAM=GASR-G2 VARIABLE=TEMP

DEFINE tgho STREAM-VAR STREAM=HTXG-G VARIABLE=TEMP

DEFINE tgCi STREAM-VAR STREAM=PUMP-E VARIABLE=TEMP

DEFINE tgCO STREAM-VAR STREAM=HTXG-E VARIABLE=TEMP

DEFINE fg STREAM-VAR STREAM=PUMP-E VARIABLE=MASS-FLOW

DEFINE ag BLOCK-VAR BLOCK=HTXG SENTENCE=RESULTS VARIABLE=AREA-CALC

DEFINE dutyg BLOCK-VAR BLOCK=HTXG SENTENCE=RESULTS VARIABLE=DUTY

DEFINE grX BLOCK-VAR BLOCK=GASR SENTENCE=FRAC VARIABLE=FRAC

DEFINE WTIX MASS-FLOW STREAM=RUGS-E COMPONENT=H2O

DEFINE flrX STREAM-VAR STREAM=RUGS-E VARIABIE=LASS-FLOW

DEFINE flrg STREAM-VAR STREAM=RUGS-G VARIABLE=MASS-FLOW

DEF INE WTpX MASS-FLOW STREAM $=$ PRD-O COMPONENT $=\mathrm{H} 20$

DEFINE flpx STREAM-VAR STREAM=PRD-O VARIABLE=MASS-FLOW

DEFINE apixi STREAM-PROP STREAM=PFW-O PROPERTY=01

DEFINE apixo STREAM-PROP STREAM=PRD-O PROPERTY $=01$

DEFINE fOXi STREAM-VAR STREAM=PFW-O VARIABLE=MASS-FLOW

DEFINE Wtix MASS-FLOW STREAM=PFW-O COMPONENT=H2O

DEFINE fOXO STREAM-VAR STREAM=PRD-O VARIABLE=MASS-FLOW

DEFINE chrX MASS-FLOW STREAM=RU3-E SUBSTREAM=CISOLID COMPONENT=COKE DEFINE pOilX MASS-FLOW STREAM=RU3-E SUBSTREAM=MIXED COMPONENT=P-OIL,

DEFINE gCh4 MOLE-FLOW STREAM=FUEL-G SUBSTREAM=MIXED COMPONENT=CH4 DEFINE GC2h6 MOLE-FLOW STREAM=FUEL-G SUBSTREAM=MIXED COMPONENT=C2H6 DEFINE gc3h8 MOLE-FLOW STREAM=FUEL-G SUBSTREAM=MIXIED COMPONENT=C3H8 DEFINE ghhe MOLE-FLOW STREAM=FUEL-G SUBSTREAM=MIXED COMPONENT=HITC DEFINE gh2 MOLE-FLOW STREAM=FUEL-G SUBSTREAM=MIXED COMPONENT=H2 DEFINE gPOiI MOLE-FLOW STREAM=FUEL-G SUBSTREAM=MIXED COMPONENT=P-OIL DEFINE htrqX INFO-VAR STREAM=HTR-Q INFO=HEAT VARIABLE=DUTY

DEFINE cost PROFIT-VAR SENTENCE=RESULTS VARIABLE=PROD-PRICE DEFINE rhOO STREAM-PROP STREAM=PRD-O PROPERTY=PRHOL DEFINE rhOi STREAM-PROP STREAM=PFW-O PROPERTY=PRHOL

DEFINE OpOiI MOLE-FLOW STREAM=PRD O COMPONENT=P-OIL

DEFINE fWf1 STREAM-PROP STREAM=HTXG-E PROPERTY=O2 DEFINE fWf2 STREAM-PROP STREAM=HTXO-E PROPERTY=O2 DEFINE fWf3 STREAM-PROP STREAM=HTXO-O PROPERTY $=02$ DEFINE fof1 STREAM-PROP STREAM=HTXG-E PROPERTY $=03$

DEFINE fof2 STREAM-PROP STREAM=HTXO-E PROPERTY $=03$ DEFINE fof 3 STREAM-PROP STREAM $=H T X O-O \quad$ PROPERTY $=03$

DEFINE V1 STREAM-PROP STREAM=HTXO-O PROPERTY $=04$

F write (nrpt, '

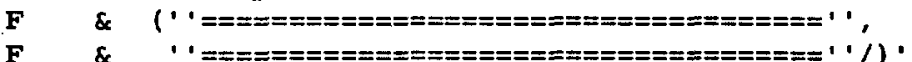

F write (nrpt, ' (' Heat Exchanger Performance' "

F \& $/ 3 x_{1}$, 'HTXG' ',

$F \& \quad \& \quad / 3 x$, Area (sqm):"',f8.0,"'sqm/kg/hr : ", f6.3,

$F \quad \& \quad 3 x, \cdots$ Duty (MW) : ' , f6.1,

$F \quad \& \quad 19 x, \cdots$ IN (C) OUT (C) $\cdots$

F \& $\quad$ (3x, ' Hot $\cdots, 2 f 8.0 / 3 x, \cdots \operatorname{cold} \cdots, 2 f 8.0 / 3 x, \cdots$ Delta' , 2f8.0)')

F \& ag,ag/fg, dutyg/1.0e6, tghi,tgho, tgci, tgco,tghi-tgco, tgho-tgci 


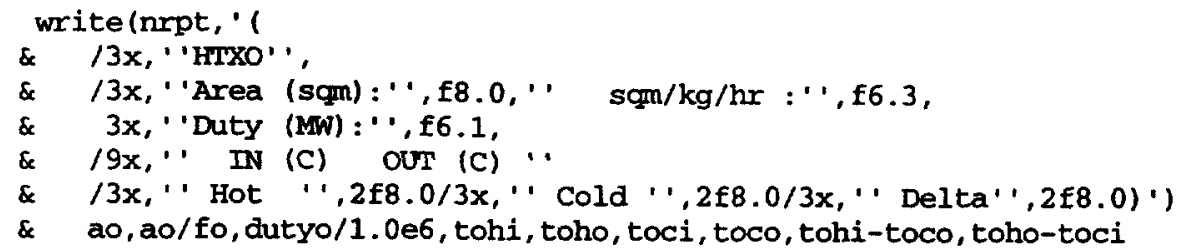




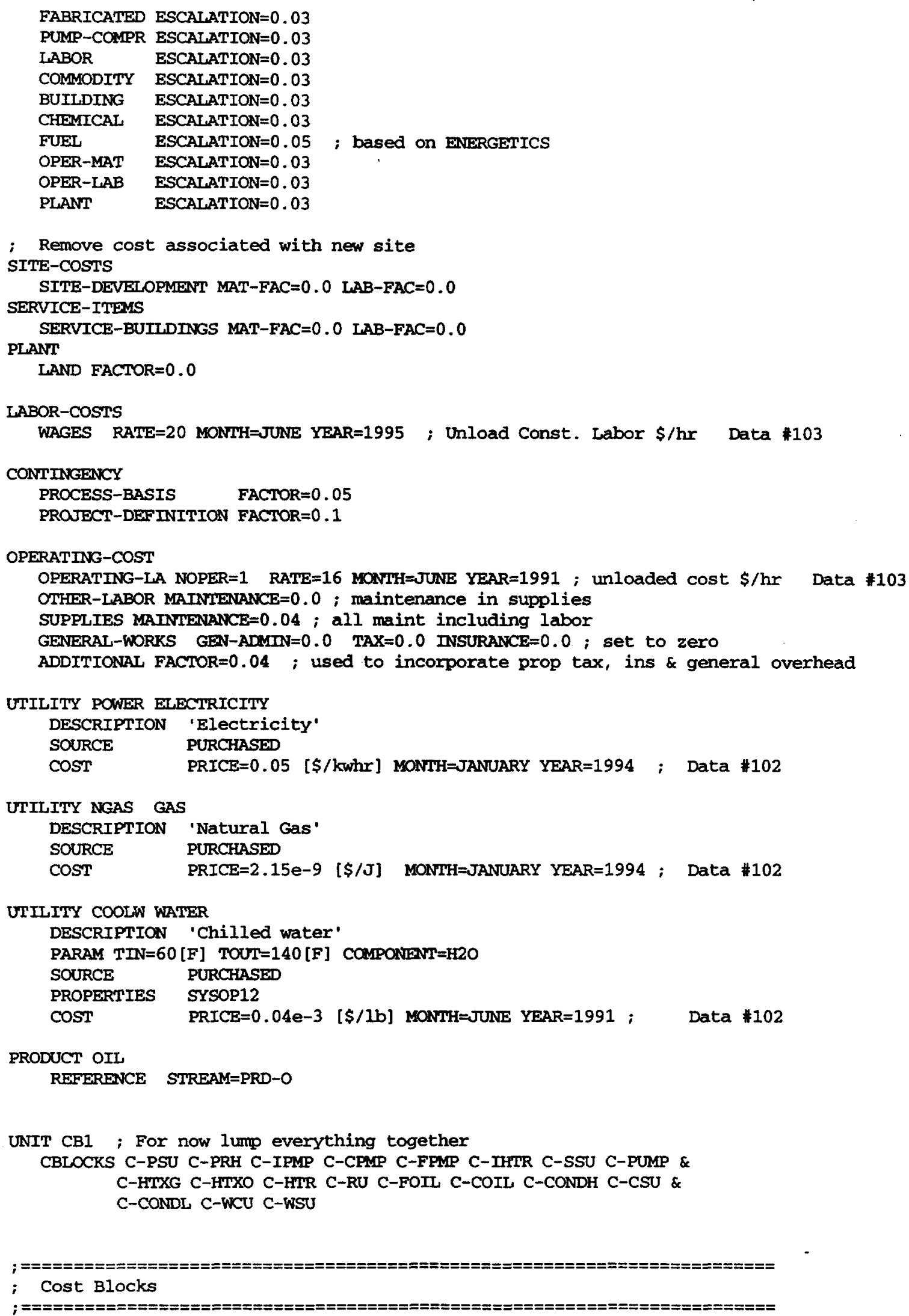


CBLOCK C-PSU TANK

DESCRIPTION 'Initial water separation'

REFERENCE INLET STREAM=FEED

SIZING-DATA RETEN-TTME $=60$ [min] ;

Data \#101

CBLOCK C-PRH V-VESSEL

DESCRIPTION 'Capture reactor vapors'

REFERENCE BLOCK=PRH

SIZING-DATA RETEN-TIME=5 [min] \&; only place holder true retention

CORROSION $=0.125<$ in $>$; set in FCPRH

Data $\# 104$

FORTRAN FCPRH

F common / usr3/ capfac

; Compute size of preheat vessel

DEFINE flowgX STREAM-VAR STREAY=PGSU-G VARIABLE=MASS-FLOW

DEFINE flwlX1 STREAM-PROP STREAM=PRH-E PROPERTY $=02$

DEFINE flWI 2 SIREAM-PROP STREAM=PRH-E PROPERTY $=03$

DEFINE denlX STREAM-PROP STREAM=PRH-E PROPERTY=PRHOL

DEFINE dengX STREAM-PROP STREAM=PRH-E PROPERTY=PRHOV

DEFINE VOIC CBLOCK-VAR CBLOCK=C-PRH SENTENCE=SIZING-DATA \& VARIABLE $=$ VOL

DEFINE diamC CBLOCK-VAR CBLOCK=C-PRH SENTENCE=SIZING-DATA \& VARIABLE $=$ DIAM

DEFINE nequip CBLOCK-VAR CBLOCK=C-PRH SENTENCE=COSTING-DATA \& VARIABLE=NEQUIP

total liquid flow

flowlx=capfac* $(f 1 w 1 \times 1+f l w l \times 2)$

set liquid volume in $\mathrm{ft}^{\star \star 3}$ based on rest minute residence time Data \#101 rest $=5.0$

vliq=rest $* 60.0 *$ flowl $/$ denlx

maximum vessel volume

Data *109

$v \max =16.0$

minimum diameter (m)

Data \#109

dmin $=4.0 * 0.3048$

write (nrpt, ' ('C-PRH' ')')

use vertical only for good contact

call sep (nrpt, 'V' , 'S' , 'Y', 'N' , flowgx, flowlx, vliq, vmax, denlx,

\& dengx, dum, dum, dum, dum, dmin, number, vol, xlen, diam, tdum)

volc=vol

nequip=number

diamc=diam

READ-VARS flowgx denlx dengx

CBLOCK C-IPMP PUMP

DESCRIPTION 'Pump initial emulsion to desired pressure'

REFERENCE BLOCK=IPMP

COSTING-DATA TYPE=SS-ANSI NSTANDBY=0 MATERIAL=SS316 ; Data *110

UTILITY ELEC=POWER

CBLOCK C-CPMP PUMP

DESCRIPTION 'Pump main product stream to desired pressure'

REFERENCE BLOCK $=$ CPMP

COSTING-DATA TYPE=SS-ANSI NSTANDBY=0 MATERIAL=CAST-ST ; Data 1110

UTILITY ELEC $=$ POWER

CBLOCK C-FPMP PUMP

DESCRIPTION 'PUाm condenser oil to desired pressure'

REFERENCE BLOCK=FPMP

COSTING-DATA TYPE=SS-ANSI NSTANDBY=0 MATERIAL=CAST-ST ; Data \#110

UTILITY ELEC=POWER 


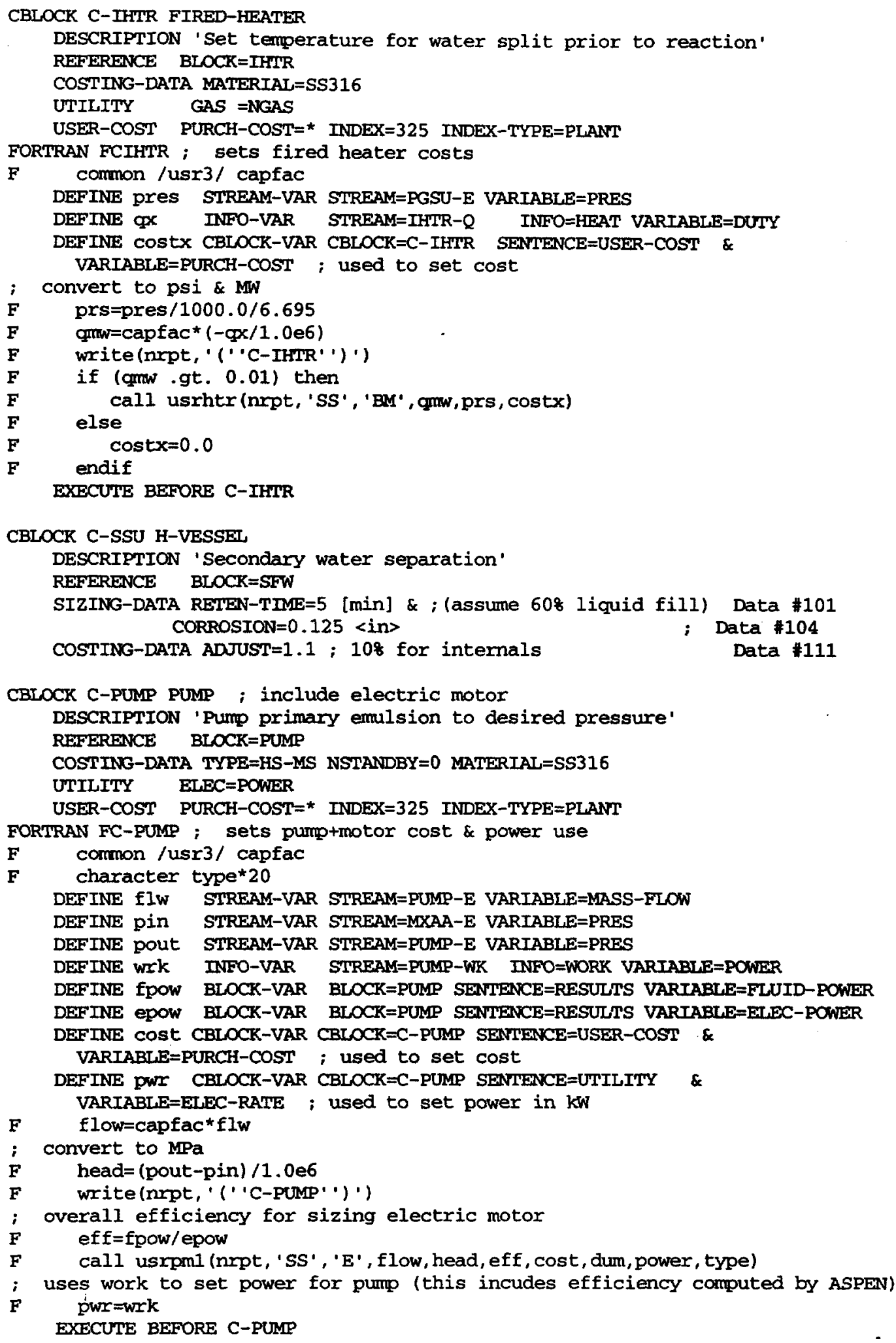




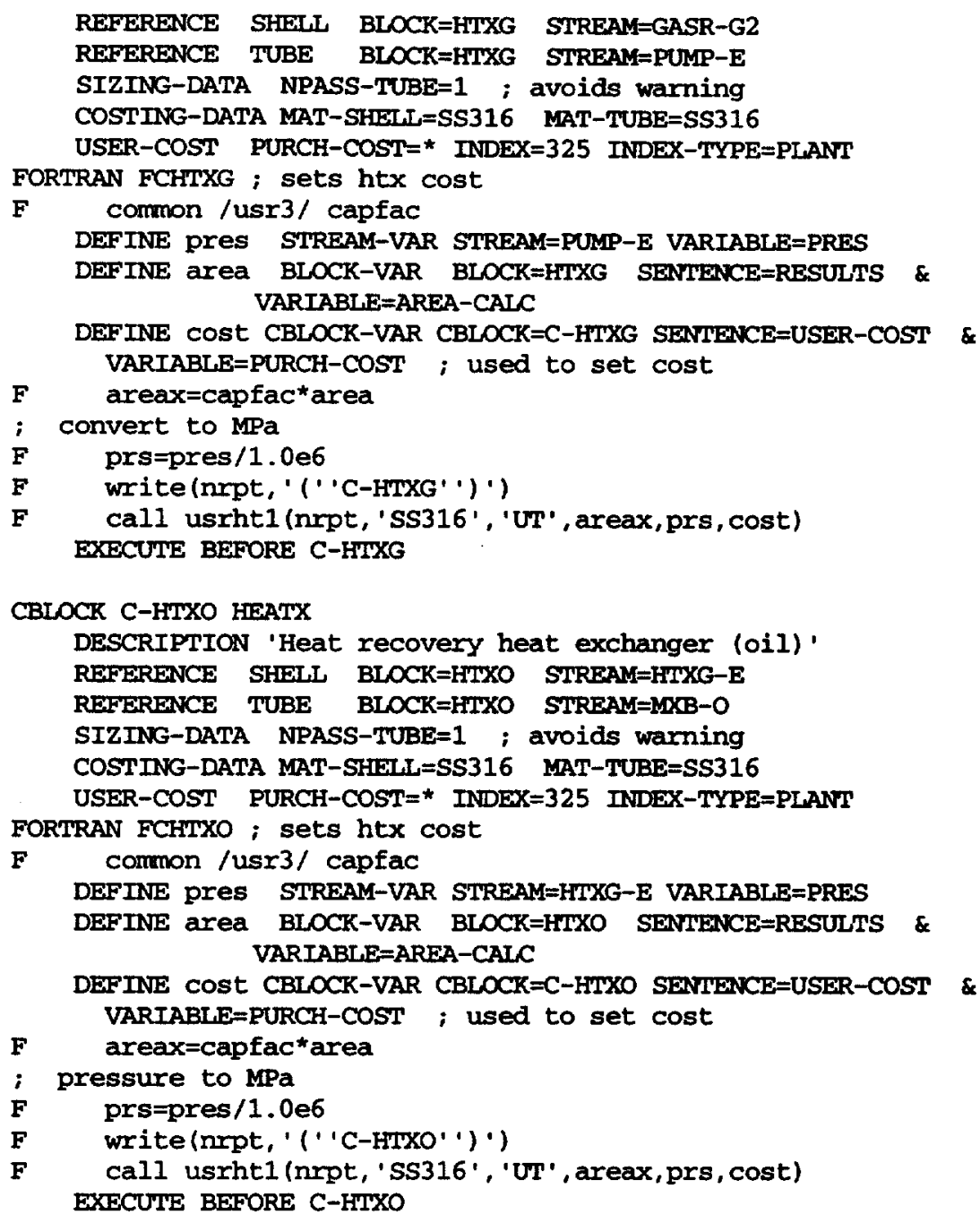

CBLOCK C-HTR FIRED-HEATER

DESCRIPTION 'Trim temperature for reactor/separator'

REFERENCE BLOCK=HTR

COSTING-DATA MATERIAL $=C S$

UTILITY GAS =NGAS

USER-COST PURCH-COST $=$ * INDEX $=325$ INDEX-TYPE=PLANT

FORTRAN FCHTR ; sets fired heater costs

F common /usr3/ capfac

DEFINE pres STREAM-VAR STREAM=PUMP-E VARIABLE=PRES

DEFINE $q$ INFO-VAR STREAM=HTR-Q INFO=HEAT VARIABLE=DUTY

DEFINE cost CBLOCK-VAR CBLOCK=C-HTR SENTENCE=USER-COST \& VARIABLE=PURCH-COST ; used to set cost

convert to psi \& MW

prs $=$ pres $/ 1000.0 / 6.895$

qmw $=\operatorname{capfac}^{\star}(-\mathrm{q} / 1.0 \mathrm{e} 6)$

efficiency

eff $=0.75$

quw $=$ quw $/$ eff

write (nrpt, '("C-HTR' ')')

call usrhtr (nrpt, 'CS', 'BM', omw, prs, cost)

EXECUTE BEFORE C-HTR

CBLOCK C-RU H-VESSEL 
DESCRIPTION 'Reactor and high temperature separation'

SIZING-DATA VOL $=100<b b l\rangle$ DIAM $=5<\mathrm{ft}\rangle$ \&; size, $P$ \& $T$ set in FRU PRES $=2000<\mathrm{psi}>$ TEMYP $=400 \&$ CORROSION $=0.125<$ in>

COSTING-DATA NEQUIP=1; number of vessels set in FRU

CBLOCK C-FOIL H-VESSEL

DESCRIPTION 'Flash to set final water'

REFERENCE LIQUID STREAM=FOIL-O

; require volume set in FCFOIL

SIZING-DATA VOL $=100[\mathrm{bb} 1]$
CORROSION $=0.125<$ in $\rangle$

FORTRAN FCFOIL

F comon / usr3/ capfac

F character 1 tdum

; Compute size of knowkout vessel for FOIL

DEFINE flowgX STREAM-VAR STREAM=FOIL-G VARIABLE=MASS-FLOW

DEFINE flowlx STREAM-VAR STREAM=FOIL-O VARIABLE=MASS-FLOW

DEFINE denlX STREAM-PROP STREAM=FOIL-O PROPERTY=PRHOL;

DEFINE dengX STREAM-PROP STREAM=FOIL-G PROPERTY=PRHOV;

DEFINE volc CBLOCK-VAR CBLOCK=C-FOIL SENITENCE=SIZING-DATA \& VARIABLE=VOL

DEFINE diamC CBLOCK-VAR CBLOCK=C-FOIL SENTENCE=SIZING-DATA\& VARIABLE $=D I A M$

DEFINE nequip CBLOCK-VAR CBLOCK=C-FOIL SENTENCE=COSTING-DATA \& VARIABLE $=$ NEQUIP

F flwg=capfac $\star$ flowgx

F flwl=capfac flowlx

- set liquid volume in $\mathrm{m}^{\star \star 3}$ based on $5 \mathrm{~min}$ residence time

F vliq $=5.0 * 60.0 *$ flwl/denlx

- maximum vessel volume

Data $\# 105$

vmax $=16.0$

minimum $L / D$ ratio

Data \#105

$x l d r=3.0$

minimum diameter (m)

Data $\# 105$ dmin $=2.0 * 0.3048$

minimum void height if horizontal (m)

Data \#105 hmin $=1.0 * 0.3048$ write (nrpt, '( 'C-FOIL' ')')

call sep (nrpt, ' ' , 'S' , 'Y', 'N' , flwg, flwl, vliq, vmax, denlx,

\& dengx, dum, dum, xlar, hmin, dmin, number, vol, xlen, diam, taum)

volc $=$ vol

nequip=number

diamc $=$ diam

READ-VARS flowlx denlx dengx

WRITE-VARS volc diame nequip

CBLOCK C-COIL AIRCOOL

DESCRIPTION 'Cool final oil product'

REFERENCE BLOCK=COIL

SIZING-DATA $U=50<B T U / H R-S Q F T-R>$; Bare surface (surfaces are finned)

; Based on oil/air system

COSTING-DATA CLASS=ORGANIC \& ; ORGANIC doen't seem to matter MATERIAL $=C S$

CBLOCK C-CONDH HEATX

DESCRIPTION 'Gas condenser - high pressure'

; Note sizing data is overridden by user cost, only dumies

REFERENCE SHELL BLOCK $=$ CONDH

REFERENCE TUBE UTILITY $=$ COOLW

SIZING-DATA NPASS-TUBE $=1 \quad U=150<B T U / H R-S Q F T-R>$

COSTING-DATA MAT-SHELL $=C S \quad$ MAT-TUBE $=S S 316$ 
USER-COST PURCH-COST= * INDEX $=325$ INDEX-TYPE=PLANT

FORTRAN FCCONDH ; sets htx cost

F common /usr3/ capfac

DEFINE t1 STREAM-VAR STREAM=HTXG-G VARIABLE=TEMP

DEFINE $t 2$ STREAM-VAR STREAM $=$ CONDH $-O$ VARIABLE=TEMP

DEFINE pres STREAM-VAR STREAM=CONDH-O VARIABLE=PRES

DEFINE qCOOI INFO-VAR STREAM=CONDH-Q INFO=HEAT VARIABLE=DUTY

DEFINE COST CBLOCK-VAR CBLOCK=C-CONDH SENTENCE=USER-COST \&

VARIABLE=PURCH-COST; used to set cost

ucool, based on computed film coefs liq/liq (w/sqm-C) ucool $=150 * 5.674$

cool side set by assumed cooling water temps (C) Data \#107 dta $=t 1-60$

$d t b=t 2-15.6$

$d t \ln =(d t a-d t b) / \log (d t a / d t b)$

area $=$ capfac ${ }^{*}$ qcool $/$ ucool/dtlm

write (nrpt, ' (" 'C-CONDH' ')')

write (nrpt, ' (' 'dta,dtb, H-dtlm, qcool, area=' ' , 2f6.0,3 (1pe12.3)) ')

\&e $d t a, d t b, d t 1 m, q c o o l$, area

convert pres to MPa

prs $=$ pres $/ 1.0$ e6

call usrht1 (nrpt, 'SS316' , 'UT' , area, prs , cost)

EXECUTE BEFORE C-CONDH

CBLOCK C-CSU H-VESSEL

DESCRIPTION 'Liquid knock out for high pressure condenser'

REFERENCE LIQUID STREAM=CSU-O

SIZING-DATA VOL $=100<\mathrm{bbl}>\mathrm{DIAM}=5<\mathrm{ft}>$; size set in FCSU CORROSION $=0.125<$ in>

DATA $* 104$

FORTRAN FCSU

F comon /usr3/ capfac

F character*1 tdum

- Compute size of knowkout vessel for CSU

DEFINE flowgX STREAM-VAR STREAM=CSU-G VARIABLE=MASS-FLOW

DEFINE flwlX1 STREAM-VAR STREAM=CSU-O VARIABLE=MASS-FLOW

DEFINE $f 1 w 1 \times 2$ STREAM-VAR STREAM=CSU-FW VARIABLE=MASS-FLOW

DEFINE denlX STREAM-PROP STREAM=CSU-O PROPERTY=PRHOL;

DEFINE dengX STREAM-PROP STREAM=CSU-G PROPERTY=PRHOV;

DEFINE VOlC CBLOCK-VAR CBLOCK=C-CSU SENTENCE=SIZING-DATA \& VARIABLE $=$ VOL

DEFINE diamC CBLOCK-VAR CBLOCK=C-CSU SENTENCE=SIZING-DATA \& VARIABLE $=$ DIAM

DEF TNE nequip CBLOCK-VAR CBLOCK $=C$-CSU SENTENCE=COSTING-DATA \& VARIABLE $=$ NEQUIP

set liquid volume in $f t^{\star \star 3}$ based on $5 \mathrm{~min}$ residence time

$f l w l=\operatorname{capfac}^{\star}(\mathrm{f} l \mathrm{w} l \times 1+f l w l \times 2)$

flwg=capfac* $f$ lowgx

vliq $=5.0 * 60.0 *$ Elwl $/$ den $l x$

maximum vessel volume

Data 106

vmax $=16.0$

minimum $L / D$ ratio

Data $\# 106$

$x l d r=3.0$

minimum diameter $(\mathrm{m})$

Data $\# 106$

dmin $=2.0 * 0.3048$

minimum void height if horizontal (m) Data \#106

hmin $=1.0 * 0.3048$

write (nrpt, ' ( 'C-CsU' ')')

call sep (nrpt, ' ' ' 'S', 'Y', 'N' , flwg, flwl, vliq, vmax, denlx, dengx,

\& dum, dum, xldr, hmin, dmin, number, vol, xlen, diam, tdum)

volc=vol

nequip=number 


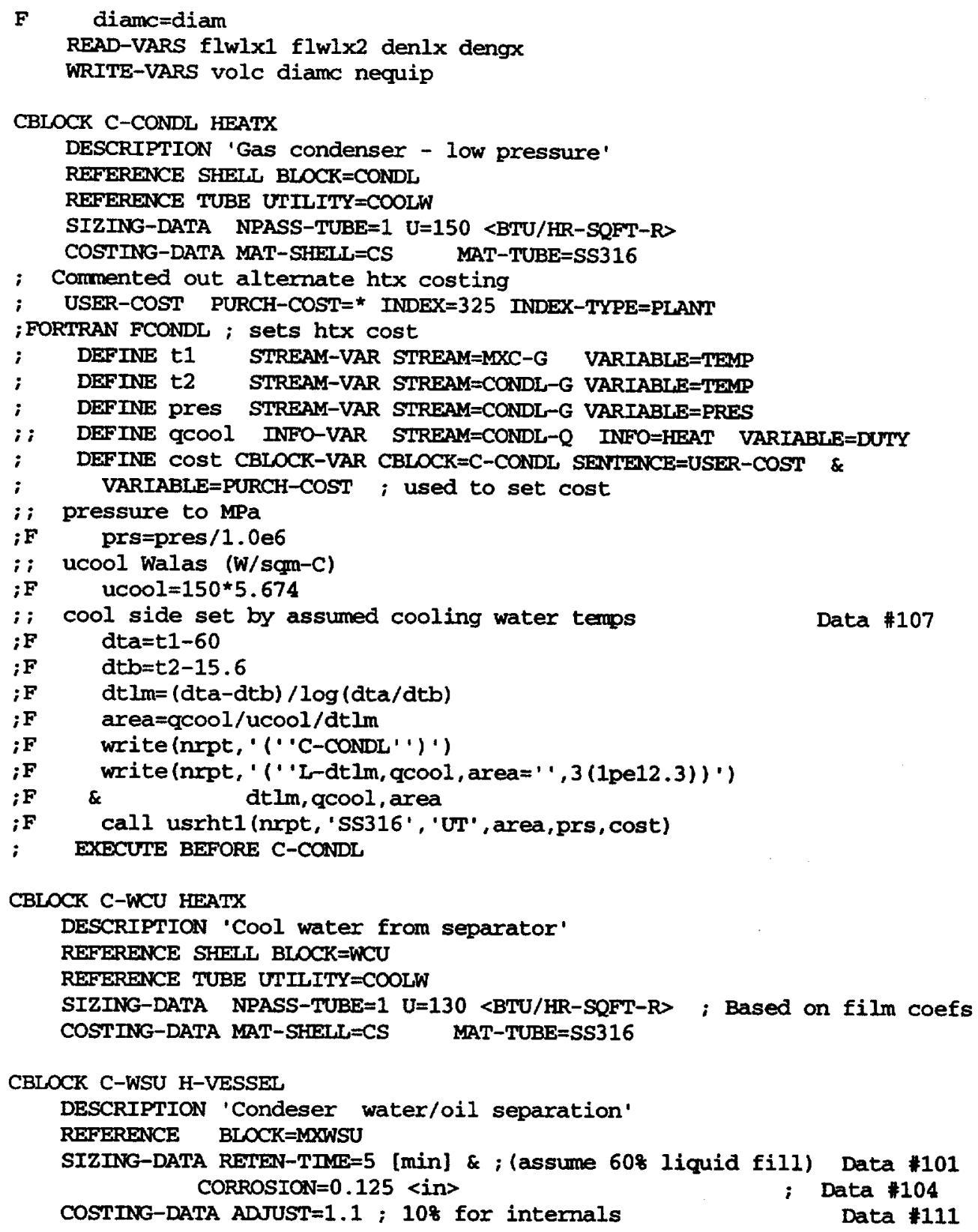




\section{APPENDIX II}

\section{WALAS BASED COST ROUTINES}

Below is a listing of the FORTRAN subroutines which are used to obtain cost information for certain process units. These cost estimates are based on information in Walas' book, Chemical Process Equipment - Selection and Design (reference 6 in main body). In each case, the output costs are in 1985 dollars. In the "usrht1" routine for costing heat exchangers, the cost correlations have been extended beyond those available in Walas. This extension was done by using selected information from Purohit ${ }^{\mathrm{n}-1}$.

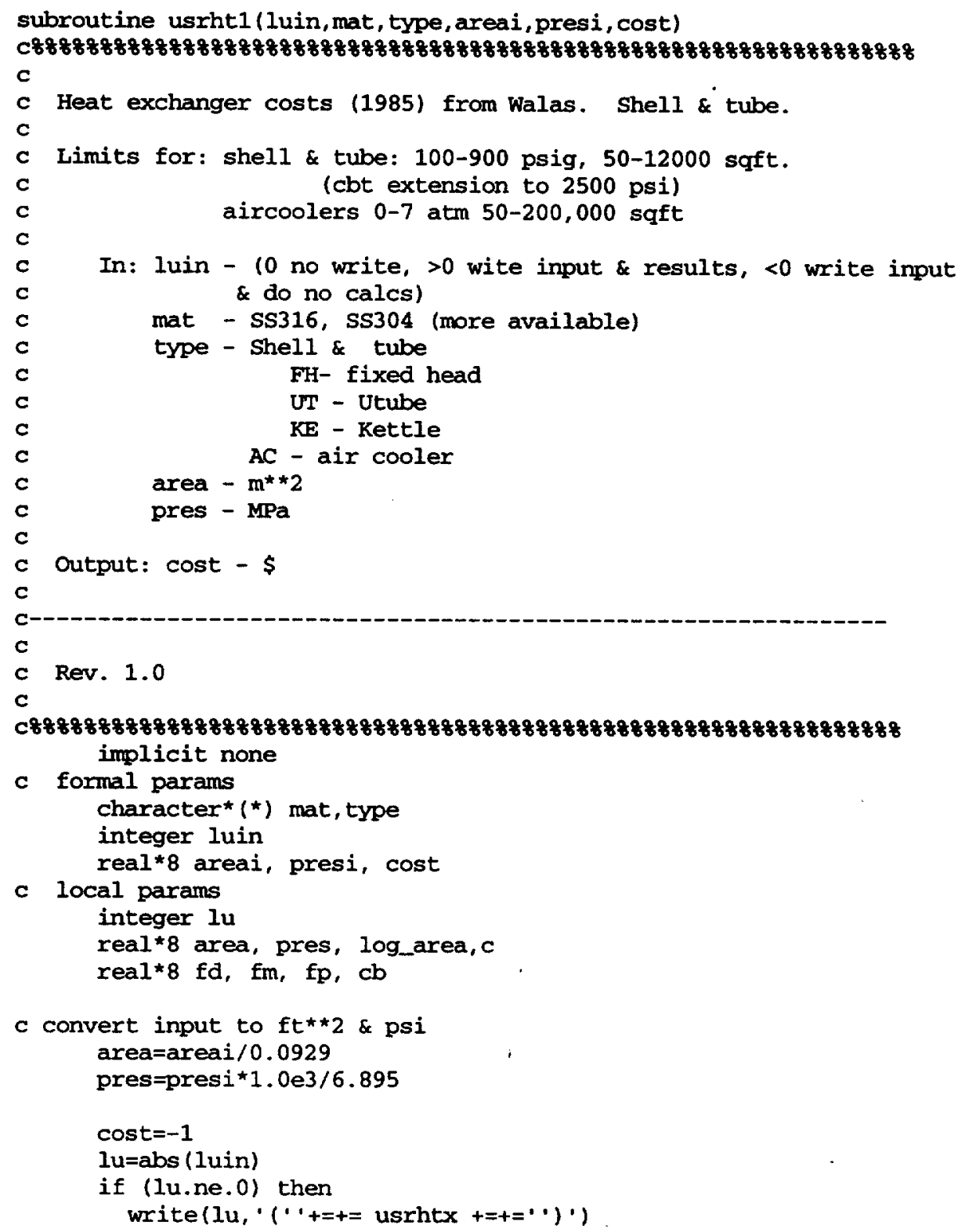




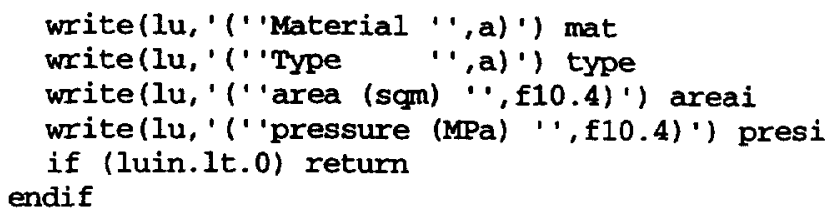

Shell \& tupe section

if (area .le. 0.0 ) return

$\log \_a r e a=\log$ (area)

$c$

$\mathrm{cb}=\exp (8.821-0.30863 * \log$ area $+0.0681 *(\log$ area $) * 2)$

c

c

if (type (1:2) .eq. 'FH' .or. type (1:2) eq. 'fh') then

fixed head

$f d=\exp \left(-1.1156+0.0906 * \log \_a r e a\right)$

elseif (type (1:2).eq. 'UT' .or. type (1:2).eq.'ut') then

c U-tube

$f d=\exp \left(-0.9816+0.083 * \log \_a r e a\right)$ else

c U-tube

$f d=\exp \left(-0.9816+0.0830 * \log \_\right.$area $)$

endif

C fp

c Pressure 100-300 psig

if (pres .1e.300) then $\mathrm{fp}=0.7771+0.04981 * \log _{\text {area }}$

c Pressure 300-600 psig elseif (pres .le. 600) then $\mathrm{fp}=1.0305+0.07140 * \log$ _area

C Pressure 600-900 psig elseif (pres .le. 900) then $\mathrm{fp}=1.1400+0.12088 * \log _{\text {area }}$

c Extension by cbt using rough data from Che Eng ' 83

c Pressure 900-1500 psig elseif (pres .le.1500) then $\mathrm{fp}=1.2+0.120^{*} \log$ _area

c Pressure 1500-2000 psig elseif (pres .le.2000) then $\mathrm{fp}=1.2+0.19 * \log$ _area

C Pressure 2000-2500 psig elseif (pres .1e.2500) then $\mathrm{fp}=1.2+0.47 \star \log$ _area else $f p=1.2+0.47 * \log _{\text {_area }}$ endif

c

if (mat $(1: 5)$.eq.'ss316' .or. type $(1: 2)$.eq. 'ss316') then

C Stainless 316 $\mathrm{fm}=0.8603+.23296 * \log _{\text {area }}$ elseif (mat (1:5).eq.'SS304' .or. type (1:2) .eq.'ss304') then. 
Stainless 304

$\mathrm{fm}=0.8193+.15984 * \log _{\text {_area }}$

else

C Stainless 304

$\mathrm{fm}=0.8193+.15984 * \log$ _area

endif

$\cos t=f d^{\star} f m^{\star} f p^{\star} c b$

if (lu.ne.0) then

write(lu, '('Cost (1985 \$) ' ',f10.0)') cost

if (area.gt.0.0)

\& write $(1 \mathrm{u},($ 'Cost $(\$ / f t)$ ' ',f10.4)') cost/area

endif

return

end

subroutine usrmtr (luin, type, power, cost)

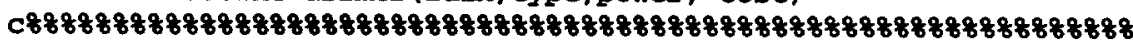

c

Cost (1985) of electric motors from Walas.

In:

luin - 10 no write, $>0$ wite input \& results, $<0$ write input \& do no calcs)

type - type EN3600 enclosed 3600 rpm

power - MN

out:

cost - capital cost \$

c

Rev. 1.0

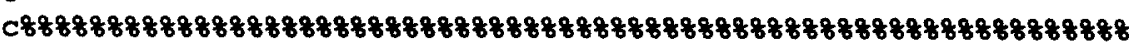

implicit none

c formal params

character type* $(*)$

integer luin

real ${ }^{*}$ power, cost

c local params

integer $\mathrm{n}, \mathrm{lu}$

real*8 hp, a1,a2,a3 ,c, fac

real*8 hpmax, hp_unit

$\cos t=-1$

hp=power*1.0e6/746 ! horsepower

lu=abs (luin)

if (lu.ne.0) then

write $\left(1 u_{,} \cdot(\cdot+=+=\right.$ usrmtr $+=+=+\cdot)$ ')

write(lu, ("'Type $\cdots, a) ')$ type

write (lu, ("'Power (MW) ' 'f10.4)') power

write $(1 \mathrm{u}$, ' (" 'Power (hp) ' ',f10.4)') hp

if (luin.1t.0) return

endif

if (type (1:6) eq. 'EN3600') then

hpmax $=400.0$

$\mathrm{n}=\mathrm{hp} / \mathrm{hpmax}$ 


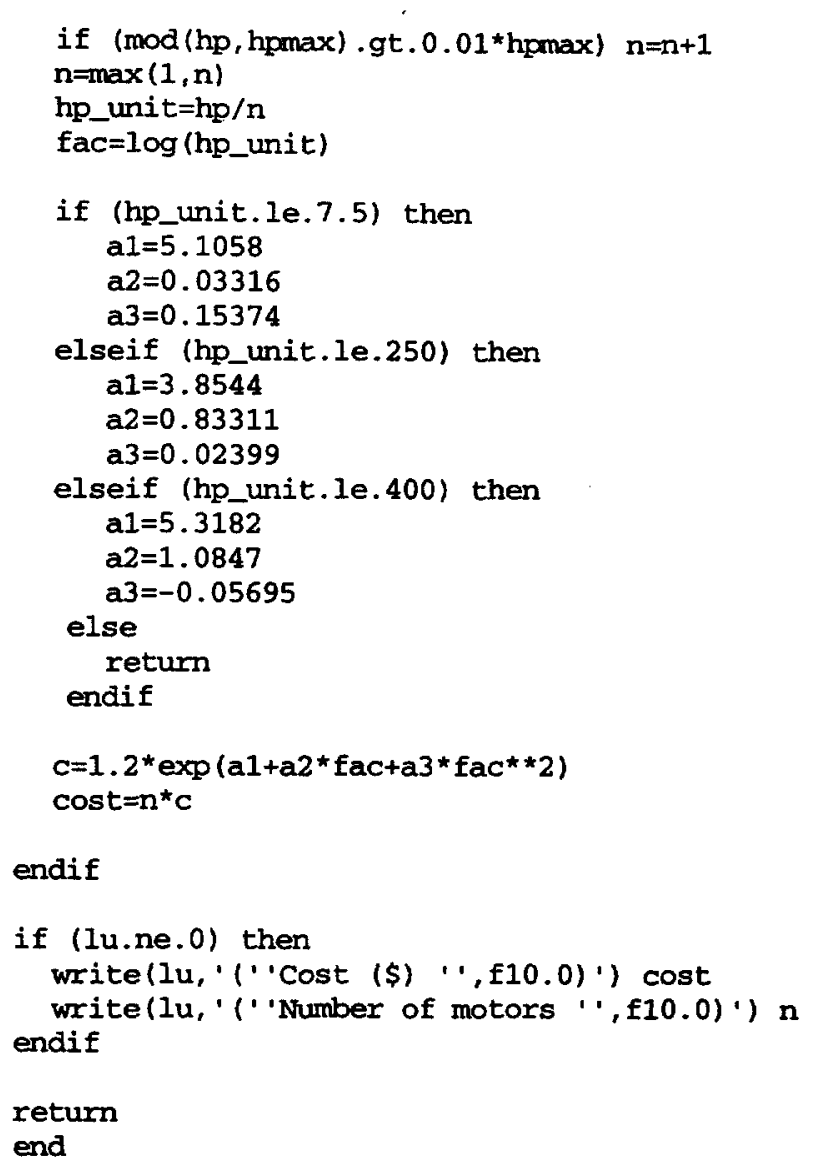




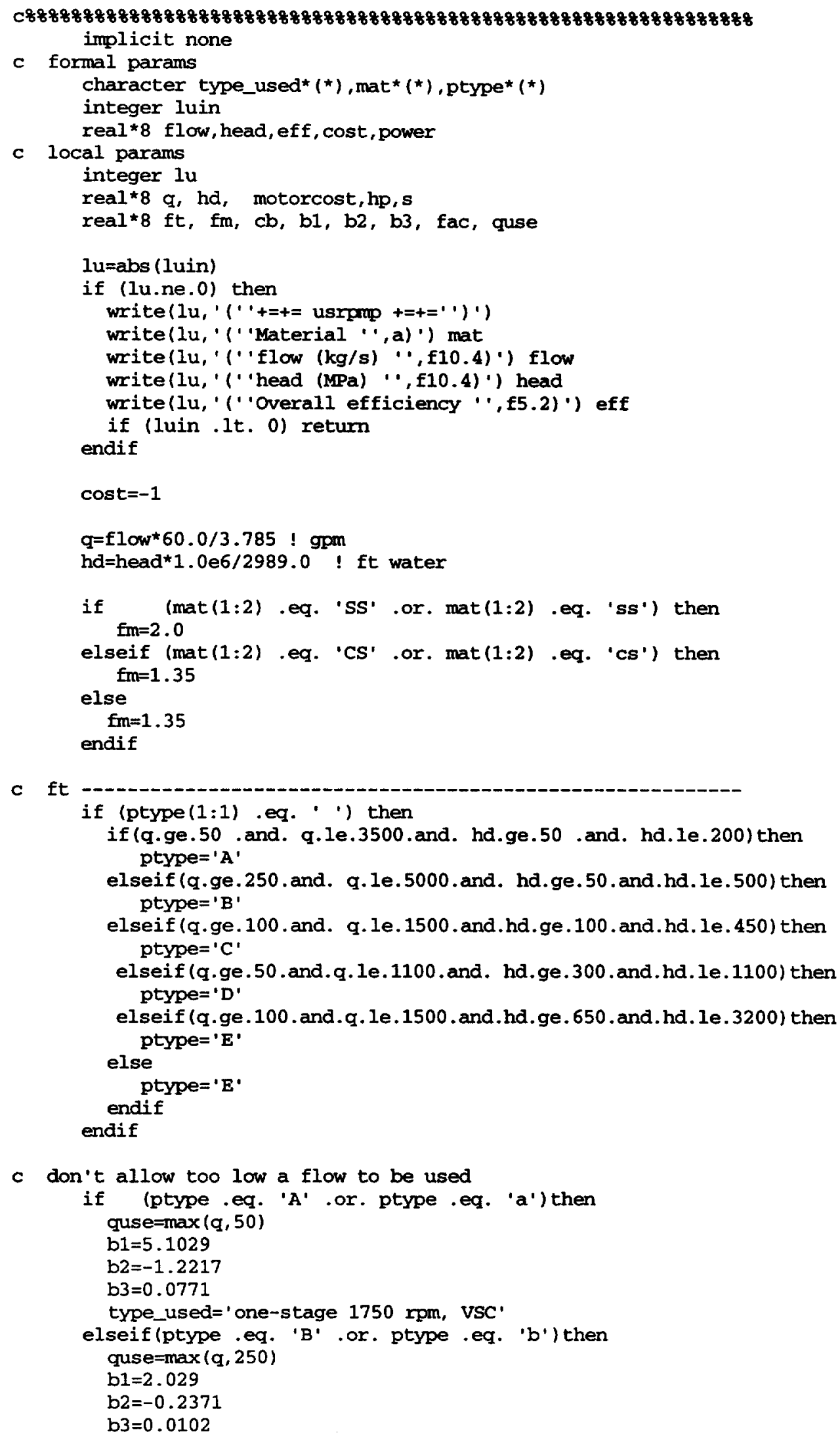


type_used=' one-stage $1750 \mathrm{rpm}$, HSC'

elseif (ptype .eq. ' $C$ ' .or. ptype .eq. ' $d$ ') then

quse $=\max (q, 100)$

$\mathrm{b} 1=0.0632$

$\mathrm{b} 2=0.2744$

b3 $=-0.0253$

type_used=' one-stage $3500 \mathrm{rpm}, \mathrm{HSC}$ '

elseif (ptype .eq. ' $D$ ' .or. ptype .eq. 'd') then quse $=\max (q, 50)$

$\mathrm{b} 1=13.7321$

$\mathrm{b} 2=-2.8304$

$\mathrm{b} 3=0.1542$

type_used=' two-stage $3500 \mathrm{rpm}$, HSC'

else ! Itype $=$ ' $\mathrm{E}$ '

quse $=\max (q, 100)$

b1 $=9.8849$

$\mathrm{b} 2=-1.6164$

b3 $=0.0834$

type_used='multi-stage $3500 \mathrm{rpm}, \mathrm{HSC}$

endif

fac $=\log \left(\right.$ quse ${ }^{\star}$ squt $($ hd $\left.)\right)$

$\mathrm{cb}=1.55^{\star} \exp \left(8.833-0.6019 * \mathrm{fac}+0.0519 * \mathrm{fac}^{* \star} \mathrm{2}\right)$

$f t=\exp (b 1+b 2 * f a c+b 3 * f a c * * 2)$

$\operatorname{cost}=f m^{\star} f t^{\star} \mathrm{cb}$

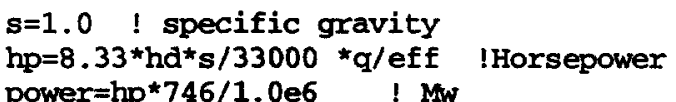

call usrmtr (luin, 'EN3600', power, motorcost)

if (1u.ne.0) then

write(lu, ("Type $"$ 'a)') type_used

write (lu, '("Pump cost (\$) "',f10.4)') cost

write $(1 \mathrm{u}$, ' ('Motor cost (\$) ', f10.4)') motorcost

write (lu, '('Power (hp) '',f10.4)') hp

write $(l u, \cdot($ 'Power (Mw) '',f10.4)') power

endif

$\cos t=\cos t+$ motorcost

return

end

subroutine usrhtr (luin, mat, type, q, pres, cost)

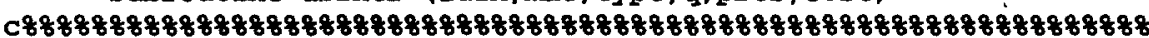

Fired heater costs (1985) from Walas.

Limits Box 20-200 Mbtu/hr (million Btu/hr), 0-3000 psi

Cylinder 2-30 MBtu/hr $0-1500$

In: luin - 10 no write, $>0$ wite input \& results, $<0$ write input \& do no calcs)

In: mat- CS-acrbon steel, SS-stianless

type- BL - Box low termp $(<300 \mathrm{C})$,

BM - Box med termo (300-500C)

BH - Box high temp (>500C)

Note: temps are approx. 


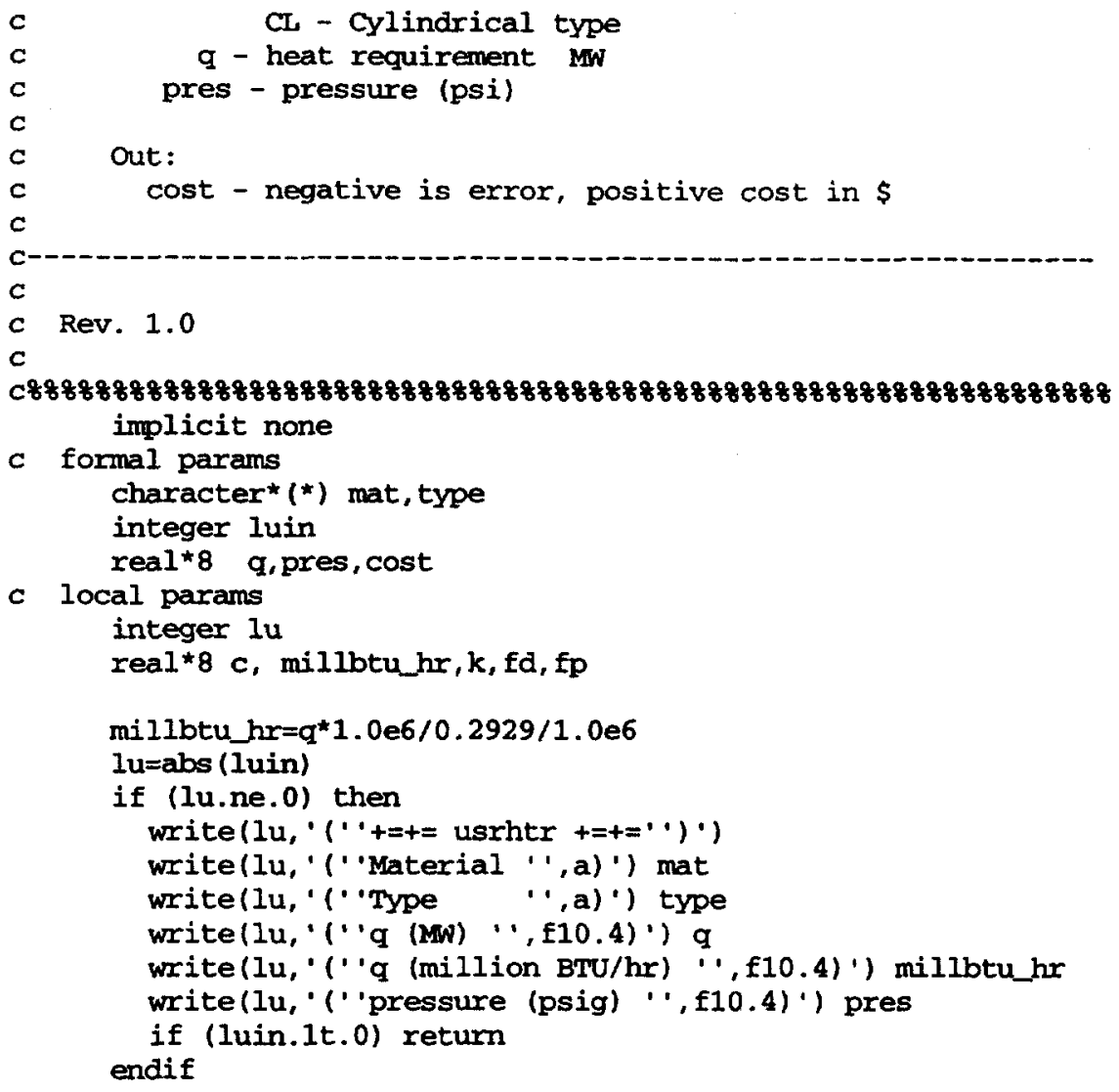

c Air cooler section

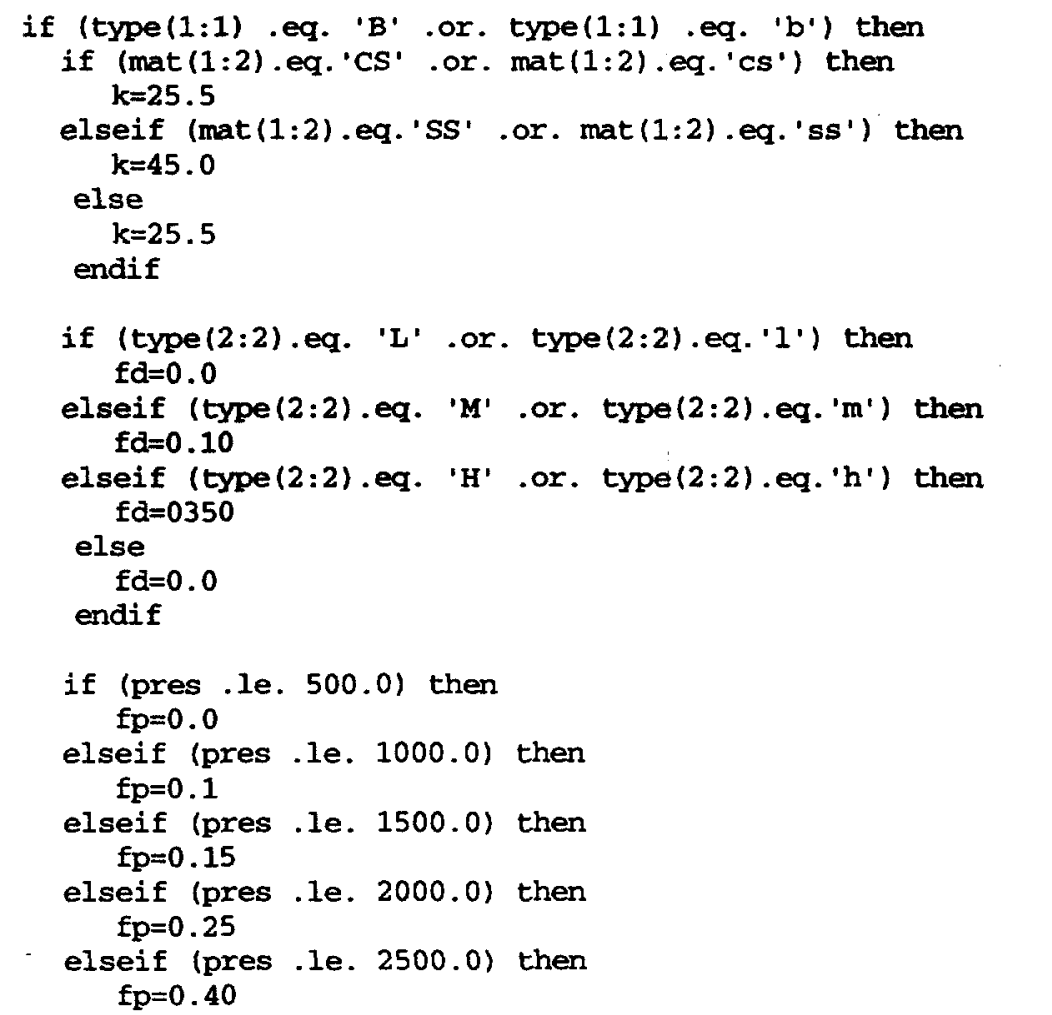




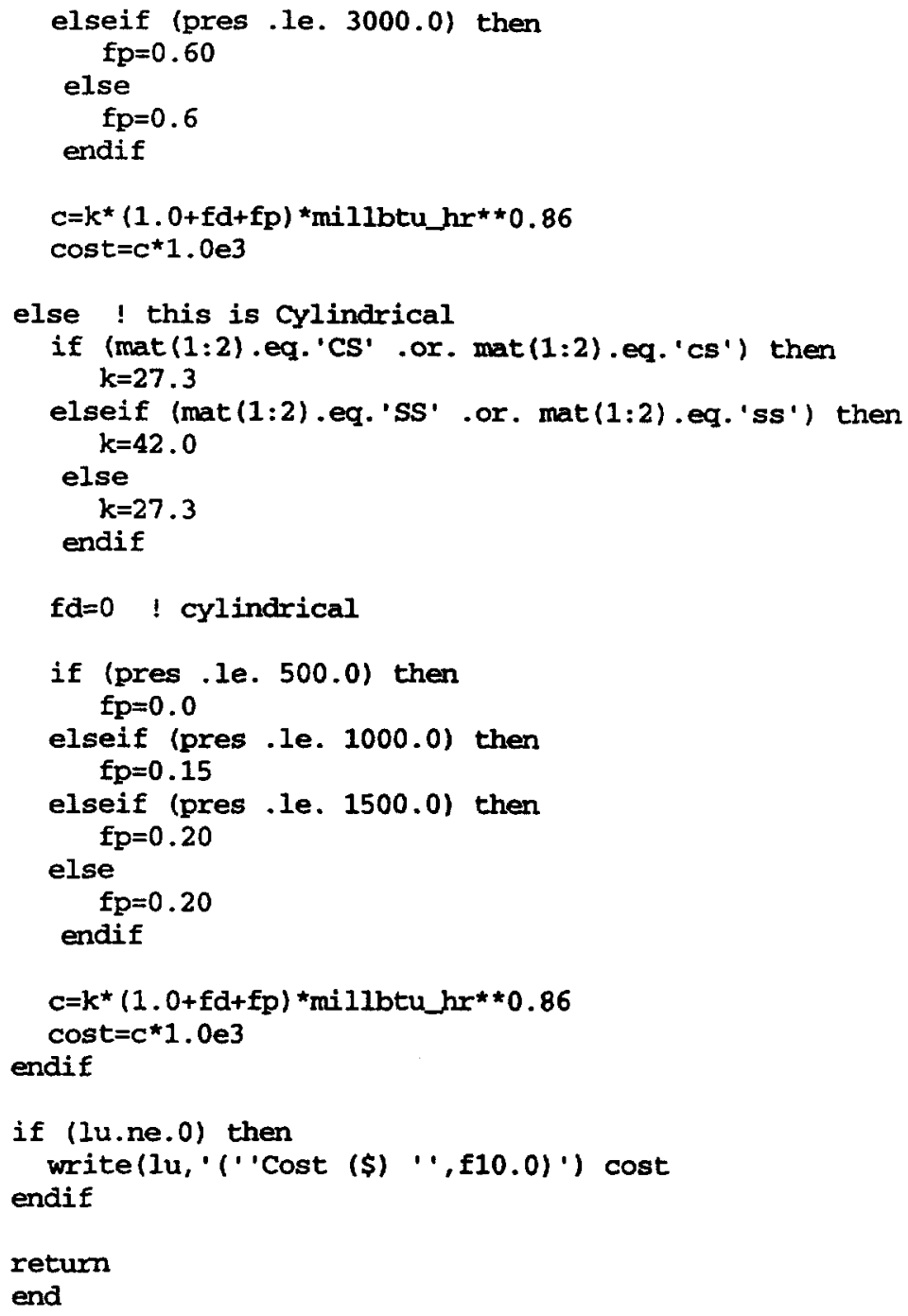

\section{REFERENCES}

II-1. G. P. Purohit, "Estimating costs of shell-and-tube heat exchangers," Chemical Engineering, Vol. 90, No. 17, pp, 54-67 (August 1983). 


\section{APPENDIX III \\ VESSEL SIZING ROUTINES, THE WATKINS' ROUTINES}

Below is a listing of the FORTRAN subroutines which are used to obtain sizes for flash vessels. The routines are based on information from Watkins, reference 7. Calls to this set of routines are intended to be made through the "sep" routine, although direct calls to other subroutines can be made if needed.

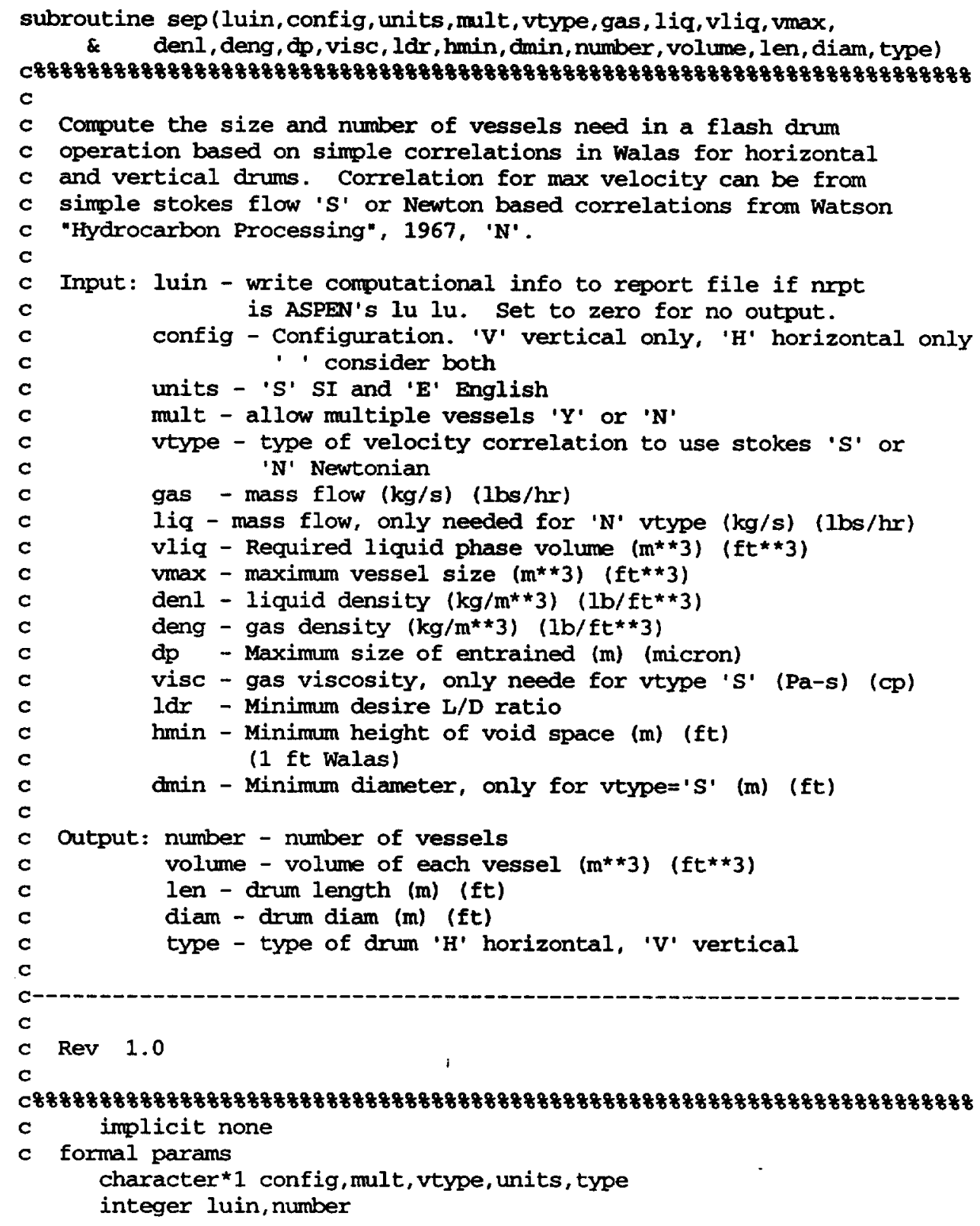


real*8 gas, liq, vliq, vmax, denl, deng, dp, visc, volume, $1 d r$, hmin real*8 len, diam, dmin

c local params

real $\star 8$ xgas, xliq, xvliq, xvmax, xdenl, xdeng, xdp, xvisc , xhmin

real *8 xvolume, xlen, xdiam, xdmin

if (units.eq. ' $E$ ') then

c

convert to SI units

$x$ gas $=$ gas $* 0.454 / 3600$

$x l i q=1 i q * 0.454 / 3600$

xvliq $=v l i q * 0.02832$

$x v \max =v_{\max }{ }^{\star} 0.02832$

$x d e n 1=$ den $1 * 16.02$

$x$ deng $=$ deng $* 16.02$

$x d p=d p * 1.0 d-6$

xvisc $=v i s c \star 1.0 e-3$

xhmin=hmin $* 0.3048$

xdmin=drain*0.3048

else

xgas=gas

xliq=lig

xvliq=vliq

xumax =umax

xdenl=den 1

xdeng=deng

$x d p=d p$

xvisc $=$ visc

xhmin=hmin

xdmin=dmin

endif

c

call SI routine

call sep1 (1uin, config, mult, vtype, xgas, xliq, xvliq, xvmax, xdenl,

\& xdeng, xdp, xvisc, $1 d r, x h m i n, x$ omin, number, xvolume, xlen, xdiam,

$\& \quad$ type)

if (units.eq. 'E') then

c convert results to English units

volume $=x v o l u m e / 0.02832$

len $=x l e n / 0.3048$

diam $=x d i a m / 0.3048$

else

volume=xvolume

len $=x l e n$

diam=xdiam

endif

return

end

subroutine sepl (luin, config, mult, vtype, gas, liq, vliq, vmax, denl,

\& deng, dp, visc, ldr, hmin, dmin, number, volume, len, diam, type)

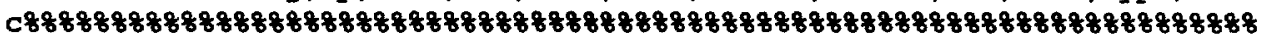

c

c Computation control routine. See sep for description of computations

c and input/output.

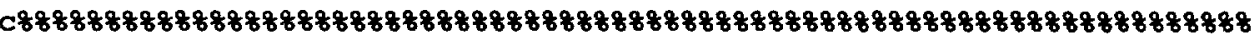

irmplicit none

c formal params

character 1 config, mult, vtype, type

integer luin, number

real*8 gas, vliq, vmax, denl, deng, dp, visc, volume, ldr, hmin, len, diam 


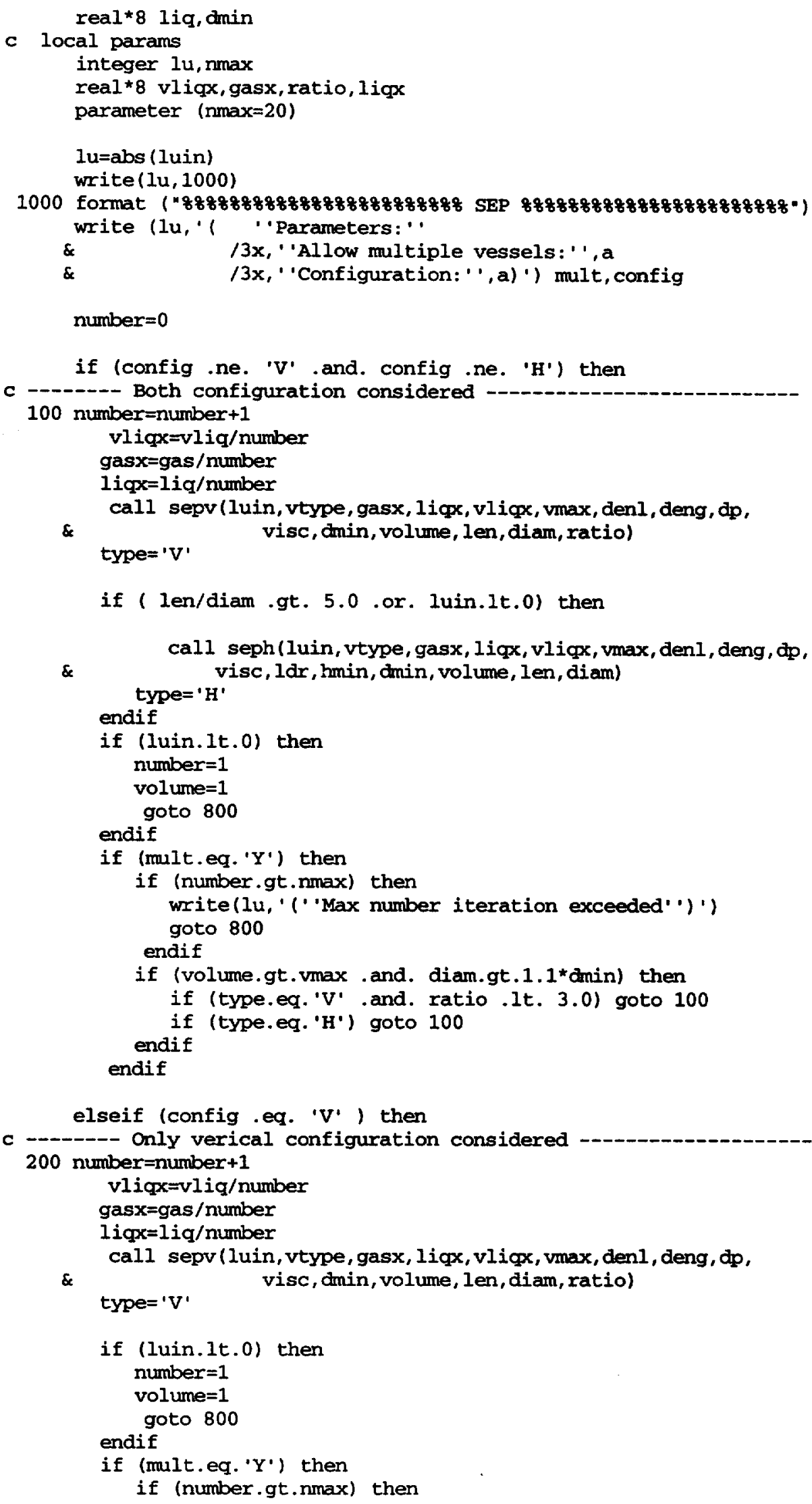




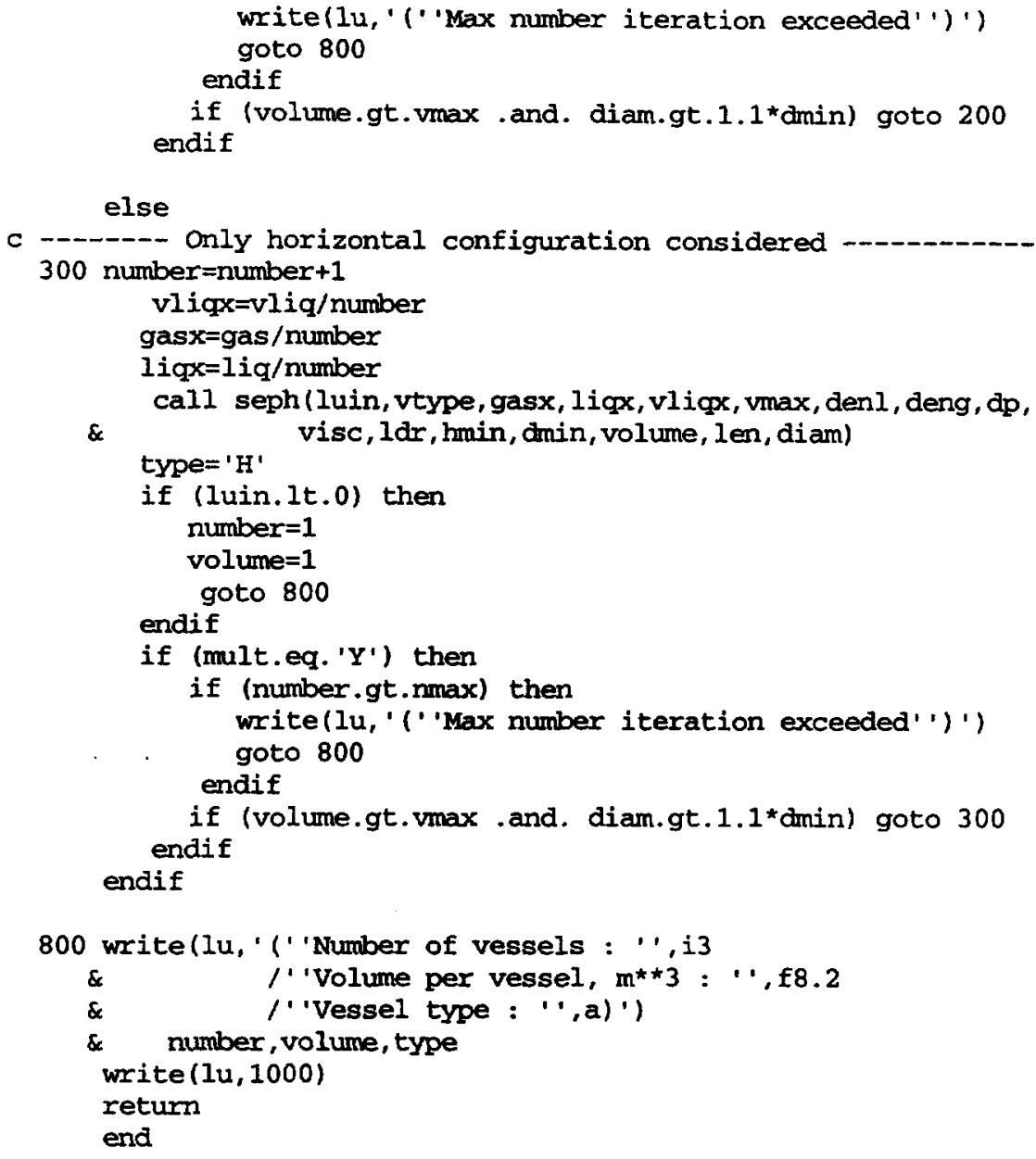




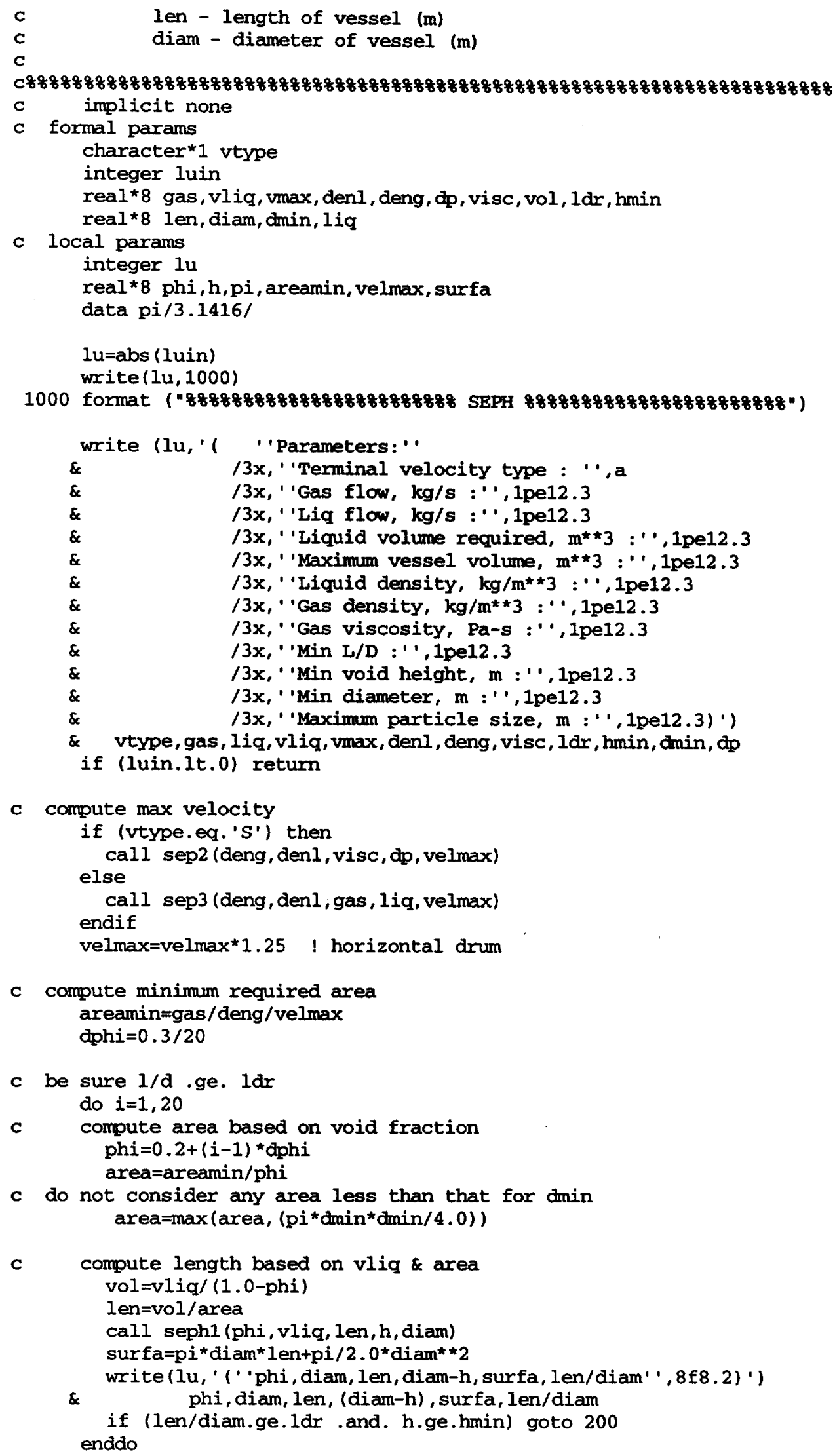


c need longer drum to meet ldr minimum, compute len len=diam*ldr

200

vol=len ${ }^{*}{ }^{\star}{ }^{\star d i a m}{ }^{\star} \star 2 / 4.0$

write llu, ' ('Computed results '",

\& $\quad / 3 x$, 'velmax :"',1pe13.3

\& /3x,''phi :', 1pe13.3

\& $\quad / 3 x$, ' 'vol :' ', Ipe13.3

\& $\quad / 3 x, '$ 'len : ' 1pe13.3

\& $\quad / 3 x$, ' 'diam : ' ', 1pe13.3

$\& \quad / 3 x, \cdots$ len/diam: ' 1 1pe13.3

$\& \quad / 3 x, \cdots h \quad: \cdots, 1$ pe13.3

\& 1 )

velmax, phi, vol, len, diam, len/diam, h

write $(1 u, 1000)$

return

end

subroutine sephl (phi, vol, len, h, diam)

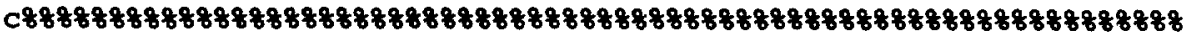

C

C Given a liquid volume, fraction area fill nd drum length compute

c liquid fill height, $h$, and drum diameter, diam.

c

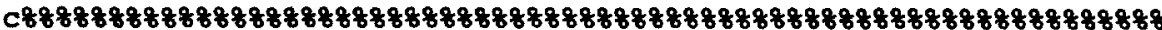

c implicit none

c formal params

real*8 phi, vol, len, $h$, diam

c local params

real* 8 y ! distance from top to interface / radius

real*8 dy,r,phix,pi

data pi/3.1416/

diam=sqrt $\left(4.0^{*}\right.$ vol $/(1.0-$ phi $) /\left(1 e^{*}\right.$ pi $\left.)\right)$

$r=\operatorname{diam} / 2.0$

$d y=0.01$

do $i=1,100$

$y=i \star d y$

phix $=(1 / p i) *\left(\operatorname{acos}(1-y)-(1-y)^{*} \operatorname{sqrt}\left(2.0^{\star} y-y^{*} * 2\right)\right)$

cccc write $(6, \cdot(\cdot y$, phi $\cdots, 2 f 10.3) \cdot y$, phix

if (phix.ge.phi) then

$h=(2-y) * x$

return

endif

endao

$h=-99$

return

end

subroutine sep2 (deng, denl, visc, dp, vel)

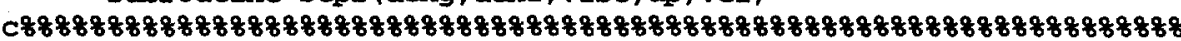

$c$

c Stokes law. Given density differences, paritcle diameter and

c fluid viscosity compute minimum velocity to, entrain particle.

Assumes laminar, but used in estimates after Walas pg 614.

Input: deng - gas density $\left(\mathrm{kg} / \mathrm{m}^{\star \star 3}\right)$

den1 - liquid density $\left(\mathrm{kg} / \mathrm{m}^{\star \star} 3\right)$

visc - gas viscosity ( $\mathrm{Pa}-\mathrm{s})$ 


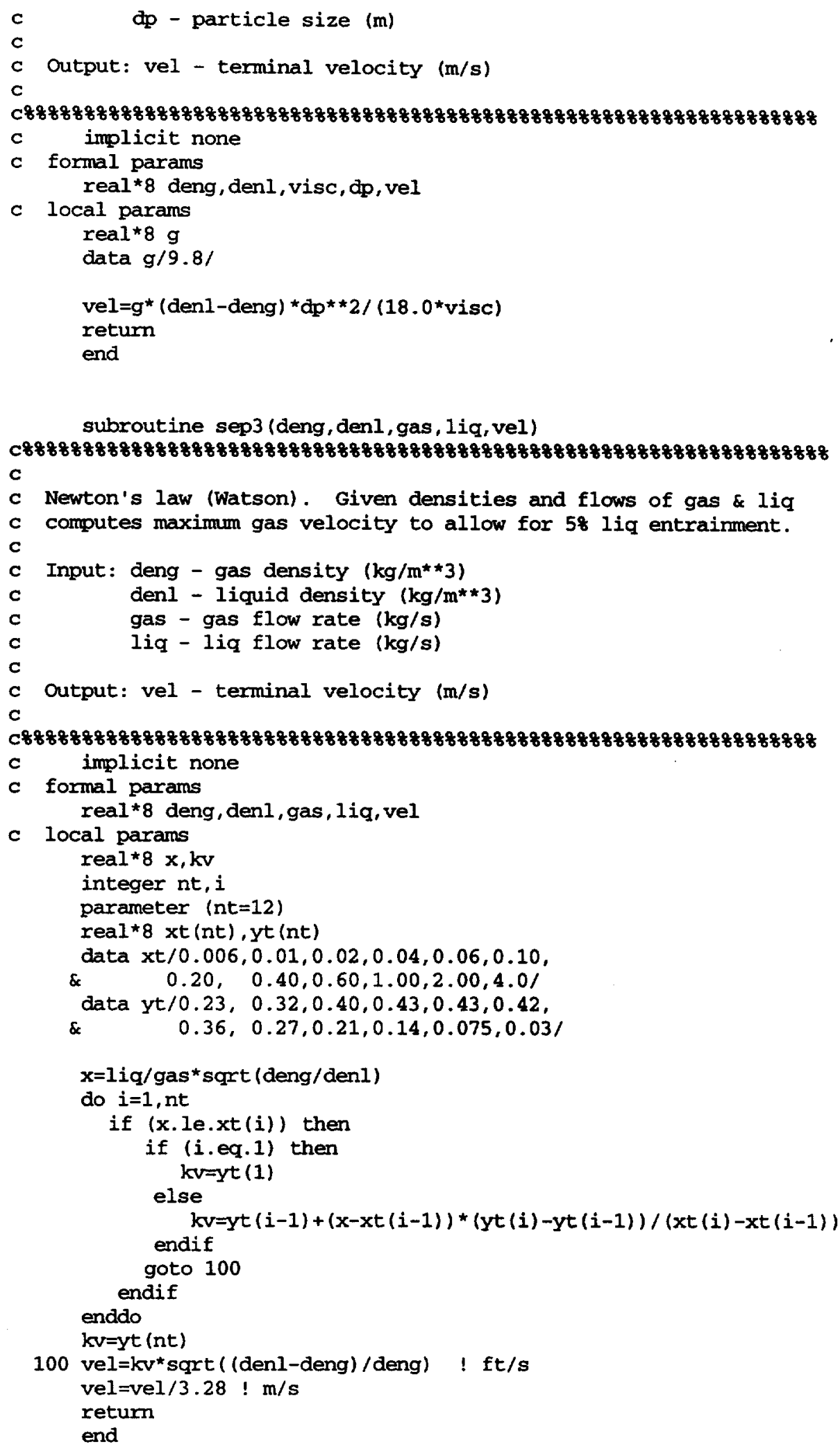




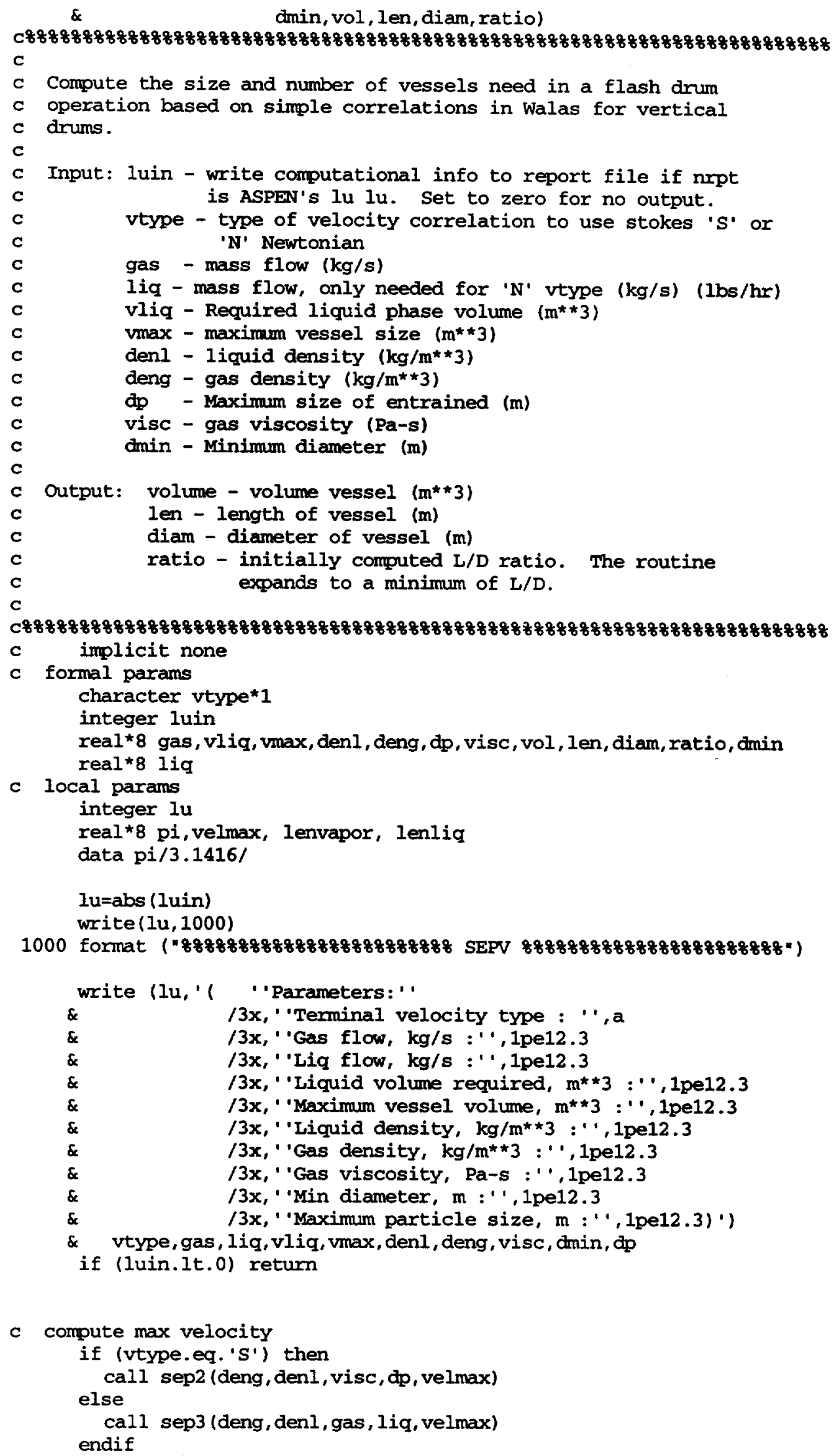


C compute equired area area $=$ gas $/$ deng/velmax

c do not consider any diameter less than dmin area $=\max \left(\operatorname{area},\left(\mathrm{pi}{ }^{*} \mathrm{dmin}{ }^{\star} \mathrm{dmin} / 4.0\right)\right)$

diam=sqrt $(4.0 *$ area $/ p i)$

lenvapor $=1.68$ ! based on walas

lenliq=vliq/area

len=lenvapor+lenliq

ratio $=$ len $/$ diam

if (len/diam.1t.3.0) then

write (lu, '('Computed ratio $L / D=$ ' ',f8.2)') ratio

len $=3.0 *$ diam ! L/D at least 3

endif

vol $=l e n * p i * \operatorname{diam}^{\star *} 2 / 4.0$

write (lu, ' ( 'Computed results ' ',

\& $\quad 13 x$, "velmax :'',1pe13.3

\& $13 x, "$ vol : ", 1pe13.3

$\& \quad / 3 x$, 'len :' ',1pe13.3

$\& \quad / 3 x$, ''diam : ', Ipe13.3

\& $\quad / 3 x$, ''len/diam:' ', Ipe13.3

\& $\quad 1 \%$

\& velmax, vol, len, diam,len/diam

write $(1 \mathrm{u}, 1000)$

return

end 


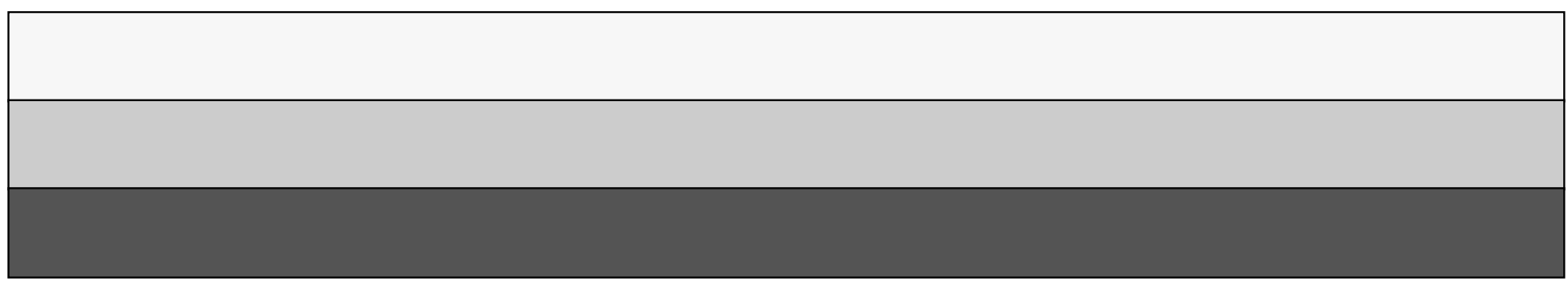

